\title{
WestVirginiaUniversity
}

THE RESEARCH REPOSITORY @ WVU

Graduate Theses, Dissertations, and Problem Reports

2014

\section{Psychosocial Predictors of Breast Awareness Behaviors}

\author{
Carol Goulet \\ West Virginia University
}

Follow this and additional works at: https://researchrepository.wvu.edu/etd

\section{Recommended Citation}

Goulet, Carol, "Psychosocial Predictors of Breast Awareness Behaviors" (2014). Graduate Theses, Dissertations, and Problem Reports. 162.

https://researchrepository.wvu.edu/etd/162

This Dissertation is protected by copyright and/or related rights. It has been brought to you by the The Research Repository @ WVU with permission from the rights-holder(s). You are free to use this Dissertation in any way that is permitted by the copyright and related rights legislation that applies to your use. For other uses you must obtain permission from the rights-holder(s) directly, unless additional rights are indicated by a Creative Commons license in the record and/ or on the work itself. This Dissertation has been accepted for inclusion in WVU Graduate Theses, Dissertations, and Problem Reports collection by an authorized administrator of The Research Repository @ WVU.

For more information, please contact researchrepository@mail.wvu.edu. 
Psychosocial Predictors of Breast Awareness Behaviors

\author{
Carol Goulet, M.S.
}

\author{
Dissertation submitted \\ to the Eberly College of Arts and Sciences \\ at West Virginia University
}

in partial fulfillment of the requirements for the degree of

Doctor of Philosophy in

Psychology

\author{
Kevin Larkin, Ph. D., Chair \\ Melissa Blank, Ph. D. \\ Barry Edelstein, Ph. D. \\ Kimberly Kelly, Ph. D. \\ Julie Patrick, Ph. D. \\ Department of Psychology
}

\author{
Morgantown, West Virginia \\ 2014
}

Keywords: Breast Awareness, Breast Self-Examination, BSE

Copyright 2014 Carol Goulet 


\section{ABSTRACT \\ Psychosocial Predictors of Breast Awareness Behaviors}

\section{Carol Goulet}

Whether women should practice breast self-examination (BSE) has been debated for decades. Current guidelines promote understanding how one's breasts normally look and feel through the practice of BSE or informal self-examination practices (referred to as breast awareness). This study investigated how modern women practice breast awareness behaviors, and how personal, theoretical, and psychosocial constructs influence engagement in these behaviors. Data from 626 women without a history of breast cancer were used to investigate associations between psychosocial variables (e.g., anxiety, body dissatisfaction, cancer fatalism; religious beliefs and participation) and breast awareness behaviors (BSE frequency and proficiency, frequency of checking for lumps, and frequency of examining breasts in the shower) within the framework of personal factors (e.g., age, knowledge of breast cancer risk factors) and health theories (Health Belief Model, Theory of Planned Behavior, and Extended Parallel Process Model) using hierarchical or multinomial logistic regressions. Women who practiced BSE excessively (weekly or daily) endorsed more body dissatisfaction and were less likely to engage in clinical breast exams by health care providers than women who practiced BSE at lesser frequencies (recommended, infrequent, or never). Among the broader sample, women who reported more body dissatisfaction demonstrated less proficiency at performing BSE. In comparison to infrequent BSE performers, those who endorsed more trait anxiety were more likely to perform $\mathrm{BSE}$ at a recommended frequency (monthly or trimonthly) or not at all. Lastly, more cancer fatalism was associated with performing BSE at a recommended frequency. None of the examined psychosocial variables predicted frequency of checking for lumps or frequency of examining breasts in the shower. Congruent with the literature, several variables associated with the Health Belief Model and Theory of Planned Behavior were also shown to be associated with breast awareness behaviors. 


\section{Acknowledgements}

First, I would like to express deep appreciation to Dr. Kevin Larkin, my advisor and dissertation committee chair, for his patience, guidance, and willingness to share his expertise throughout this project and throughout my entire time at West Virginia University.

I also would like to thank my committee members, Dr. Barry Edelstein, Dr. Julie Patrick, Dr. Melissa Blank, and Dr. Kimberly Kelly, for their efforts and advice.

I thank all the other members of the Dr. Larkin's lab, both past and present, for their collegiality and friendship.

I also thank Dr. Lynda Szymanski, my undergraduate mentor and advisor, for sparking my interest in psychological research in general, and in clinical psychology specifically.

I wish to thank my father, Raymond, and my brothers, Scott and Michael, for all of their love and support.

Finally, I would like to thank my husband, James, for his love, support, and patience. 


\section{Table of Contents}

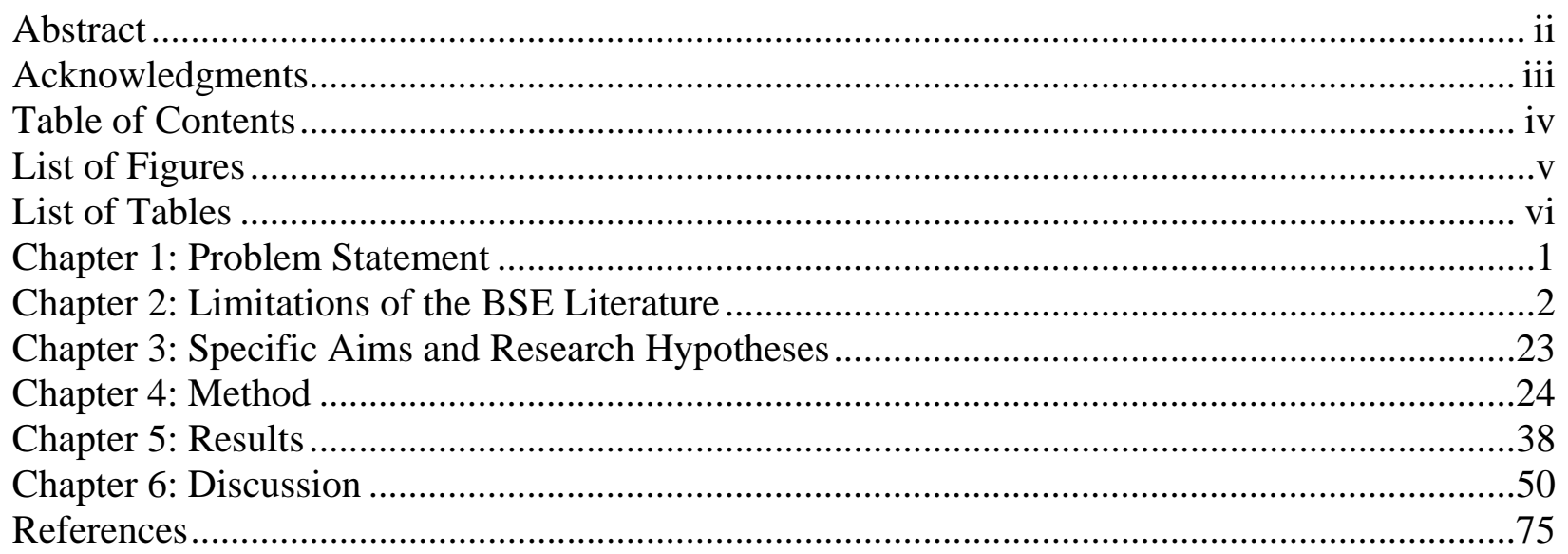




\section{List of Figures}

Figure 1: Consort Diagram Showing Participant Breakdown ..................................................92 


\section{List of Tables}

Table 1: Comparisons between BRFSS Sample and the Current Sample .93

Table 2: Descriptive and Normality Distribution Information for Study Variables ......................95

Table 3: Correlations between Independent Variables ...........................................................97

Table 4: Descriptive Information for Study Variables for Each BSE Frequency Group ..............98

Table 5: One-Way ANOVAs investigating Differences in Predictor Variables by BSE Frequency Groups...

Table 6: Chi-Square Investigating Differences in BSE Frequency Group Membership by Marital Status. .100

Table 7: Chi-Square Investigating Differences in BSE Frequency Group Membership by Having Ever Had a Mammogram.....

Table 8: Chi-Square Investigating Differences in BSE Frequency Group Membership by Having Ever Had a Clinical Breast Exam. .102

Table 9: Chi-Square Investigating Differences in BSE Frequency Group Membership by Having Health Insurance.

Table 10: Chi-Square Investigating Differences in BSE Frequency Group Membership by Cued by Health Care Provider. .104 Table 11: Chi-Square Investigating Differences in BSE Frequency Group Membership by Cued by Public Health Campaign.

Table 12: Chi-Square Investigating Differences in BSE Frequency Group Membership by Cued by Disclosure by a Celebrity or Public Figure...

Table 13: Chi-Square Investigating Differences in BSE Frequency Group Membership by Cued by Experiencing Breast Cancer Symptoms

Table 14: Chi-Square Investigating Differences in BSE Frequency Group Membership by Cued by Family or Friend with Breast Cancer .

Table 15: Chi-Square Investigating Differences in BSE Frequency Group Membership by Encouraged by Friend or Relative.

Table 16: Multinomial Logistic Regression Predicting BSE Group Membership (Reference = Never).

Table 17: Multinomial Logistic Regression Predicting BSE Group Membership (Reference = Infrequent)......

Table 18: Multinomial Logistic Regression Predicting BSE Group Membership (Reference = Recommended).

Table 19: Correlations between BSE Proficiency and Personal and Demographic Variables ..115

Table 20: Correlations between BSE Proficiency and Theory Variables.

Table 21: Correlations between BSE Proficiency and Psychosocial Variables.

Table 22: One-Way ANOVAs investigating Differences in BSE Proficiency by Potential Categorical Predictors.....

Table 23: Hierarchical Regression predicting BSE Proficiency

Table 24: Correlations between Lump Checking Frequency and Personal and Demographic Variables

Table 25: Correlations between Lump Checking Frequency and Theory Variables...................122

Table 26: Correlations between Lump Checking Frequency and Psychosocial Variables.........123 Table 27: One-Way ANOVAs investigating Differences in Lump Checking Frequency by Potential Categorical Predictors. 
Table 28: Hierarchical Regression predicting Lump Checking Frequency .125 Table 29: Correlations between Checking in Shower Frequency and Personal and Demographic Variables .126

Table 30: Correlations between Checking in Shower Frequency and Theory Variables............127 Table 31: Correlations between Checking in Shower Frequency and Psychosocial Variables..128 Table 32: One-Way ANOVAs investigating Differences in Checking in Shower Frequency by Potential Categorical Predictors.....

Table 33: Hierarchical Regression predicting Checking in Shower Frequency..... .130 


\section{Psychosocial Predictors of Breast Awareness Behaviors \\ Chapter 1: Problem Statement}

Breast cancer is the most common form of cancer diagnosed among women in the world (World Health Organization, 2008), and it is the second leading cause of cancer death among American women (Centers for Disease Control and Prevention, 2012). It was once believed that breast cancer was a disease of the developed world; however, due to longer life expectancies and adoption of Western lifestyles, nearly $70 \%$ of breast cancer deaths worldwide occur in developing nations. Within these countries, rising rates of breast cancer death may be due to a relative lack of early detection programs and delayed diagnosis and treatment. As a result, breast cancer may be diagnosed at more advanced stages of the disease, which is more difficult to treat (World Health Organization, 2008) and is linked to a lower relative 5-year survival rate (National Cancer Institute, 2012).

Research has identified a number of risk factors associated with developing breast cancer. Risk nearly doubles among women who have a first-degree relative with breast cancer, which comprises approximately $15 \%$ of women who are diagnosed with the disease (World Health Organization: International Agency for Research on Cancer, 2008). Another 5-10\% of breast cancer diagnoses are linked to gene mutations (e.g., BRCA1, BRCA2; National Cancer Institute, 2012). Other known risk factors include age, prolonged exposure to estrogen (e.g., early age at menarche), being overweight, physical inactivity, alcohol use, and exposure to environmental toxins (e.g., BPA, Bisphenol A, in certain plastic products; President's Cancer Panel, 2010).

Despite a growing scientific understanding of factors that increase risk of developing breast cancer, women often have limited knowledge of these risk factors. For example, collegeaged women overestimated their personal risk of developing breast cancer (Early, Armstrong, 
Burke, \& Thompson, 2011; Wendt, 2005), but were unaware of most risk factors of the disease, with the exception of family history of breast cancer (Early et al., 2011). Healthy women (30-85 years old) were unaware that breast and ovarian cancers are linked, risk increases with age and earlier age at menarche, and African American women are at increased risk of developing breast cancer compared to women of other races (Katapodi \& Aouizerat, 2005). Among women diagnosed with early onset breast cancer (prior to age 50 ), only $35 \%$ were aware that family history of non-breast malignancies increases risk for breast cancer (Miesfeldt, Cohn, Ropka, \& Jones, 2001). Both women diagnosed with early onset breast cancer and healthy women (30-85 years old) were unaware that history of breast cancer in the paternal family line also increases risk (Katapodi \& Aouizerat, 2005; Miesfeldt, et al, 2001). Overall, these findings suggest that women generally lack knowledge of breast cancer risk factors, and personal characteristics, such as age and history of breast cancer, do not necessarily increase the likelihood that women will be aware of these risk factors.

\section{Chapter 2: Literature Review}

\section{History of Breast Cancer Screening and Current Recommendations}

Because several risk factors associated with breast cancer are not amenable to behavior change programs (e.g., family history, race), it is unlikely that prevention strategies would eliminate the majority of diagnosed breast cancer cases (World Health Organization, 2008). Therefore, rather than developing and promoting efforts at preventing breast cancer, the healthcare community has long emphasized early detection of breast cancer through screening methods. Screening promotes awareness of early signs and symptoms of breast cancer, which ideally allows for earlier treatment and lower overall mortality risk associated with the disease (Anderson et al., 2008). The three primary modes of breast cancer screening include clinical 
breast examination (visual and manual inspection of the breasts and surrounding tissue by a health care provider), mammography (an X-ray of the breast tissue), and breast self-examination (BSE; a multistep, systematic procedure to identify breast tissue abnormalities (e.g., new lumps, dimpling of the breast tissue) through a self-examination; Susan G. Komen for the Cure, 2012). The sensitivity and specificity of mammography ranges from $70-95 \%$ and $94-97 \%$, respectively, which can be affected by age, density of breast tissue, equipment, skill of interpreting radiologist, and time since last examination (U.S. Preventive Services Task Force, 2009). The sensitivity and specificity of CBE ranges from $40-69 \%$ and $88-99 \%$, respectively. For BSE, the sensitivity ranges from $12-41 \%$ (U.S. Preventive Services Task Force, 2009), and the specificity is $88.9 \%$ (Wilke et al., 2009).BSE is one of the earliest devised screening tools for breast cancer. It was developed in the 1950s by Dr. Cushman Haagensen, a breast surgeon at Columbia University (Haagensen, 1952). After treating multiple female patients who presented with advanced, inoperable breast lumps, he devised the procedure to encourage patients to find breast lumps earlier, while they are still operable. The healthcare community initially embraced BSE and promoted its use among women, citing it as an inexpensive, private screening tool for breast cancer. By 1977, the American Cancer Society recommended that all women 20 years of age or older practice BSE on a monthly basis (Holmberg, Ekbom, Calle, Mokdad, \& Byers, 1997). During the 1980s, the medical literature began to question whether practicing BSE promoted earlier diagnosis and treatment of breast cancer (Frank \& Mai 1985; Miller, Chamberlain, \& Tsechkovski, 1985; Skrabanek, 1985). By this time, healthcare providers had also embraced mammography screening, which became more commonly used during the late 1970s. By 1987, the U.S. Preventive Services Task Force reported the data were inconclusive regarding the efficacy of BSE (Holmberg et al., 1997). In 1991, England's Chief Medical Officer, Sir Donald 
Acheson furthered the controversy surrounding BSE after he announced that the screening tool was ineffective and provided women a false sense of security (Austoker, 2003). Much of the debate surrounding BSE has pertained to its impact on psychological well-being among women who practice it (e.g., worry about finding a lump; anxiety associated with biopsying a lump detected during BSE) and whether the practice diminishes risk of breast cancer mortality.

\section{Limitations of the BSE Literature}

Two randomized controlled trials (Semiglazov et al., 1999; Thomas et al., 2002) attempted to study the relation between BSE and breast cancer mortality. Both studies reported that BSE did not decrease rates of breast cancer mortality among Chinese and Russian women who were enrolled in BSE education programs. Notably, there are a number of methodological and statistical limitations across the studies that have examined the efficacy of BSE. For example, there is little consistency in the definition of BSE and researchers often neglected to assess if participants were ever educated about BSE or if they performed BSE with technical skill. These studies also tend to over sample populations with relatively low incidences of breast cancer in favor of samples composed of groups with higher rates of breast cancer diagnosis and mortality. Other concerns include non-randomization of participants to BSE or control groups, recall bias regarding past BSE behavior, and length-time biased sampling, which refers to the better prognosis associated with slow-growing or noninvasive tumors that may not require treatment and are detected in greater frequency by BSE performers (Feig, 2000).

In addition, within these studies, BSE performers often were younger, premenopausal, of a higher SES, and more educated than nonperformers. The mortality differences observed between performers and nonperformers could have been due to these or other confounding factors, and yet, the lack of statistical control of variables linked to increased breast cancer risk 
(e.g., family history), breast cancer development (e.g., age), and mortality (e.g., availability of treatment) was pervasive.

\section{Impact of BSE Studies on Policy}

Despite the methodological flaws and limitations of these studies (e.g., these studies examined effects of BSE education programs, rather than the screening tool itself, on breast cancer mortality), their findings have contributed to policy recommendations by major health organizations regarding the practice of BSE and the teaching of BSE to women by health care providers. For example, the U.S. Preventive Services Task Force (2009) currently recommends against teaching BSE, whereas the American Cancer Society (2012) has not denounced the practice of BSE, but instead has altered their screening recommendations to emphasize the practice of "breast awareness." Breast awareness refers to engaging in behaviors that allow women to understand how their breasts normally look and feel, which may be accomplished through the practice of BSE or, more likely, through informal self-examination practices.

Although BSE screening recommendations have been modified by multiple health organizations, there has been limited study of the practice of other (non-BSE) breast awareness behaviors among women. Furthermore, the debate surrounding the efficacy of BSE at diminishing mortality has likely lead to decreased study of the procedure, at least in Western countries. As a result, research has yet to adequately study women's practice of breast awareness behaviors or to address the influence of BSE on rate of breast cancer mortality.

Despite these lingering questions, recent studies have suggested that BSE may promote other advantages, including benefits related to psychological health, and potentially, physical health as well. For example, among women who had genetic markers associated with increased risk of breast cancer, the majority of women who performed BSE regularly (77\%) felt that it 
provided them a sense of control over their health (Spiegel, Hill, \& Warner, 2009). Additionally, women who reported higher levels of confidence in performing BSE were more likely to use all three major breast cancer screening methods (Gürsoy et al., 2011). Given that regular practice of BSE appears to promote a positive sense of well-being and is associated with engagement in other self-care behaviors, it is important to consider whether psychological factors and/or health care behaviors influence engagement in BSE. Certainly, there is evidence that engaging in screening programs for other types of health problems (e.g., blood pressure checks for hypertension; vision exams for retinal disease; fecal exams for colon and rectal cancer) is influenced by psychosocial factors (Benjamins, 2007; Consedine, 2012; Diefenbach, Miller, \& Daly, 1999; Egede, Ellis, \& Grubaugh, 2009; Gil-Lacruz \& Gil-Lacruz, 2010; McLachlan, Clements, \& Austoker, 2012). It is not surprising, then, that research has examined the influence of psychosocial factors on engagement in BSE. One of the most common theoretical models used for examining psychosocial factors associated with numerous diseases and disabling health conditions as well as engagement in detection and/or prevention programs associated with them, like BSE, is the Health Belief Model.

\section{Health Belief Model and Breast Self-examination}

The Health Belief Model is the most frequently examined theory in health behavior research (Glanz, Rimer, \& Lewis, 2003). It was developed in the 1950s by social psychologists Rosenstock, Hochbaum, Kegeles, and Leventhal in response to the public's limited use of tuberculosis screening programs at that time (Glanz \& Bishop, 2010). Broadly, the Health Belief Model posits that beliefs and/or perceptions about a particular health concern will influence performance of behaviors that may influence outcomes associated with that health concern (Becker \& Maiman, 1975; Rosenstock, 1965). As it was initially proposed, the Health Belief 
Model stated that engagement in a particular health behavior is influenced by four constructs: (a) the perceived seriousness of the health concern, (b) the perceived susceptibility of being affected by the health concern, (c) the perceived benefits of performing behavior(s) that may influence outcomes associated with the health concern, and (d) the perceived barriers to performing those behavior(s). Additional constructs have been added to the model to address prevention, detection, and lifestyle behaviors (Glanz \& Bischop, 2010), including (e) self-efficacy regarding performance of the behavior(s), (f) motivation to perform the behavior(s), and (g) whether one has been cued to perform the behavior(s) (Stretcher \& Rosenstock, 1997). Among studies of BSE within the framework of the Health Belief Model, each of its seven constructs has received some empirical support:

Perceived seriousness/severity. Perceived seriousness of breast cancer positively predicted BSE frequency ( $\beta=.18$ and $\beta=.11$, respectively) among American (18-74 years old; Millar, 1997) and Iranian (20-66 years old; Noroozi, Jomand, \& Tahmasebi, 2011) women, but was inversely correlated with BSE frequency $(r=-.24)$ among English women (18-35 years old; Umeh \& Rogan-Gibson, 2001). Regarding level of skill at performing BSE, perceived seriousness did not significantly predict BSE proficiency among Taiwanese women (22-57 years old; $\mathrm{Lu}, 2001)$.

Perceived susceptibility. Compared to women who endorsed low perceived susceptibility of developing breast cancer, BSE frequency was higher among women from Australia (18-64 years old; Ashton, Karnilowicz, \& Fooks, 2001), China (19-57 years old; Fung, 1998), Jordan (18-59 years old; Petro-Nustus \& Mikhail, 2002), and Turkey (20-70 years old; Secginli \& Nahcivan, 2006) who endorsed higher perceived susceptibility $(\beta=.18, \beta=.12, \beta=$ .15 , and $\beta=.08$, respectively). These findings were replicated among Israeli women ( $M_{\text {age }}=$ 
31.3, S.D. $=7.9)$ who had a first-degree relative with localized breast cancer $(r=.19)$ or recurrent breast cancer $(r=.28$; Cohen, 2002). Perceived susceptibility also significantly predicted BSE proficiency $(\beta=.23)$ among American women (35-81 years old, Champion, 1988) but not Taiwanese women (22-57 years old; Lu, 2001). In contrast, Iranian women (20-66 years old) who perceived greater susceptibility engaged in BSE less frequently $(\beta=-.18$; Noroozi et al., 2011). Although it seems counterintuitive that greater perceived risk of developing breast cancer may be related to diminished engagement in a self-screening behavior, it is possible that other factors that were not measured in the study, such as anxiety, may have influenced the relation between perceived susceptibility and engagement in BSE in this study.

Perceived benefits. Turkish women (22-54 years old; Canbulat \& Uzun, 2008) who reported practicing BSE (yes or no response) perceived more benefits associated with the behavior compared to those who reported not practicing BSE. Similarly, among Iranian women (20-66 years old), perceiving more benefits predicted BSE frequency $(\beta=.18$; Noroozi et al., 2011). In contrast, perceived benefits did not significantly predict BSE proficiency among Taiwanese women (22-57 years old; $\mathrm{Lu}, 2001)$.

Perceived barriers. As expected, among women from China (19-57 years old; Fung, 1998), Turkey $\left(M_{\text {age }}=34.2, S . D .=9.6\right.$; Gürsoy et al., 2011), Iran (20-66 years old; Noroozi et al., 2011), and England (18-35 year old; Umeh \& Rogan-Gibson, 2001), perceiving fewer barriers to performing BSE was associated with more frequent engagement in the behavior $(\beta=$ $.18, \beta=-.04, \beta=-.08$, and $r=-.50$, respectively). In addition, perceived barriers significantly predicted BSE proficiency $(\beta=-.31)$ among American women (35-81 years old; Champion, 1988) but not Taiwanese women (22-57 years old; Lu, 2001).

Self-efficacy. Among women from Australia (18-64 years old; Ashton et al., 2001), 
Jordan (18-59 years old; Petro-Nustus \& Mikhail, 2002), and multiple samples from Turkey $\left(M_{\text {age }}=34.2\right.$, S.D. $=9.6$, Gürsoy et al., 2011; 18-67 years old, Nahcivan \& Secginli, 2007; $M_{\text {age }}=$ 34.2, S.D. $=9.6$, Noroozi et al., 2011), those who reported greater self-efficacy regarding knowledge and ability to properly perform BSE engaged in the behavior more frequently $(\beta=$ $.39, \beta=.34, \beta=.08, \beta=.09, \beta=.10$, respectively $)$ and more proficiently $(r=.57$; American sample; 18-73 years old; Alagna \& Reddy, 1984) than their low self-efficacy counterparts.

Health motivation. Higher levels of motivation or behavioral intention to consistently engage in BSE predicted BSE frequency $(\beta=.14 ; \beta=.26$, respectively) among Jordanian (18-59 years old; Petro-Nustus \& Mikhail, 2002) and Chinese women (19-57 years old; Fung, 1998), and BSE proficiency $(\beta=.34)$ among American women (35-81 years old, Champion, 1988).

Cues to action. Turkish women (20-61 years old) who were cued to perform BSE by family members $(O R=4.90-5.64)$ engaged in BSE more frequently (Kara \& Acikel, 2009). Similarly, rate of having heard or read about BSE was higher among Turkish women (20-70 years old) who reported performing BSE (yes or no response) compared to those who reported not performing the behavior (Secginli \& Nahcivan, 2006).

Several studies have investigated the influence of other demographic and psychosocial variables over and above the constructs identified with the Health Belief Model. In brief, frequency of BSE has been shown to increase if one has children (Fung, 1998), a family history of breast cancer $(\beta=-.13$; Noroozi et al., 2011), more years of education $(O R=2.62$; Kara $\&$ Acikel, 2009), an earlier age at menarche ( $\beta=.10$; Noroozi et al., 2011), health insurance (OR= .57; Nahcivan \& Secginli, 2007), and a solid knowledge base regarding breast cancer risk factors $(O R=2.94 ;$ Nahcivan \& Secginli, 2007).

Additionally, single/never married and separated women endorsed less intent to practice 
BSE than married, divorced, and widowed women (Champion, 1985). These findings suggest that constructs (i.e. demographic, personal) beyond the Health Belief Model influence engagement in BSE, and therefore, should be included in studies examining factors that promote and/or diminish engagement in the screening tool.

\section{Theory of Planned Behavior and Breast Self-examination}

A second theory that often guides research investigating health behavior is the Theory of Planned Behavior. Although fewer studies have examined its influence on BSE practice, this theory includes important theoretical components that are lacking in the Health Belief Model. The Theory of Planned Behavior posits that health behavior engagement is influenced by four constructs: (a) one's attitudes about the behavior(s), (b) one's perception of how others view practicing the behavior(s), or subjective norm, (c) one's perceived ability to perform the behavior(s) (perceived behavioral control, frequently assessed as self-efficacy), and (d) one's intention to perform that behavior(s) (Ajzen, 1985). Among studies of BSE based upon the Theory of Planned Behavior, each of its four constructs has also received some empirical support:

Attitude. Positive attitudes about BSE were associated with BSE engagement at a onemonth follow-up $(r=.20)$ among Australian women (17-49 years old; Mason \& White, 2008), as well as current BSE practice $(r=.31)$ and BSE practice at a one-month follow-up $(r=.43)$ among British women (18-63 years old; Norman \& Hoyle, 2004). In a structural equation model predicting a latent variable composed of past and intended BSE behavior, attitude significantly predicted BSE practice $(\beta=.46)$ among American college students (71\% younger than 21 years old; Ronis \& Kaiser, 1989). These finding suggest that positive attitudes about BSE are associated with greater engagement in the screening behavior among women. 
Subjective norm. In a sample of British women (18-63 years old), subjective norm was associated with current BSE practice $(r=.24)$ and BSE practice at a one-month follow-up $(r=$ .35; Norman \& Hoyle, 2004). Similarly, among Australian women (17-49 years old), subjective norm was positively associated with BSE engagement at a one-month follow $(r=.15$; Mason $\&$ White, 2008). It also significantly predicted BSE proficiency $(\beta=.22)$ among Taiwanese women (Lu, 2001). These findings indicate that perceiving that others believe you should perform BSE is associated with greater frequency and skill at which women perform BSE.

Perceived behavioral control/self-efficacy. In a sample of American college students who participated in an educational intervention about BSE, perceived behavioral control $(\beta=$ $.27)$ and self-efficacy $(\beta=.30)$ significantly predicted engagement in BSE at a three-month follow-up (McCaul, Sangren, O’Neill, \& Hinsz, 1993). Similarly, among Australian women (1749 years old), perceived behavioral control was positively associated with BSE engagement at a one-month follow $(r=.43$; Mason $\&$ White, 2008). Self-efficacy was associated with current BSE practice $(r=.32)$ and BSE practice at a one-month follow-up $(r=.51)$ among British women (18-63 years old; Norman \& Hoyle, 2004). It also predicted BSE practice/intention $(\beta=$ .54) among American college students (71\% younger than 21 years old; Ronis \& Kaiser, 1989). Regarding technical skill, self-efficacy significantly predicted BSE proficiency $(\beta=.22)$ among Taiwanese women (Lu, 2001). As expected, these studies suggest self-efficacy and perceived behavioral control are associated with BSE intention, frequency, and proficiency among women.

Intention. Intention to perform BSE significantly predicted engagement in BSE at a three-month follow-up $(\beta=.30)$ among American college students (McCaul et al., 1993), as well as current BSE practice $(r=.47)$ and BSE practice at a one-month follow-up $(r=.72)$ among British women (18-63 years old; Norman \& Hoyle, 2004). It also significantly predicted BSE 
proficiency $(\beta=.22)$ among Taiwanese women ( $\mathrm{Lu}, 2001)$. As expected, greater intention to perform BSE was associated with greater engagement and skill at performing the behavior.

Within the framework of the Theory of Planned Behavior, several other demographic and personal variables have been investigated in relation to BSE practice. Briefly, knowledge of breast cancer symptoms $(r=.38)$, knowledge of breast cancer prevalence $(r=.46)$, beliefs about the benefits and costs of performing BSE $(r=.34)$, and perceived severity of breast cancer $(r=$ .22) each have been significantly associated with BSE behavior (Ronis \& Kaiser, 1989).

\section{Extended Parallel Process Model and Breast Self-examination}

Although examined less frequently in health behavior literatures, the Extended Parallel Process Model (Witte, 1994) overlaps significantly with the constructs that compose the Health Belief Model. This model includes five constructs: (a) perceived susceptibility, (b) perceived severity of a threatening condition, (c) self-efficacy, and (d) response efficacy (perceived benefits of performing a health behavior at preventing or combating a threatening condition). These constructs influence (e) fear of a threatening condition, which impacts engagement in the health behavior(s) through fear-control processing (low self-efficacy, high perceived susceptibility and severity) or danger-control processing (high self-efficacy, high perceived susceptibility and severity).

Only one known study to date has investigated BSE behavior within the framework of the Extended Parallel Process Model. Of note, the authors of this study employed qualitative methods. In a sample of Mexican-American Immigrants (17-79 years old) who participated in a discussion series about breast screening behaviors, those who endorsed high self-efficacy and low perceived threat (low perceived susceptibility and low perceived severity) of developing breast cancer reported performing BSE less frequently than women who endorsed low self- 
efficacy and low perceived threat (Hubbell, 2006). The participants' responses were not consistent with either danger-control processing or fear-control processing proposed by the Model. In addition, the sample endorsed lack of accurate information about breast cancer and how to perform BSE properly, lack of health insurance, and transportation issues as barriers to engaging in screening behaviors.

In line with the Extended Parallel Process Model, fear of developing breast cancer has been studied indirectly as a processing response and directly as an independent construct. Few studies have examined the influence of breast cancer fear on engagement in breast cancer screening. In one such study, American women (40-75 years old) who endorsed greater breast cancer fear also endorsed more frequent practice of BSE, having had a mammogram, greater intent to perform BSE, and greater intent to receive a mammogram compared to women who endorsed lower levels of breast cancer fear (McCaul, Reid, Rathge, \& Martinson, 1996a). Utilizing qualitative methodology, Williams, Abbott, and Taylor (1997) found that AfricanAmerican women (40-65 years old) reported fear of finding a lump and fear of losing one's breasts due to breast cancer as barriers to performing BSE. Despite the novelty of these findings, these studies neglected to examine breast cancer fear within the context of the broader Extended Parallel Process Model, hindering any understanding of how the Model may influence BSE behavior among women.

\section{Psychosocial Variables and Breast Self-examination}

Most studies that have attempted to predict BSE behavior within the framework of the Health Belief Model, with or without consideration of additional demographic or psychosocial variables, have accounted for 9-27\% of the variance in BSE frequency (e.g., Mason \& White, 2008; Millar, 1997; Petro-Nustus \& Mikhail, 2002) and 37-56\% of the variance in BSE 
proficiency (e.g., Alagna \& Reddy, 1984; Champion, 1988). Studies predicting BSE practice using the Theory of Planned Behavior have accounted for $48-72 \%$ of the variance in BSE frequency (e.g., McCaul et al., 1993; Norman \& Hoyle, 2004) and 21\% of the variance in BSE proficiency (Lu, 2001). Due to the limited study of BSE behavior within the context of the Extended Parallel Process Model, the predictive power of this model for BSE behavior is currently unknown. These outcomes suggest there is room to consider additional variables to more systematically predict BSE behavior among women. The current study aimed to examine seven psychosocial variables: trait anxiety, breast cancer worry, body dissatisfaction, cancer fatalism, God locus of health control, religious beliefs, and organizational religiousness. Although scarcely examined in relation to BSE, each of these psychosocial factors has the potential to influence engagement in important cancer screening strategies like BSE. It is possible that by assessing these additional parameters, additional variance could be explained regarding BSE frequency and proficiency, as well as the frequency of other breast awareness behaviors.

Anxiety. The rise in media attention to breast cancer has resulted in heightened public awareness of familial factors that increase risk of breast cancer development (Epstein et al., 1997). Some studies suggest that this awareness may generate feelings of anxiety and worry among women with a family history of breast cancer. It has been proposed that the presence of breast cancer-related anxiety may either inhibit or promote engagement in breast cancer screening behaviors (McCaul, Schroeder, \& Reid, 1996b). Specific to BSE, women with elevated levels of anxiety may refrain from engaging in the behavior to avoid experiencing negative thoughts or feelings associated with the screening behavior or their physical health (e.g., "I couldn't deal with the anxiety of finding a lump and would rather not know."). A contrasting 
perspective argues that women with elevated anxiety may perform BSE excessively (i.e., more frequent than monthly) in an attempt to detect cancer as soon as possible (Brain, Norman, Gray, \& Mansel, 1999). Of note, excessive engagement in BSE has been found to be counterproductive. Over-adherence to BSE may result in reduced efficacy of the procedure, more frequent but less thorough self-examinations, and reinforcement of anxiety. Factors that have previously predicted excessive BSE performance include: African American ethnicity $(O R=$ 2.3), greater perceived risk of developing breast cancer compared to other women without a family history of breast cancer $(O R=2.9)$, and frequency of breast cancer-related thoughts $(O R$ $=5.5$; Epstein et al., 1997). Other factors that have been positively associated with excessive BSE performance include age (50 years of age or older), having a daughter with breast cancer, and having two or more first-degree relatives with breast cancer, whereas education was inversely associated with the behavior (authors did not report statistical values in the article for these relations).

Multiple studies have examined the relation between anxiety and BSE. Among women from Wales (17-77 years old) who had a family history of breast cancer, state and trait anxiety were highest among those who endorsed excessive BSE practice compared to women who practiced BSE infrequently or appropriately (Brain et al., 1999). Similarly, state anxiety predicted BSE frequency $(\beta=.54)$ among women $\left(M_{\text {age }}=31.3\right.$, S.D. $\left.=7.9\right)$ whose mothers were diagnosed with localized or recurrent breast cancer (Cohen, 2002). To further complicate understanding of how anxiety may influence BSE practice, Bowen, Alfano, McGregor, and Andersen (2004) reported a quadratic relation between general anxiety and BSE frequency in a sample of American women (18-74 years old). Specifically, a small portion of women who endorsed experiencing no anxiety performed BSE, relatively few women who endorsed moderate 
levels of anxiety performed BSE, and a large portion of women who endorsed elevated levels of anxiety performed BSE excessively (twice or more a month). Overall, these findings suggest that anxiety may function to either inhibit BSE engagement or to promote over-adherence to the behavior.

Breast cancer worry. Breast cancer worry was positively associated with breast cancer screening performance ( $r=.13-.24)$ in a sample of American women (40-75 years old; McCaul et al., 1996a). Similarly, among British women who had a family history of breast cancer (17-77 years old), breast cancer worry was positively associated with BSE frequency $(r=.33$; Brain et al., 1999). Regarding over-adherence, breast cancer-specific distress predicted excessive engagement in the screening behavior $(\beta=.13)$ among Dutch women younger than 40 years old (van Dooren et al., 2003). Within the framework of the Health Belief Model, feeling emotionally upset during BSE $(O R=2.16)$ and having intrusive thoughts about breast cancer $(O R=4.35)$ predicted excessive engagement in BSE (more than once a month) among American women $\left(M_{\text {age }}=41.6, S . D .=10.1\right)$ compared to those who practiced BSE the recommended frequency (monthly or bimonthly; Erblich, Bovbjerg, \& Valdimarsdottir, 2000). Together these studies provide initial evidence to suggest that breast cancer worry may promote over-adherence to BSE among both healthy women and women who have a personal history of breast cancer.

Body dissatisfaction. Dissatisfaction with one's body is so common among women in Western society that some have termed it a "normative discontent" (Rodin, Silberstein, \& Striegel-Moore, 1985). Given that BSE involves a thorough examination of one's body, women who are more dissatisfied with their bodies may be less likely to perform this behavior (Chait, Thompson, \& Jacobsen, 2009). Only three studies to date (Brewer \& Dewhurst, 2013; Chait et al., 2009; Clark et al., 2009) have examined the relation between body dissatisfaction and cancer 
screening behaviors. The first study found no relation between body dissatisfaction and frequency of BSE among American women (28-82 years old; Chait et al., 2009). In addition, body esteem (i.e., how one feels about and cares for one's body) differentiated women who intended to perform BSE from those who did not intend to perform the behavior among British college students (18-60 years old; Brewer \& Dewhurst, 2013). Specifically, women who endorsed greater intention to perform BSE also reported higher body esteem. Regarding the relation between body dissatisfaction and other cancer screening behaviors, unmarried American women (40-75 years old) who endorsed body image concerns reported less engagement in colorectal $(O R=0.30)$ and comprehensive cancer screenings $(O R=0.50$; Clark et al., 2009). Although the findings are inconclusive regarding the influence of body dissatisfaction on BSE behavior, it is possible that greater body dissatisfaction may decrease motivation to perform BSE, as engaging in a behavior that requires examination of a body that one is dissatisfied with might promote negative affect or cognitions.

Cancer fatalism. The belief that being diagnosed with cancer will result in death has been cited as a potential barrier to engagement in cancer screenings (Spurlock \& Cullins, 2006). Individuals who hold these beliefs may feel powerless, helpless, and as if they lack control over their health; thus, they may be less likely to engage in cancer screening behaviors. Multiple studies have found that perceptions of cancer fatalism are common among ethnically, economically, and culturally diverse populations, including African American, Asian, and Latin women as well as women who are older, are less educated, and have fewer financial resources (Facione, Miaskowski, Dodd, \& Paul, 2002; Mayo, Ureda, \& Parker, 2001; Straughan \& Soew, 1998). 
The relation between cancer fatalism and engagement in breast cancer screening has been examined in only a few studies. Among African American women (20-73 years old), cancer fatalism did not differentiate compliance (with recommendations proposed by the American Cancer Society) versus non-compliance of BSE or clinical breast examination in women younger than 40 years old (Spurlock \& Cullins, 2006). Cancer fatalism was higher among women who were over 40 years old who were non-compliant with clinical breast exam and mammography screening recommendations compared to their compliant counterparts. In addition, women who were unemployed and without health insurance expressed more beliefs consistent with fatalistic thinking. Also, the majority of women in the study (45.0-56.8\%), regardless of age, income, employment status, or health insurance status, endorsed the belief that women diagnosed with breast cancer are meant to have the disease.

In studies examining the relation between cancer fatalism and breast cancer screening within the framework of the Health Belief Model, cancer fatalism was a barrier to mammography screening $(\beta=.34)$ among low-income African American women (50-98 years old; Farmer, Reddick, D’Agostino, \& Jackson, 2007), but did not predict mammography screening adherence among African American or Caucasian women (40-97 years old; Russel, Perkins, Zollinger, \& Champion, 2006). Within the latter sample, African American women endorsed more fatalistic beliefs than their Caucasian counterparts. Together, the findings provide preliminary evidence to suggest that cancer fatalism may inhibit engagement in breast cancer screening, at least among African American women. However, its potential influence on BSE behavior remains relatively untested at this time.

God locus of control \& religious beliefs. Prior research has found that religious views may impact health perceptions and engagement in health behaviors (e.g., Banning, 2011; 
Benjamins, 2007; Mitchell, Lannin, Mathews, \& Swanson, 2002), especially among African American women (e.g., Kinney, Emery, Dudley, \& Croyle, 2002; Mitchell et al., 2002). One perspective posits that individuals who identify as highly religious may be less likely to engage in health promoting behaviors due to greater reliance upon God to control one's health. Supporting this perspective, a majority of a sample of American women (40-99 years old) believed that God works through doctors to cure breast cancer, and some even believed that medical treatment was unnecessary because only God could cure breast cancer (Mitchell et al., 2002). This latter belief was predicted by age $(\beta=.11)$, African American ethnicity $(\beta=.41)$, education $(\beta=-.19)$, and family income $(\beta=-.03)$. In regard to breast cancer screening practices, believing God controlled one's health inversely predicted engagement in mammography $(O R=$ $.88)$ and clinical breast examination $(O R=.88)$ among African American women (18-78 years old) with a BRCA1 mutation (Kinney et al., 2002).

The contrasting perspective argues that religious beliefs may encourage individuals to be more vigilant regarding their health, as individuals may view their bodies as gifts from God (i.e., one must take responsibility for one's body). Additionally, individuals may be encouraged by members of their religious communities to engage in health-promoting behaviors. In support of this perspective, African American women (30-84 years old) who disclosed their breast cancer symptoms to a family member or church member sought medical care earlier $(O R=.25)$ than those who confided their symptoms only to God (Gullatte, Brawley, Kinney, Powe, \& Mooney, 2010). In addition, religious salience (i.e., importance of one's religious beliefs; $O R=1.32-1.38$ ) and worship attendance one to three times yearly $(O R=1.23-1.53)$ predicted BSE frequency among American women (51-61 years old; Benjamins, 2006). Weekly and greater than weekly attendance did not predict BSE frequency. In addition, worship attendance also predicted BSE 
engagement $(O R=1.16-1.25)$ in a similar sample of American women $(50-79$ years old;

Salmoirago-Blotcher et al., 2011). Thus, the findings from studies examining the relation between religion and engagement in BSE are mixed; however, there is initial evidence to suggest that religious views may impact broader engagement in breast cancer screening, including BSE.

As mentioned above, only a few studies have investigated the influence of anxiety, breast cancer worry, body dissatisfaction, cancer fatalism, God locus of health control, religious beliefs, and organizational religiousness on engagement in BSE frequency, and among those that have been conducted, the findings have been inconsistent. Furthermore, many of the studies that examined psychosocial variables did so without considering components of common health behavior theories that have been shown to be associated with BSE frequency. Finally, nearly all of the studies that comprise this literature have emphasized BSE frequency, neglecting to consider BSE proficiency (i.e., skill level at performing BSE) as well as other breast awareness behaviors.

\section{Significance and Purpose of the Present Study}

The role of self-examination at detecting breast cancer has been debated for decades; however, recent findings from a U.S. nationally-representative self-report health survey indicate a substantial portion of women self-detect their breast cancers through self-examination (25\%) or by accident (18\%; Roth et al., 2011). Furthermore, among women surgically treated for breast cancer at Mayo Clinic in Rochester, Minnesota in 2000, 43\% were diagnosed through a palpable presentation (remaining cases diagnosed through abnormal mammography screening). Of these cases, 30\% detected through BSE, 26\% detected by accident, 30\% detected through unspecified means, and only 14\% detected through a clinical breast exam (Mac Bride, Pruthi, \& Bevers, 2012). Perhaps even more unsettling is that among women whose breast cancers were diagnosed 
through a palpable presentation, $38 \%$ had a normal mammogram within the previous 13 months. Together these findings suggest that a sizable portion of women self-detect their breast cancers despite modern advances in breast cancer screening and the declining promotion of BSE by health organizations. Therefore, some form of self-examination is likely vital to maintaining women's health.

Likely due to the decades-long controversy surrounding BSE, research in this area has diminished and is primarily being conducted in developing countries where other methods of breast cancer screening (e.g., mammography) are less available. As a result, many of the methodological limitations that were present in the studies on which current BSE policies are typically based have yet to be addressed through modern research. One such limitation includes the dearth of research examining the proficiency, or skill level, at which women perform BSE. Prior research suggests that even among women who report consistent practice of BSE, women often neglect to perform the procedure accurately (Stevens, Hatcher, \& Bruce, 1994). This is particularly concerning as BSE that is performed proficiently has been associated with reduced breast cancer death (e.g., Harvey, Miller, Baines, \& Corey, 1997; Newcomb et al., 1991). Thus, if women choose to practice BSE as a means to screen for breast cancer, it is important that they perform the behavior with technical skill. This may be especially important if they do not utilize other methods of breast cancer screening (e.g., mammography), which also have been associated with diminished breast cancer death.

Another limitation of this literature is the lack of investigation of other breast awareness practices. Current guidelines recommend that women practice breast awareness; however, no known studies have examined women's engagement in these less prescribed, non-BSE, selfexamination behaviors. The practice of breast awareness behaviors may be especially important 
to the health of young women because they have fewer breast cancer screening tools available to them. Although rates of breast cancer are much lower among young women, when they do develop breast cancer, they often are diagnosed with more advanced stages of the disease and have a higher rate of breast cancer mortality compared to older women who are diagnosed with the disease (Early et al., 2011).

Because self-examination continues to be a significant method of detection among women, it is imperative to understand factors that predict engagement in or serve as barriers to performing breast awareness behaviors. This study attempted to expand upon this literature by investigating the role of seven psychosocial variables that may be useful for predicting breast awareness behaviors over and above the components of three common health behavior theories: the Health Belief Model, Theory of Planned Behavior, and Extended Parallel Process Model.

The psychosocial variables selected for examination in this study included trait anxiety, breast cancer worry, body dissatisfaction, cancer fatalism, God locus of health control, religious beliefs, and organizational religiousness. These variables were chosen for multiple reasons. Specifically, they may act as barriers or serve to promote breast awareness behaviors, they have been rather sparsely studied, they primarily have been studied in specialty samples, and research on many of them has yielded inconsistent findings. Prior findings suggest that both anxiety and breast cancer-specific worry may be associated with BSE frequency; therefore, the study measured both trait anxiety and breast cancer worry. Dissatisfaction with one's body also may inhibit the performance of a health behavior that involves regular visual and manual examination of one's body. Furthermore, whether one believes death is inevitable if one develops cancer or God controls one's health outcomes could influence engagement in breast awareness behaviors. Therefore, measures of body dissatisfaction, cancer fatalism, and God locus of health control 
were included in the study. Finally, religious beliefs or attendance could serve to encourage or inhibit engagement in breast awareness behaviors; thus, religious beliefs (an internal component of religiousness) and religious community involvement (an external component of religiousness) were measured in this study.

Furthermore, a majority of the previous empirical work investigating the influence of psychosocial variables on BSE practice has neglected to examine these relations within the context of health behavior theories. Thus, this study examined psychosocial variables within the context of the frameworks of the Health Belief Model, Theory of Planned Behavior, and Extended Parallel Process Model.

Additionally, BSE frequency has been studied extensively, whereas few studies to date have examined factors that predict BSE proficiency. The study applied the above mentioned predictive framework to BSE proficiency as well as other breast awareness behaviors (e.g., checking for lumps, examining breasts while showering). Finally, the recruitment of the sample for the proposed investigation targeted a national sample of women as opposed to a convenience sample comprised of college students.

\section{Chapter 3: Specific Aims and Research Hypotheses}

\section{Specific aim 1. To investigate whether psychosocial variables predict BSE frequency.}

Given the considerable variance that remains to explain BSE frequency and their conceptual relevance to BSE, it was expected that the psychosocial variables would predict BSE frequency over and above the constructs of the Health Belief Model, Theory of Planned Behavior, and Extended Parallel Process Model. Specifically, it was expected that breast cancer worry, trait anxiety, organizational religiousness, and religious beliefs would be positively associated with 
BSE frequency, while body dissatisfaction, God locus of health control, and cancer fatalism would be inversely associated with BSE frequency.

Specific aim 2. To explore whether the health theories and psychosocial variables predict BSE proficiency. Assuming that variables would similarly influence frequency and proficiency of BSE, it was expected that the psychosocial variables would predict BSE proficiency over and above the constructs of the Health Belief Model, Theory of Planned Behavior, and Extended Parallel Process Model. Specifically, it was expected that breast cancer worry, trait anxiety, organizational religiousness, and religious beliefs would be positively associated with BSE proficiency, while body dissatisfaction, God locus of health control, and cancer fatalism would be inversely associated with BSE frequency.

Specific aim 3. To explore whether the health theories and psychosocial variables predict other breast awareness behaviors - specifically, frequency of lump checking and checking in the shower. Although no known studies have examined breast awareness behaviors, except BSE, it was expected that the psychosocial variables would similarly predict engagement in frequency of lump checking and examining breasts in the shower. Specifically, it was expected that breast cancer worry, trait anxiety, organizational religiousness, and religious beliefs would be positively associated with BSE frequency, while body dissatisfaction, God locus of health control, and cancer fatalism would be inversely associated with BSE frequency.

\section{Chapter 4: Method}

\section{Participants}

Data from 667 adult women were used in the present study. Participants were recruited using Amazon's Mechanical Turk (2012) for two weeks during January 2014, restricting 
participation to individuals 18 years and older who resided within the United States. Mechanical Turk is an on-line crowdsource on which individuals may post tasks for people to complete for a small monetary sum. These tasks can include market research, interest group participation, transcription, professional assistance (e.g., editing curriculum vitae), and participation in academic research. Participants were paid $\$ 1$ to their Amazon accounts for their participation.

Initially, 1301 individuals were recruited (see Figure 1). Multiple methods were employed to identify participants who may have inappropriately completed the survey. Four validity questions were interspersed throughout the survey to assess whether participants were fully reading and comprehending the survey items (e.g., in a measure of anxiety, the item "I have read this question entirely, and I will answer disagree to demonstrate that I have done so" was added). Seventy-two individuals who omitted or failed to correctly answer more than one of these validity questions were removed. Additionally, 183 individuals failed to complete enough of the survey for their data to be usable. Of the remaining participants, 369 were men who had been directed to participate in a parallel study of testicular self-examination, and thus were excluded from the current study. Finally, ten women who had been diagnosed with breast cancer at some point prior to the study were removed because this experience may uniquely influence engagement in breast awareness behaviors. For example, there is some evidence to suggest that survivors of breast cancer experience fear of recurrence and concurrent psychological distress and diminished quality of life (Taylor et al., 2012). This psychological phenomenon is clearly unique to those women with a personal history of breast cancer, differentiating them from women who lack this experience.

Participants were 18 to 73 years of age $(M=33.2, S . D .=11.56)$ and primarily Caucasian (81.0\%), with 9.0\% African American, 3.7\% Hispanic/Latino, 3.7\% Asian/Pacific Islander, 1.2\% 
Native American, and $0.7 \%$ multi-ethnic. Slightly more than one-third of the sample reported being married (34.1\%), with $30.1 \%$ reporting being single/never married, $22.8 \%$ a member of an unmarried but committed couple, $8.4 \%$ divorced, $2.4 \%$ separated, and $1.2 \%$ widowed. The majority of participants were employed or self-employed (64.2\%), while $12.7 \%$ were students, $12.3 \%$ were homemakers, $4.9 \%$ were unemployed, $2.7 \%$ were unable to work due to disability, and $2.5 \%$ were retired. A significant majority (89.8\%) reported at least some education beyond high school, with $34.7 \%$ reporting having earned a bachelor's degree, $12.1 \%$ having earned a master's degree, and $1.3 \%$ having earned a doctorate degree. However, despite their high level of education, $78.3 \%$ reported having at least some difficulty meeting financial obligations. The participants' mean BMI based upon self-reported height and weight was 27.7 (S.D. = 7.52; overweight classification), with a mean chest size of 36.7 inches $(S . D .=3.46$, median $\&$ mode $=$ 36 inches) and median and mode cup size of "C."

Regarding breast screening, $85.2 \%$ reported having had at least one clinical breast exam within their lifetime, and $26.9 \%$ reported having had at least one mammogram within their lifetime. Specific to BSE, $85.5 \%$ reported having performed a breast self-examination at least once, although only $74.9 \%$ reported having been given instruction regarding proper performance of BSE. Finally, participants reported having first heard about BSE at a mean age of 17.0 years $(S . D .=5.24)$.

Finally, characteristic comparisons between the current sample and the Behavioral Risk Factor Surveillance Survey sample (BRFSS; Center for Disease Control, Behavioral Risk Factor Surveillance System; 2012) can be viewed in Table 1. Of note, the current sample is significantly younger than the BRFSS sample, which is likely due to use of different data collection methods (e.g., online survey versus telephone survey). Also, this age difference likely contributed to the 
other significant differences observed between these samples, including a greater proportion of the current sample having attained post-secondary education, being employed or self-employed, lacking health insurance, having a normal body mass index, and not having had a mammogram in the last two years (final comparison excluded participants younger than 40 years old).

\section{Materials and Measures}

Below are descriptions of each of the questionnaires and measures used. Means, standard deviation, range, skew, and kurtosis information can be found in Table 2. For each measure, if there were missing data, individual mean substitution was used. Individual mean substitution refers to calculating a mean value of the answered items on a scale, then substituting this mean as the value of the missing items (Widaman, 2006). After verifying that there was no discernible pattern in missing items (e.g., participants omitting responses for one particular item at a higher rate than others), individual mean substitution was used if, and only if, $75 \%$ of the items on a scale (i.e. 3 out of 4 questions on a scale) were answered. If participants answered less than $75 \%$ of the items, their data for the scale was excluded from further analysis. Due to the low rate of missing data, this method preserved only one to two data points per construct.

Demographic variables. The demographic questionnaire included background and personal items pertaining to characteristics such as age, ethnicity, subjective breast cancer risk, highest level of education, occupational status, personal history of breast cancer, health insurance coverage, and belief about the effectiveness of BSE at detecting breast cancer.

To assess objective breast cancer risk based on family history of cancer, participants were asked to report up to ten family members who had been diagnosed with cancer. For each family member, participants were asked to report age at which cancer was diagnosed, type of cancer, 
and the relationship between the participant and the family member who had been diagnosed with cancer (e.g., paternal grandmother). This information was then used to calculate objective breast cancer risk using the Ontario Family History Assessment Tool. This assessment was devised to provide physicians a simple instrument to determine which female patients to refer for genetic counseling (Gilpin, Carson, \& Hunter, 2000). Using this tool, patients are asked to report each member of their family who was diagnosed with breast, ovarian, prostate, or early-onset colon cancer (diagnosed before age 50). Individual scores are assigned for each family member diagnosed with cancer; scores are weighted based on characteristics including age at cancer onset, type of cancer, and degree of relationship to patient (first-third degree relatives). A total score is calculated for each side of a patient's family. A score greater than nine warrants a referral for genetic counseling. In the present study, this procedure was modified slightly. Despite being instructed to do so, participants overwhelmingly neglected to distinguish between paternal and maternal relatives. Therefore, a total score was calculated based on both sides of a participant's family, with higher scores indicating greater objective breast cancer risk.

Participants also were asked to complete a series of items pertaining to knowledge of breast cancer risk factors and breast cancer symptoms that have been used in prior research (e.g., Grunfeld, Ramirez, Hunter, \& Richards, 2002). Regarding breast cancer risk factors, participants were presented with a list composed of ten established risk factors (e.g., family history of breast cancer) and five non-risk factors (e.g., stress), then were asked, "Please choose the factors that increase a woman's chance of developing breast cancer." Correct answers were summed to produce a total score (no points were awarded or subtracted for identification of non-risk factors), with higher scores indicating greater knowledge of breast cancer risk factors (possible score range $=0-10)$. 
Knowledge of breast cancer symptoms was similarly assessed. Participants were presented with a list of 12 breast changes (e.g., painless breast lump, breast swelling), eight of which have been identified as potential symptoms of breast cancer (e.g., Grunfeld et al., 2002). Participants were then asked, "Please select all of the symptoms that are potential symptoms of breast cancer." Once again, correct responses were summed to produce a total score, with higher scores indicating greater knowledge of breast cancer symptoms (possible score range $=0-8$ )

Finally, multiple items from the BRFSS were included in the survey to allow for comparisons to be made between the study sample and the BRFSS's nationally-representative sample (Table 1). Items included assessments of health status, "Would you say that in general your health is?" $(1$ = Poor, $5=$ Excellent $)$, and health care access, "Do you have any kind of health care coverage, including health insurance, prepaid plans such as HMOs, or government plans such as Medicare or Indian Health Services?" $(1=$ no, $2=$ yes $)$. Also, one breast cancer screening item was included, "A mammogram is an x-ray of each breast to look for breast cancer. Have you ever had a mammogram?” $(0=$ no, $1=$ yes $)$.

Breast self-examination frequency. As has been done in prior studies (e.g., Ashton et al., 2001), frequency of BSE behavior was measured by asking participants two questions. First, participants were asked "Have you ever performed a BSE?" $(0=$ no, $1=$ yes $)$. Then, participants were asked "How often have you performed BSE during the past six months?" using a six-point scale $(1=$ never, $2=$ once every 6 months, $3=$ once every three months, $4=$ monthly $5=$ weekly, $6=$ daily) to measure frequency of BSE. Participants were then coded into four groups: Never (those who endorsed never performing BSE), Infrequent (those who endorsed once every 6 months), Recommended (those who endorsed once every three months or monthly, based on recommendations by the American Cancer Society, 2012), and Excessive (those who endorsed 
weekly or daily BSE). Although an abundance of research has studied BSE frequency using a single item, there is a lack of reported psychometric data regarding this measure of BSE frequency.

Breast self-examination proficiency. For the purpose of this study, a scale that included a series of knowledge-based items pertaining to BSE protocol was created to measure BSE proficiency, based on proposals from prior research (e.g., Harvey et al., 1997; Champion, 1988). Seven items were created based on current BSE guidelines that were updated by the American Cancer Society in 2012. The total number of correct responses (some items had multiple correct responses, each of which contributed to the total score) was summed, ranging from 0 to 11 . Higher scores indicated greater BSE proficiency.

Breast awareness behaviors. For the purpose of this study, breast awareness behaviors were measured using two items, frequency of lump checking and frequency of examining one's breasts in the shower (Kelly et al., 2000; Kelly et al., 2001). Frequency of lump checking was measured using the item, "How many times in the last month have you felt for lumps?" Frequency of shower examinations was measured with the item, "How many times in the last month have you examined your breasts while in the shower?" A five-point scale was used for both items $(1=$ not at all, $5=$ more than once a day $)$.

Health Belief Model. The Health Belief Model was measured using Champion's Health Belief Model Scale (HBM Scale; Champion, 1993). The scale is composed of seven subscales, including Susceptibility ( 7 items), Seriousness (5 items), Benefits (6 items), Barriers (6 items), Health Motivation (7 items), Self-efficacy (11 items), and Cues to Action (6 items) that correspond to the components of the Health Belief Model using a 5-point Likert-type scale $(1=$ 
strongly disagree, 5 = strongly agree). Example items include, "Completing breast selfexamination each month will allow me to find lumps early" (Benefits subscale) and "I am confident I can perform breast self-examination correctly" (Self-efficacy subscale). A composite score was calculated for each subscale by summing responses for the subscale items with higher scores indicating greater perceived benefits, barriers, etc. In previous research, Cronbach's alphas for the scales ranged from .80 to .93 , indicating good internal consistency, and test-retest correlations after two months ranged from .45 to .70 (Champion, 1993). The authors of the scale conducted a content analysis of scale items using a panel of Health Belief Model experts. They also conducted an exploratory factor analysis to confirm the construct validity of the components of the Health Belief Model. The scale's predictive validity has been demonstrated through associations between HBM Scale responses and past BSE behavior, which was positively associated with susceptibility $(r=.20)$, health motivation $(r=.35)$, and self-efficacy $(r=.25)$; inversely associated with barriers $(r=-.33)$; and not significantly associated with benefits ( $r=$ $.14)$ or perceived seriousness ( $r=-.01$; Champion, 1993).

In the present study, all subscales had acceptable internal consistency: Seriousness ( $\alpha=$ $.80)$, Susceptibility ( $\alpha=.93)$, Benefits $(\alpha=.82)$, Barriers $(\alpha=.81)$, Self-Efficacy $(\alpha=.91)$, and Health Motivation $(\alpha=.77)$. In addition to the HBM scales, participants were given the opportunity to identify whether any of the following sources cued them to perform BSE: a health care provider (73.2\%), public health campaign (44.6\%), celebrity/public figure's health disclosure (13.8\%), experiencing breast cancer symptoms (11.8\%), family or friend with breast cancer (20.1\%), and/or encouragement from friends or relatives (13.5\%).

Theory of Planned Behavior. The Theory of Planned Behavior was measured with items that have been used in multiple prior studies (e.g., McCaul et al., 1993). To assess attitudes 
about BSE, participants were presented with ten semantic-differential scales. The scales ranged from one to seven with endpoints labeled harmful-beneficial, pleasant-unpleasant, etc. In prior studies, Cronbach's alpha for this scale was .78 (McCaul et al., 1993); in the present study, the Cronbach's alpha was .89. Additionally, subjective norm was assessed using a single item, “How likely is it that most people important to you think that you should conduct a breast selfexamination once a month?” ( 1 = extremely unlikely, 7 = extremely likely). Intention to perform BSE also was assessed using a single item, "I intend to conduct breast self-examination regularly over the next six months." ( 1 = strongly disagree, $5=$ strongly agree $)$. Finally, self-efficacy was measured using the Self-efficacy Subscale of the Champion Health Belief Model Scale. Regarding validity, BSE practice has been positively associated with attitudes $(r=.43)$, subjective norm $(r=.35)$, self-efficacy $(r=.51)$, and intention $(r=.72$; Norman \& Hoyle, 2004), suggesting the theory demonstrates predictive validity.

Extended Parallel Process Model. The Extended Parallel Process Model overlaps significantly with the Health Belief Model. Specifically, perceived seriousness, perceived susceptibility, self-efficacy, and perceived benefits composes both theories; thus, these constructs were measured with the Champion's Health Belief Model Scale as described above. To assess the fear component of this model, participants completed the Breast Cancer Fear Scale (Champion et al., 2004). Participants were asked to complete eight items pertaining to breast cancer specific fear using a five-point Likert-type scale $(1=$ strongly disagree, $5=$ strongly agree). Sample items include, "The thought of breast cancer scares me" and "When I think about breast cancer, I feel nervous". The Cronbach's alpha in prior studies was .91 (Champion et al., 2004); in the present study, the Cronbach's alpha was .95. Additionally, construct validity has been verified through factor analysis, with all items loading on a single factor. The Breast Cancer 
Fear Scale also has demonstrated good test-retest reliability after two months $(r=.70$; Champion et al., 2004) and convergent validity (correlations with cancer fatalism $=.19$; perceived susceptibility $=.26$; perceived seriousness $=.48$; self-efficacy $=-.085$; and cancer information avoidance $=.24$; Miles, Voorwinden, Chapman, \& Wardle, 2008).

Trait anxiety. Trait anxiety was measured using the 21-item Trait Anxiety subscale of the State-Trait Inventory for Cognitive and Somatic Anxiety (STICSA; Ree, French, MacLeod, \& Locke, 2008). Trait anxiety refers to how uneasy individuals generally feel. Participants were asked to read each statement then to indicate "How often, in general, the statement is true of you" using a four-point scale $(1=$ not at all, $4=$ very much so $)$. Sample items include, "My heart beats fast," "I picture some future misfortune," and "I worry I cannot control my thoughts as well as I would like to.” In prior research (e.g., Grös, Antony, Simms, \& McCabe, 2007), this subscale evidenced a Cronbach's alpha of .91; in the present study, the alpha was .93. The scale has also demonstrated convergent (correlations with the STAI Trait $=.66$; DASS Anxiety $=.68$ ) and discriminant (observably lower correlations with the DASS Depression $=.58$; STAI State $=$ .58) validity. Of note, the STAI-Trait subscale, the most widely used measured of trait anxiety in psychological research, evidenced a stronger relation with the DASS Depression scale $=.64$ and a weaker relation with the DASS Anxiety $=.52$ than did the Trait Anxiety subscale of the STICSA. Together these findings suggest that the STICSA may better discriminate between anxiety and depression symptoms that the STAI; thus, it may be a more specific measure of anxiety.

Breast cancer worry. Breast cancer worry was measured using the seven-item Worry Interference Scale (WIS; Trask et al. 2001). The WIS measures the degree to which thoughts of breast cancer interfere with an individual's daily functioning using a 5-point scale $(1=$ not at all, 
$5=\mathrm{a}$ lot). Sample items include "Fears of developing breast cancer have affected my relationships with others" and "Thoughts of breast cancer have affected my ability to sleep." A composite worry score was calculated by summing responses with higher scores indicating greater breast cancer worry. Cronbach's alpha coefficients have been reported to range from .89 to .94 across samples of clinic patients (Trask et al., 2001), and similar internal consistency was found in the present sample $(\alpha=.91)$. The WIS has good test-retest reliability after one month $(r$ $=.73$ ) and convergent validity (correlations with the POMS Anxiety $=.40$; POMS Depression $=$ .30 ; POMS Confusion $=.30$; Total Mood Disturbance $=.39$; and SF-36 Mental Health Functioning $=-.27$; SF-36 Emotional Role Functioning $=-.28$; SF-36 Physical Role Functioning $=-.20)$.

Body dissatisfaction. Body dissatisfaction was measured using the seven-item Appearance Evaluation subscale of the Multidimensional Body-Self Relations Questionnaire (MBSRQ-AE; Cash, Winstead, \& Janda, 1985). Participants rated items, such as "I like my looks just the way they are" and "Most people would consider me good looking," using a 5-point Likert-type scale $(1=$ definitely disagree, $5=$ definitely agree $)$. A composite score was calculated by summing responses to the seven scale items and dividing by the number of items, with higher scores reflecting greater dissatisfaction with one's body. Prior studies have found strong internal consistency for the MBSRQ-AE ( $\alpha=.88$; Brown, Cash, \& Mikulka, 1990) and test-retest reliability over three months $(r=.91$; Cash, 1994). In the present study, the Cronbach's alpha was .92. Additionally, the MBSRQ-AE has been correlated with BMI ( $r=-.38$ to -.39$)$, body shame ( $r=-.31$ to -.47$)$, body surveillance ( $r=-.45$ to -.47 ), binge eating $(r=-.32$ to -.57$)$, and appearance control ( $r=.22$; Kelly et al., 2012). 
Cancer fatalism. The Powe Cancer Fatalism Scale (Powe, 1995) was used to measure cancer fatalism, the notion that death is inevitable if cancer develops (Powe \& Finnie, 2003). The scale is comprised of 15 items rated using a 5 -point scale $(1=$ strongly agree, $5=$ strongly disagree). Sample items include, "I believe if someone has cancer, it is already too late to do anything about it" and "I believe if someone gets cancer, it was meant to be." In prior studies, Cronbach's alphas have ranged from .84 to .89 (Powe, 2001); in the present study, the Cronbach's alpha coefficient was .90 . Validity has been demonstrated through associations with breast cancer fear ( $r=.19$; Miles et al., 2008), non-engagement in mammography screening ( $\beta=$ .34; Farmer et al., 2007), and education ( $r=-.48$; Powe, 1995).

God locus of health control. The God Locus of Health Control Scale (GLHC, Wallston et al., 1999) was used to measure the belief that God controls health changes and outcomes. The scale is comprised of six items rated using a 6 -point scale $(1=$ strongly disagree, $6=$ strongly agree). A sample item includes, "If my health worsens, it is up to God to determine whether I will feel better again." In prior studies, Cronbach's alphas ranged from .87 to .91 (Holt, Clark, \& Klem, 2007); in the present study, the Cronbach's alpha coefficient was .98. The scale has evidenced convergent validity; it has been positively associated with the powerful others $(r=$ $.22)$ and chance $(r=.47)$ subscales of the Multidimensional Health Locus of Control Scale, passive pain coping $(r=.19)$, religiosity subscale of the Ways of Coping Checklist Revised ( $r=$ $.49)$, and negative affect $(r=.31)$, and inversely associated with positive affect $(r=-.18$; Holt et al., 2007).

Religiousness. The Brief Multidimensional Measure of Religiousness/Spirituality (BMMRS) was developed to provide a variety of brief measures of religion for psychological research (Fetzer Institute, 1999). The wording of the scale items are designed to apply across a 
broad range of religious groups. Religious beliefs, a cognitive religious construct measuring the extent to which an individual endorses strong religious beliefs, was measured using the five-item Religious Beliefs Scale of BMMRS. The scale uses a 5-point Likert-type scale ( $1=$ agree strongly, 5 = disagree strongly), with sample items including "When faced with a tragic event I try to remember that God still loves me and that there is hope for the future" and "I think that everything that happens has a purpose." Psychometric data for the Religious Beliefs Scale have not been reported; however, when used in conjunction with the Religious Values Scale of the BMMRS, the Cronbach's alpha has been reported as .64. In the present study, the Religious Beliefs Scale had strong internal consistency $(\alpha=.90)$. In addition, the Religious Beliefs Scale has been correlated with connectedness to nature/world $(r=.22)$ and mysticism $(r=.41$; Johnstone, McCormack, Yoon, \& Smith, 2012).

Organizational religiousness. The second measure of religiousness was a five-item organizational religiousness scale from Kenney, Vaughn, and Cromwell (1977). Participants were asked to answer questions regarding their religious involvement, such as "I take part in various religious organizations" and "I attend religious services," using a 4-point scale $(1=$ rarely/never, $4=$ very frequently). A composite score was calculated by summing the responses from the five items. In the present study, the scale had strong internal consistency $(\alpha=.92)$, consistent with prior research $(\alpha=.88$; Kenney et al., 1977). A factor analysis of the broader scale used by Kenney et al. (1977) showed that organizational religiousness diverged from attitudes toward religiosity in one's personal and family life and consumption of religious media. Also, the organizational religiousness scale has been significantly correlated with self-rated religiosity $(r=.35)$ and church attendance $(r=.71$; Kenney et al., 1977).

\section{Design and Procedure}


Individuals who wished to participate selected the study on Amazon's Mechanical Turk, and were redirected to SurveyMonkey. Participants were then presented with an informed consent form that outlined the purpose of the study and informed them that they have the opportunity to discontinue participation at any time. Those who consented were presented with the above-mentioned measures, with the opportunity to decline answering any question they did not wish to answer. Initially, participants were asked to indicate their sex. Those who answered "male" were redirected to a parallel study of testicular self-examination. Those who answered "female" were directed to questions about BSE, their health, and their utilization of screening procedures (e.g., mammography), followed by questions regarding their personal and family history of breast and other cancers, questions regarding their knowledge of breast cancer risk factors and symptoms, Champion's Health Belief Model Scale, Theory of Planned Behavior items, the Breast Cancer Fear Scale, Powe Cancer Fatalism, the trait subscale of the State-Trait Inventory for Cognitive and Somatic Anxiety, the Worry Interference Scale, the Multidimensional Body-Self Relations Questionnaire, the Religious Beliefs Scale, the Organizational Religiousness scale, the God Locus of Health Control Scale, questions regarding their health insurance, and the demographic questionnaire. After completing the survey, participants were thanked for their participation and provided a list of local and national counseling and clinical providers as well as the researchers' contact information. Within five days of participation, after participants' data were reviewed for validity, participants were provided payment for completing the study $(\$ 1)$, paid to their Amazon accounts.

\section{Chapter 5: Results}

Prior to any analyses, the data were screened for violations of assumptions of the statistical analyses. After the data were screened, preliminary analyses were conducted to 
determine which potential predictors to include in analyses predicting each of the outcome variables (BSE frequency, BSE proficiency, lump checking frequency, and frequency of examining breasts while in the shower). Based on the strategy outlined by Hosmer and Lemeshow's (2000), preliminary analyses were conducted to examine relations between each hypothetical construct and each outcome variable. All significant relations between variables identified through preliminary analyses (or those trending toward significance: $p<.10$ ) were then used in the primary analysis for examining proportion of variance explained for BSE frequency, BSE proficiency, lump checking frequency, and frequency of examining breasts while in the shower.

For BSE frequency, the primary analytic approach involved conducting a series of multinomial logistic regressions with each of the predictors entered simultaneously. Multinomial logistic regressions were chosen for multiple reasons. First, recall that over-adherence to BSE may result in reduced efficacy of the procedure and less thorough examinations (Brain et al., 1999). Given that the association between frequency of BSE performance and the quality of outcomes is not linear, treating the variable as a linear outcome was not considered appropriate. Second, multinomial logistic regressions allow researchers to determine whether particular characteristics differentiate between groups; thus, if different frequencies of BSE performance are associated with different health benefits or outcomes, it is particularly relevant to identify characteristics that may increase or decrease the likelihood of one's adherence to this health behavior. Third, multinomial logistic regression does not require normality or homoscedasticity (Tabachnick \& Fidell, 2007). Of note, only $5.4 \%$ of the sample $(\mathrm{n}=34)$ endorsed excessive performance of BSE. Although this sample size is small, it did allow for examination of relatively robust predictors of group membership. 
For BSE proficiency, lump checking frequency, and frequency of examining one's breasts while in the shower, the primary analytic approach employed conducting three-step hierarchical regressions. For each of these analyses, personal and demographic variables (e.g., age) were entered in the first step, theory-related constructs (e.g., attitudes, benefits, cues) were entered in the second step, and hypothesized psychosocial constructs of interest (e.g., anxiety, religiousness) were entered in the third step.

As part of the preliminary analyses, potential differences in outcomes based on marital status of study participants were investigated. However, for certain statuses, the total number of participants was too small for inclusion in regression analyses (e.g., separated $=2.4 \%$ of sample, widowed $=1.2 \%)$. To attempt to retain as much power as possible, t-tests and Mann-Whitney $\mathrm{U}$ tests comparing the small- $N$ groups to the other groups on each of the four outcome measures were conducted to determine whether groups could be collapsed. Although the analyses indicated that there was no clear group with which the widowed participants could be combined, the divorced and separated participants were not significantly different on any outcomes $(p s=$ .332-.816); in fact, the divorced and separated groups were not significantly different on any of the variables of interest in this study $(p=.105-.973)$. Thus, divorced and separated participants were collapsed into a single group for purposes of analysis.

\section{Data Screening}

Data were initially screened to determine the nature of missingness. A total of 20 participants were missing data on one or more relevant constructs. When individuals with complete data were compared to those who were missing scores, it was found that all missing data was missing completely at random, as there were no significant differences between those 
who had scores on particular scales and those who did not on any construct, suggesting that missing data would not affect conclusions. In fact, for a majority of the constructs, fewer than five participants were missing scores.

Next, univariate outliers were explored by converting raw scores to z-scores. Converting raw scores to z-scores revealed a total of 21 univariate outliers (z-scores greater than $|3|$; Tabachnick \& Fidell, 2007): three in identification of breast cancer symptoms, 15 on the measure of breast cancer worry, one on the measure of cancer fatalism, one on the measure of trait anxiety, and on the measure of attitudes. These 21 participants were removed from further analysis. Skew and kurtosis were also explored. A complete documentation of constructs' skew and kurtosis, and subsequent transformations, can be found in Table 2. Transformation was considered if skew or kurtosis statistics (corrected for by standard error) exceeded a value of |3|. Eight variables which had skew or kurtosis issues were not transformed to preserve the meaning associated with particular scores (e.g., BMI). Untransformed scores were used for an additional three variables with skew or kurtosis issues because transformations exacerbated these issues. Ten variables underwent square root or logarithmic transformations to correct issues with non-normality; of note, all but one of these variables maintained either skew or kurtosis concerns post-transformation, but their distributions were closer to normal.

After investigating outliers, skew, and kurtosis, linearity of relations among study variables was examined using scatterplots, and homoscedasticity was assessed using regressions and a series of one-way ANOVAs. There were no indications of nonlinear relations between the constructs. Regressions with each of the variables predicting BSE frequency, BSE proficiency, checking for lumps, and examining breasts in the shower were used to assess homoscedasticity, with the P-P plots showing little deviation from the least squares line. The scatterplot with the 
standardized residuals regressed onto the standardized predicted value also showed no perceptible pattern. The Levene Statistics from a series of one-way ANOVAs examining differences among BSE frequency groups on each of the continuous variables were not significant, indicating that there were no homogeneity of variance issues.

Finally, using a regression with each of the constructs predicting participant ID scores, tolerance and VIF scores were used to assess multicollinearity, and multivariate outliers were assessed using participants' leverage and Mahalanobis distance scores. All tolerance and VIF scores were at acceptable levels (tolerance greater than .4, VIF less than 2.5; Tabachnick \& Fidell, 2007). Additionally, no participants exerted excessive leverage (greater than three times the average leverage score; Tabachnick \& Fidell, 2007). Lastly, a total of 20 participants exceeded the critical value for Mahalanobis distance, meaning their combination of scores was different from the majority of participants; thus, those 20 participants were excluded from further analyses.

\section{Overview of Breast Awareness Behaviors}

Based on reported frequency of BSE performance, participants were divided into four groups: Never $(\mathrm{n}=155 ; 24.8 \%)$, Infrequent $(\mathrm{n}=168 ; 26.8 \%)$, Recommended $(\mathrm{n}=269 ; 43.0 \%)$, and Excessive $(\mathrm{n}=34 ; 5.4 \%)$. In addition, on average, participants endorsed checking for lumps and examining breasts in the shower about once per month. Regarding proficiency, participants, on average, identified $6.2(S . D .=1.81)$ of the 11 components of a proper BSE. The responses were as follows: $33.7 \%$ identified the appropriate parts of the hand to use to examine the breast tissue, $21.3 \%$ identified the correct levels of pressure to apply, 29.3\% identified all of the parts of the body that should be examined during BSE, $28.1 \%$ correctly identified the length of time (in 
minutes) it takes to perform BSE properly, $78.9 \%$ identified the recommended frequency to perform BSE, $49.4 \%$ identified the recommended pattern of examination, and 35.6\% identified both positions in which BSE should be performed.

In addition, the intercorrelations between the study outcome variables are presented in Table 3. BSE frequency was positively correlated with lump checking $(r=.547)$ and shower checking $(r=.464)$, and lump checking and shower checking also were positively correlated $(r=$ .553). Notably, BSE proficiency was not significantly correlated with any of the frequency measures, including BSE frequency.

\section{BSE Frequency Preliminary Analyses}

To determine which variables should be included as predictors of BSE frequency in the multinomial logistic regression predicting BSE frequency, a series of one-way ANOVAs and chi-square analyses were conducted. Descriptive information for study variables for each BSE frequency group can be found in Table 4. From the one-way ANOVAs (for complete results from the one-way ANOVAs, see Table 5), differences between the four groups (Never, Infrequent, Recommended, Excessive) were found in the following variables: age $(F(3,619)=$ $18.91, p<.001)$, bra size $(F(3,612)=2.48, p=.060)$, perceived BSE effectiveness $(F(3,619)=$ $5.71, p=.001)$, knowledge of breast cancer risks $(F(3,622)=3.85, p=.009)$, knowledge of breast cancer symptoms $(F(3,622)=2.48, p=.060)$, attitudes $(F(3,622)=24.82, p<.001)$, subjective norm $(F(3,622)=15.33, p<.001)$, intention $(F(3,622)=77.29, p<.001)$, benefits $(F(3,622)=20.65, p<.001)$, barriers $(F(3,622)=32.95, p<.001)$, self-efficacy $(F(3,622)=$ $52.92, p<.001)$, health motivation $(F(3,622)=16.07, p<.001)$, anxiety $(F(3,622)=4.28, p=$ $.005)$, body dissatisfaction $(F(3,621)=2.30, p=.077)$, cancer fatalism $(F(3,622)=3.06, p=$ 
$.028)$, god locus of health control $(F(3,622)=3.99, p=.008)$, religious beliefs $(F(3,622)=$ $4.40, p=.004)$, and organizational religiousness $(F(3,621)=2.63, p=.050)$.

From the chi-square analyses (Tables 6-15), significant differences were found for marital status $\left(\chi^{2}(9)=29.91, p<.001\right)$, having ever had a mammogram $\left(\chi^{2}(3)=37.75, p<\right.$ $.001)$, having ever had a clinical breast exam $\left(\chi^{2}(3)=30.92, p<.001\right)$, being cued by a health care provider to perform BSE $\left(\chi^{2}(3)=46.84, p<.001\right)$, being cued by a family member or friend with breast cancer to perform BSE $\left(\chi^{2}(3)=10.97, p=.012\right)$, and being encouraged by a friend or relative to perform $\operatorname{BSE}\left(\chi^{2}(3)=12.40, p=.006\right)$.

\section{Multinomial Logistic Regression Predicting BSE Frequency}

A series of three multinomial logistic regressions were conducted to investigate whether personal, theory, and/or psychosocial variables that were identified in the preliminary analyses differentiated the four BSE frequency groups (never, infrequent, recommended, and excessive). Of note, the predictors in each of the three multinomial logistic regressions were identical. The only aspect of the analysis that changed across regressions was the reference group [the reference group was "never" in the first analysis (contrasted with "infrequent," "recommended," and "excessive"), "infrequent" in the second analysis (contrasted with "recommended" and "excessive"), and "recommended" in the third analysis (contrasted with "excessive")]. The multiple analyses were necessary to view comparisons between all groups. The chi-square statistics $\left(\chi^{2}(78)=412.711, p<.001\right)$ and effect size statistics (McFadden Pseudo $\left.R^{2}=.291\right)$ were identical for each analysis, reflecting an overall significant association between predictor variables and BSE frequency category.

The first analysis (Table 16) revealed that, relative to participants in the "never" group, 
participants in the "infrequent" group reported a smaller bra size $(O R=0.91)$, greater intention $(O R=1.98)$, fewer barriers $(O R=0.41)$, greater self-efficacy $(O R=1.95)$, being cued by a health care provider $(O R=2.76)$, being encouraged by a friend or relative to perform BSE $(O R=$ 4.60), and less anxiety $(O R=0.37)$. Relative to participants in the "never" group, participants in the "recommended" group were older $(O R=1.08)$ and reported greater intention $(O R=3.83)$, fewer barriers $(O R=0.38)$, greater self-efficacy $(O R=2.21)$, being cued by a health care provider $(O R=2.73)$, and being encouraged by a friend or relative to perform BSE $(O R=6.28)$. Finally, relative to participants in the "never" group, participants in the "excessive" group were older $(O R=1.07)$, had a greater knowledge of breast cancer risk factors $(O R=1.26)$, perceived BSE to be more effective $(O R=2.89)$, reported greater intention $(O R=6.89)$, perceived fewer barriers $(O R=0.06)$, reported greater self-efficacy $(O R=2.80)$, and were encouraged by a friend or relative to perform $\mathrm{BSE}(O R=5.19)$

The second analysis (Table 17) revealed that, relative to participants in the "infrequent" group, those in the "recommended" group were older $(O R=1.05)$ and reported greater intention $(O R=1.94)$, greater health motivation $(O R=1.09)$, greater anxiety $(O R=2.54)$, and greater cancer fatalism $(O R=1.03)$. Relative to those in the "infrequent" group, those in the "excessive" group reported having a greater knowledge of breast cancer risk factors $(O R=1.34)$, perceived BSE to be more effective $(O R=4.13)$, had never had a clinical breast exam $(O R=0.17)$, reported greater intention $(O R=3.49)$, perceived fewer barriers $(O R=0.14)$, and reported greater body dissatisfaction $(O R=1.88)$.

The final analysis (Table 18) revealed that, relative to participants in the "recommended" group, participants in the "excessive" group reported having a greater knowledge of breast cancer risk factors $(O R=1.24)$, perceived BSE to be more effective $(O R=3.53)$, had never had 
a clinical breast exam $(O R=0.15)$, perceived fewer barriers $(O R=0.15)$, and greater body dissatisfaction $(O R=1.89)$.

\section{Exploratory Analyses}

Additional analyses were conducted to determine if frequency of BSE engagement was predicted by having a first-degree relative (e.g., mother) diagnosed with breast cancer. These analyses were not significant. In addition, follow-up mediation and moderation analyses were conducted to more thoroughly examine the relations among $\mathrm{CBE}$, body dissatisfaction, and excessive engagement in BSE relative to recommended BSE engagement. The mediational test examined whether body dissatisfaction mediated the association between having ever had a CBE and performing BSE excessively relative to performing BSE at recommended frequencies. This test was not significant, indicating that body dissatisfaction did not mediate the relation between having a clinical breast exam and excessive BSE engagement. The moderation analysis found that, among women who had never had a clinical breast exam, those with less body dissatisfaction performed BSE at the recommended frequency while those with high body dissatisfaction performed BSE excessively. An additional follow-up moderation analysis did not find evidence of an interaction effect for health insurance and body dissatisfaction among women who practiced BSE excessively relative to women who practiced BSE at a recommended frequency.

\section{BSE Proficiency Preliminary Analyses}

To determine which variables should be included as predictors in the hierarchical regression predicting BSE proficiency, a series of correlations and one-way ANOVAs were conducted. Personal and demographic variables correlated with BSE proficiency (Table 19) 
included age ( $r=-.14)$, having financial difficulties $(r=-.07)$, age at which participants heard of BSE $(r=-.10)$, knowledge of breast cancer risk factors $(r=.24)$, knowledge of breast cancer symptoms $(r=.26)$, subjective breast cancer risk $(r=.13)$, and objective breast risk $(r=.07)$. Theory variables associated with BSE proficiency (Table 20) included intention $(r=.09)$, susceptibility $(r=.13)$, benefits $(r=.12)$, self-efficacy $(r=.11)$, and breast cancer fear $(r=.07)$, and psychosocial variables with associations with BSE proficiency (Table 21) included anxiety $(r=.11)$, breast cancer worry $(r=.08)$, cancer fatalism $(r=-.07)$, body dissatisfaction $(r=-.09)$, and religious beliefs $(r=-.09)$.

For the one-way ANOVAs (Table 22), significant differences in BSE proficiency were found on four cues: a public health campaign $(F(1,612)=4.08, p=.044)$, experiencing breast cancer symptoms $(F(1,612)=5.89, p=.016)$, a family member or friend having breast cancer $(F(1,612)=8.07, p=.005)$, and being encouraged by a friend or relative to perform BSE $(F(1$, $612)=6.09, p=.014)$.

\section{Hierarchical Regression predicting BSE Proficiency}

Based on the preliminary analyses, age, financial difficulties, age at which participants heard of BSE, knowledge of breast cancer risk factors, knowledge of breast cancer symptoms, subjective breast cancer risk, and objective breast cancer risk were entered in the first step of the hierarchical regression predicting BSE proficiency (Table 23); intention, susceptibility, benefits, self-efficacy, being cued by a public health campaign, being cued by experiencing breast cancer symptoms, being cued by a family member or friend with breast cancer, being encouraged by a friend or relative, and breast cancer fear were entered in step two; and anxiety, breast cancer worry, cancer fatalism, body dissatisfaction, and religious beliefs were entered on step three. 
Step one significantly predicted BSE proficiency $\left(R^{2}=.136\right.$, Adjusted $R^{2}=.125, F(6,579)=$ $12.98, p<.001)$, with age $(\beta=-.193)$, knowledge of breast cancer risk factors $(\beta=.168)$, and knowledge of breast cancer symptoms $(\beta=.216)$ as unique predictors. Step two also significantly predicted BSE proficiency $\left(R^{2}=.161\right.$, Adjusted $\left.R^{2}=.138, F(16,570)=6.85, p<.001\right)$ and accounted for significantly more variance than step one $\left(R^{2} \Delta=.026, F \Delta(9,570)=1.94, p=\right.$ $.044)$. The unique predictors were age $(\beta=-.221)$, knowledge of breast cancer risk factors $(\beta=$ $.158)$, knowledge of breast cancer symptoms $(\beta=.189)$, and self-efficacy $(\beta=.103)$. The final step $\left(R^{2}=.181\right.$, Adjusted $\left.R^{2}=.151, F(21,565)=5.95, p<.001\right)$ predicted significantly more variance as well $\left(R^{2} \Delta=.020, F \Delta(5,565)=2.72, p=.019\right)$, with age $(\beta=-.211)$, knowledge of breast cancer risk factors $(\beta=.157)$, knowledge of breast cancer symptoms $(\beta=.191)$, selfefficacy $(\beta=.126)$, and body dissatisfaction $(\beta=-.085)$ as unique predictors.

\section{Frequency of Lump Checking Preliminary Analyses}

As with BSE proficiency, a series of correlations and one-way ANOVAs were conducted to determine which variables to include as predictors of lump checking frequency. Among personal and demographic variables (Table 24), only age $(r=.16)$ and perceived BSE effectiveness $(r=.15)$ were significantly correlated with lump checking frequency, though it was significantly correlated with several theory-related constructs (Table 25): attitudes $(r=.19$ ), subjective norm $(r=.16)$, intention $(r=.34)$, benefits $(r=.16)$, barriers $(r=-.25)$, self-efficacy $(r$ $=.22)$, and health motivation $(r=.10)$. Psychosocial variables with associations with lump checking frequency (Table 26) were religious beliefs $(r=.07)$ and organizational religiousness $(r$ $=.07$ ). In the one-way ANOVAs (Table 27), significant differences in lump checking frequency were found with undergoing mammography $(F(1,618)=16.95, p<.001)$, experiencing breast cancer symptoms $(F(1,623)=17.74, p<.001)$, and being encouraged by a friend or relative to 
perform BSE $(F(1,612)=3.14, p=.077)$.

\section{Hierarchical Regression Predicting Frequency of Lump Checking}

Based on preliminary analyses, age, perceived BSE effectiveness, and mammography were entered on the first step of the hierarchical regression predicting frequency of lump checking (Table 28); attitudes, subjective norm, intention, benefits, barriers, self-efficacy, health motivation, being cued by experiencing breast cancer symptoms, and being encouraged by a friend or relative were entered on the second step; and religious beliefs and organizational religiousness were entered on the third step. Variables entered in the initial step did significantly predict lump checking frequency $\left(R^{2}=.051\right.$, Adjusted $\left.R^{2}=.046, F(3,606)=10.88, p<.001\right)$, with perceived BSE effectiveness $(\beta=.144)$ and mammography $(\beta=.110)$ as unique predictors.

The second step accounted for significantly more variance than the first step $\left(R^{2}=.187\right.$, Adjusted $\left.R^{2}=.171, F(12,597)=11.46, p<.001 ; R^{2} \Delta=.136, F \Delta(9,597)=11.11, p<.001\right)$, with only intention $(\beta=.299)$, barriers $(\beta=-.132)$, and being cued by experiencing breast cancer symptoms $(\beta=.165)$ as unique predictors. The final step, though significant $\left(R^{2}=.188\right.$, Adjusted $R^{2}=.169$, $F(14,595)=9.86, p<.001)$, did not account for significantly more variance than the third step $\left(R^{2} \Delta=.001, F \Delta(2,595)=0.36, p=.697\right)$. The unique predictors were age $(\beta=.100)$, intention ( $\beta=.303)$, barriers $(\beta=-.128)$, and being cued by experiencing breast cancer symptoms $(\beta=$ $.166)$.

\section{Frequency of Shower Examinations Preliminary Analyses}

Identical to the preliminary analyses for BSE proficiency and checking for lumps, a series of correlations and one-way ANOVAs were conducted for frequency of examining one's breasts in the shower. The demographic and personal variables correlated with shower examinations 
(Table 29) were age $(r=.09)$, education $(r=-.07)$, perceived BSE effectiveness $(r=.10)$, subjective breast cancer risk $(r=-.11)$, and objective breast cancer risk $(r=-.09)$. In addition, several theory variables were significantly correlated with shower examinations (Table 30), including attitudes $(r=.25)$, subjective norm $(r=.13)$, intention $(r=.33)$, susceptibility $(r=-$ $.09)$, benefits $(r=.18)$, barriers $(r=-.23)$, self-efficacy $(r=.26)$, and health motivation $(r=.10)$, but body dissatisfaction $(r=.08)$ and organizational religiousness $(r=.07)$ were the only psychosocial variables that were significantly correlated with the frequency of shower examinations (Table 31). From the one-way ANOVAs (Table 32), the only variable showing even a trend toward being associated with frequency of shower examinations was mammography $(F(1,614)=2.84, p=.092)$.

\section{Hierarchical Regression Predicting Frequency of Shower Examinations}

As with the hierarchical regressions predicting BSE proficiency and lump checking frequency, personal variables (age, education, perceived BSE effectiveness, subjective breast cancer risk, objective breast cancer risk, and having undergone a mammography) were entered in the first step of the hierarchical regression predicting frequency of examining one's breasts in the shower (Table 33); theory variables (attitudes, subjective norm, intention, susceptibility, benefits, barriers, self-efficacy, and health motivation) were entered in the second step; and psychosocial variables (body dissatisfaction and organizational religiousness) were entered in the third step. Step one was significant $(F(6,593)=3.77, p=.001)$, though it only accounted for $3.7 \%$ of the variance $\left(\right.$ Adjusted $\left.R^{2}=.027\right)$, with only education $(\beta=-.083)$ and perceived BSE effectiveness $(\beta=.086)$ as unique predictors. Step two accounted for significantly more variance $\left(R^{2}=.158\right.$, Adjusted $\left.R^{2}=.138, F(14,585)=7.83, p<.001 ; R^{2} \Delta=.121, F \Delta(8,585)=10.50, p<.001\right)$, even though intention $(\beta=.268)$ and self-efficacy $(\beta=.094)$ were the only unique predictors. Step 
three did not account for significantly more variance $\left(R^{2}=.158\right.$, Adjusted $R^{2}=.135, F(16,583)$ $=6.84, p<.001 ; R^{2} \Delta=.0003, F \Delta(2,583)=0.11, p=.898$. $)$, with intention $(\beta=.270)$ and selfefficacy $(\beta=.092)$ once again as the only unique predictors.

\section{Exploratory Analyses}

A number of other exploratory analyses considering possible interactions using two-step regressions were conducted to predict frequency of shower examinations, lump checking, and BSE. Excessive performers of BSE were excluded from the exploratory analyses predicting BSE frequency as greater engagement in BSE may have detrimental effects if performed more frequently than monthly. For the regressions, constructs of interest were entered on the first step, and the interaction term was entered on the second step. Interaction terms included breast cancer worry, breast cancer fear, or trait anxiety by knowledge of breast cancer risk factors, knowledge of breast cancer symptoms, objective breast cancer risk, subjective breast cancer risk, or perceived susceptibility. Additional terms examining health insurance by fatalism or education were also examined. None of these interaction terms significantly predicted BSE frequency, lump checking, or shower examinations.

\section{Chapter 6: Discussion}

Whether women should practice breast self-examination (BSE) has been debated for nearly three decades (e.g., Austoker, 2003), and has prompted many established health organizations to modify their recommendations regarding breast cancer screening. Regarding the fate of BSE, it is recommended that women who choose to perform BSE be educated about the perceived benefits and limitations of the behavior. In place of BSE, current guidelines broadly reflect that women should practice "breast awareness," a vague term that refers to knowing how 
one's breasts normally look and feel. Much like BSE, the purpose of practicing breast awareness is to identify breast changes, then to report these changes to a health care professional. In practice, breast awareness can include BSE, but BSE is not a required component of breast awareness. The purpose of this study was two-fold: (1) to investigate how modern women practice breast awareness behaviors, and (2) to empirically examine how personal, theoretical, and psychosocial constructs may influence women's engagement in breast awareness behaviors, including BSE.

This study is significant in multiple ways. First, it examines how personal and psychosocial variables may influence breast awareness behaviors within the framework of common health behavior theories: the Health Belief Model, the Theory of Planned Behavior, and the Extended Parallel Process Model. Second, prior studies (e.g., Noroozi et al., 2011; PetroNustus \& Mikhail, 2002) have primarily conceptualized and analyzed BSE frequency as a continuous variable; however, this may be inappropriate as there is evidence to suggest a negative tipping point between frequency of BSE performance and any health benefits associated with its practice. More specifically, over-adherence or excessive engagement in BSE, defined as performing BSE more often than monthly, has been associated with more frequent but less thorough examinations and reinforcement of underlying anxiety (Epstein et al., 1997). Within the present study, women were categorized into four groups based on reported frequency of BSE performance: Never, Infrequent, Recommended, or Excessive. Not only was group categorization conceptually appropriate, but is also allowed for identification of variables that differentiated these groups.

\section{Factors Predicting BSE Frequency}


Overall, the Theory of Planned Behavior and Health Belief Model provided an excellent framework to differentiate group membership based on frequency of BSE engagement. Specifically, greater self-efficacy (a component of both theories), perceiving fewer barriers (Health Belief Model), having been cued by a relative or friend (Health Belief Model), and greater intention to perform BSE (Theory of Planned Behavior) differentiated those who never performed BSE from those who performed BSE at any frequency (Infrequent, Recommended, or Excessive). Thus, for the current sample, women who performed BSE were more confident regarding their ability to conduct self-exams and experienced fewer barriers to performing the screening behavior, which is consistent with findings from prior studies (Ashton et al., 2001; Champion, 1988; Gürsoy et al., 2011; Nahcivan \& Secginli, 2007; Noroozi et al., 2011; PetroNustus \& Mikhail, 2002; Umeh \& Rogan-Gibson, 2001). In addition, women who intended to perform BSE within the next six months were more likely to already be practicing BSE, suggesting they intended to continue to engage in the behavior in the future.

The Health Belief Model posits that being internally or externally cued to perform a behavior may facilitate behavior change in multiple ways, by providing information, promoting awareness, and serving as a reminder, which has been supported across a number studies (e.g., Asare, Sharma, Bernard, Rojas-Guyler, \& Wang, 2013; Chin, Huang, \& Hsu, 2013; Juniper, Oman, Hamm, \& Kerby, 2004) that have examined a variety of health behaviors (e.g., condom use, diabetic foot exams, physical activity), including BSE (e.g., Kara \& Acikel, 2009). Expanding on this notion, the findings from the present study suggest that the source of the cue may also be important, at least for BSE. Having been cued to perform BSE by sources such as a public health campaign, celebrity or public figure, personally experiencing abnormal breast symptoms (e.g., change in breast shape), or even being cued by a relative or friend's diagnosis of 
breast cancer did not differentiate performance from nonperformance. In contrast, as stated above, women who performed BSE at any frequency reported having been cued by encouragement from a relative or friend to perform the behavior. Additionally, having been cued by a health care provider differentiated infrequent and regular performers from nonperformers. Together these findings suggest that women who were cued by explicit advice or encouragement from individuals with whom they have personal (e.g., friend, relative) or professional relationships (i.e., health care provider) were more likely to engage in BSE. Simply being cued to perform the behavior through a knowledge-based medium (e.g., public health campaign) or a potentially emotionally-charged experience (e.g., having a family member or friend diagnosed with breast cancer) was not sufficient to promote behavioral engagement in this study sample.

In addition to differentiating performance of BSE from nonperformance, factors also differentiated over-adherence to BSE from all other groups. Women who reported excessive BSE performance (weekly or daily) believed that BSE is an effective screening tool for breast cancer and experienced fewer psychological (e.g., embarrassment) or practical (e.g., limited privacy) barriers to performing the screening behavior compared to all other groups. It logically follows that women who engage in BSE frequently would perceive it to be efficacious and would perceive fewer obstacles to performing the behavior. In addition, excessive practitioners were more knowledgeable of breast cancer risk factors, had never had a clinical breast exam (CBE), and were more dissatisfied with their bodies. These findings could be interpreted in a variety of ways.

First, women who perform BSE excessively in the current study sample had either passively received or actively acquired knowledge about breast cancer. Perhaps this implies that women who have attained knowledge of breast cancer also understand that screening for breast 
cancer, including self-examination, is important for early detection, treatment, and health outcomes. However, they simultaneously may be unaware that practicing BSE too much is counterproductive (Epstein et al., 1997), as this caveat seems to be relatively absent in discussions of BSE or within readily available resources (e.g., internet) about the procedure.

One might expect psychological factors to serve as the mechanism through which knowledge of breast cancer risk factors leads to excessive BSE performance, including perhaps anxiety, fear, or worry about developing breast cancer (e.g., Brain et al., 1999). However, none of these variables was associated with excessive BSE performance, indicating that the function of BSE engagement for this sample may not have been to alleviate negative affect or cognitions about breast cancer, but instead, may have been seemingly innocuous - to simply examine for symptoms of breast cancer. This is speculative as knowledge and beliefs about the role of breast cancer screening in detection, treatment, and health outcomes were not measured in this study. It also is entirely possible that a psychological construct that was not included in the study better explains the mechanism through which knowledge of breast cancer risk factors might lead to excessive engagement in BSE.

Women who over-adhered to BSE reported never having had a clinical breast exam at higher rates than women who practice BSE at recommended and lesser frequencies, even though this method of screening is often a component of regular annual physical exams (American Cancer Society, 2014). Current guidelines recommend that women between 20 and 39 years of age have a clinical breast exam once every three years, and women 40 years of age and older have an exam annually. The age of the study sample $(M=33.22$, S.D. $=11.56)$ was well beyond the initial age at which women typically begin having clinical breast exams. Additionally, 75.9\% of the sample endorsed having health insurance. Thus, it is unlikely that either age or access to 
healthcare were inhibitory factors to these women in explaining the low frequency of clinical breast exams. Perhaps women who performed BSE excessively either opted out of the CBE portion of their annual exams, or more simply, may not adhere to having an annual exam. Either way, as a result, they may be less likely to discuss appropriate breast cancer screening behaviors with health care professionals. As already noted above, the health care provider may uniquely impact BSE engagement. For this group of women, the effect of learning about appropriate breast screening behaviors through interactions with health care providers could potentially promote decreased engagement in BSE to a recommended frequency.

Finally, it was hypothesized that body dissatisfaction would function as a barrier to BSE performance, as it has been demonstrated to inhibit engagement in other cancer screening behaviors (Clark et al., 2009). However, the opposite effect was observed. Women who practiced BSE excessively were more dissatisfied with their bodies. Alternatively, there is some evidence to suggest that women who endorse greater body dissatisfaction are more likely to engage in body checking (Vartanian \& Grisham, 2012), which refers to repeated monitoring of different aspects of one's body for changes through behaviors such as scrutinizing one's body in the mirror or pinching certain body parts to measure "fatness." Extrapolating these findings to BSE, perhaps among women who are dissatisfied with their bodies, these body checking behaviors include BSE or mimic it in appearance. Because these body checking behaviors occur regularly (more than monthly), these women are categorized as excessive BSE practitioners. This is purely speculative as no known study, including the present study, has examined the relation between body checking and engagement in breast screening behaviors.

Given that greater body dissatisfaction was observed among those in the excessive BSE group, and that this group also reported higher rates of not having a clinical breast exam, it may 
be that greater body dissatisfaction may be linked with lesser engagement in CBE in this group due to fear of revealing their bodies to the examining healthcare professional (Clark et al., 2009). As a result, CBE may be perceived as uncomfortable, anxiety-provoking, or even intrusive. BSE may be more appealing to women who are dissatisfied with their bodies because the exam is done alone and in private. Thus, choosing BSE over other methods of screening may allow women to avoid negative affect or cognitions associated with having their bodies examined by an unfamiliar person.

The other psychosocial variables associated with BSE frequency were trait anxiety and cancer fatalism. Similar to many behaviors, it has been hypothesized that anxiety may function to either inhibit or promote engagement in BSE (McCaul et al., 1996b). The findings from this study supported both perspectives. Trait anxiety differentiated nonperformance and regular performance of BSE from infrequent performance. This suggests that trait anxiety had a dual effect on BSE engagement, at least within this sample, by both inhibiting and promoting the frequency of BSE behavior. Perhaps women who never practiced BSE desired to avoid discovering symptoms of breast cancer altogether, whereas women who practiced BSE at recommended rates desired to assure that these symptoms were detected as soon as possible. Women with less trait anxiety did not necessarily avoid practicing BSE, but they also did not perform them exactly as prescribed.

In addition, cancer fatalism was higher among women who practiced BSE at a recommended frequency compared to practicing it infrequently. Although it may seem counterintuitive that fatalistic beliefs predicted engagement in a health behavior, perhaps those with greater cancer fatalism believed that more frequent BSE engagement would allow them to detect their cancers earlier. A majority of the items that compose the Powe Cancer Fatalism 
Scale assess beliefs about predisposition to developing cancer, while a minority of these items measure beliefs about inevitable death from cancer despite undergoing treatment for cancer or engagement in health behaviors that have been inversely associated with cancer development (e.g., exercise). An item-level analysis revealed that the participants who reported recommended BSE performance endorsed the items pertaining to predisposition to developing cancer at considerably higher levels (more than 50\% agreeing with statements about predisposition) than the death-inevitability items (less than 25\% agreeing with statements about death inevitability). In addition, for the item 'I believe if someone gets cancer, it doesn't matter when they find out about it, they will still die from it", $85.1 \%$ of participants in the recommended group disagreed or strongly disagreed with this statement. This finding suggests that women may perceive less environmental or behavioral control over developing cancer, but do not perceive that death from cancer is guaranteed once diagnosed; thus, they may engage in BSE to detect cancer as soon as possible to increase odds of survival. Notably, of the remaining psychosocial variables examined in the study, breast cancer worry, God locus of health control, and the religious variables did not predict BSE frequency.

An additional interesting finding included that recommended $\left(M_{\text {age }}=36.5\right.$ years $)$ and excessive ( $M_{\text {age }}=37.1$ years) BSE practitioners generally were older than those who practiced BSE infrequently ( $M_{\text {age }}=30.4$ years $)$ or not at all $\left(M_{\text {age }}=29.5\right.$ years $)$. This suggests the recommended and excessive practitioners were late adolescents or young adults in the early to mid-1990s, whereas the never and infrequent practitioners did not reach this milestone until the early 2000s. This age difference may be important to predicting BSE engagement as the climate around BSE changed dramatically from the early 1990s to the early 2000s. During the 1990s, the veracity of BSE was being questioned, but the practice was still promoted by many health care 
providers and health organizations. This would indicate that women in the recommended and excessive groups may have been encouraged to practice BSE as it was still an acceptable practice when these women were emerging into adulthood. In contrast, the study most often cited as the "definitive" argument against BSE (Thomas et al., 2002) was published around the time the never and infrequent practitioners reached young adulthood, the time when women are traditionally first taught and encouraged by health care providers to perform BSE. As a result, these groups may not have been encouraged to practice BSE, as it was widely viewed to be ineffective and even harmful to women's health. Although recommended and excessive practitioners may have been exposed to these same anti-BSE messages, they already had on average six to seven years to establish BSE as part of their health behavior routine. Thus, the age differences observed in this study may in fact be cohort effects.

Although some of the hypothesized relations between theory-related constructs and BSE frequency were detected in the data, many of these proposed relations were not significant. This is not unusual. In none of the studies on which these hypotheses were based (e.g., Alagna \& Reddy, 1984) were all components of the health theories significantly associated with BSE frequency. Within the present study, attitudes, subjective norm, and perceived benefits were significant in preliminary analyses but not predictive analyses of BSE frequency. These constructs were correlated with several other theory-related constructs; thus, they may have shared variance in predicting BSE frequency, decreasing the likelihood that each variable would be a significant predictor of BSE frequency in regressions. Perceived susceptibility, seriousness, and breast cancer fear were not even significantly associated with BSE frequency in preliminary analyses. This may be due to a number of factors. First, compared to samples from prior studies that found support for these relations (e.g., Ashton et al., 2001), the women in the present study 
were relatively young and well-educated. The sample was also composed of American women, whereas many of the prior studies included samples of European (e.g., Umeh \& Rogan-Gibson, 2001) or Asian women (e.g., Fung, 1998). Across these geographic regions, prevalence of breast cancer (e.g., Bray, McCarron, \& Parkin, 2004), recommendations about whether one should practice BSE (e.g., World Health Organization, 2008), cultural comfort with engaging in a selfexamination (e.g., Lor, Khang, Xiong, Moua, \& Lauver, 2013), and access to other means of breast cancer screening methods certainly vary (e.g., World Health Organization, 2008). These conditions may uniquely influence factors associated with women's engagement in BSE. Even among the reported studies that exclusively used American samples (e.g., Alagna \& Reddy, 1984; Champion, 1988; Millar, 1997), the eras in which these studies were conducted differed from the present study. More specifically, they were primarily conducted in the 1980s and 1990s, which represent a time when the climate surrounding the practice of BSE was more favorable in the United States.

\section{Factors Predicting BSE Proficiency}

Significantly fewer studies in the literature have investigated BSE proficiency, which refers to adherence to proper technique while performing the behavior. Past studies have examined proficiency in one of two ways: through a series of knowledge-based items about proper BSE technique (e.g., Lu, 2001), or through direct observation of BSE performed on a simulated breast model (e.g., Alagna \& Reddy, 1984). For the purpose of this study, the former proficiency measurement was employed. Participants answered items measuring correct technique based on BSE guidelines updated by the American Cancer Society in 2012. It is important to examine BSE proficiency as a separate construct; as noted above, BSE proficiency was not correlated with frequency of BSE, lump checking, or shower testing. 
Within this sample, age was inversely associated with BSE proficiency. More specifically, women who were older performed BSE with less technical skill. Perhaps older participants were more familiar with BSE guidelines that predate the update in 2012; thus, when they were completing the measure, they answered the proficiency items based on out-of-date recommendations. This likely would result in lower scores for these women.

In addition, knowledge of breast cancer risk factors and symptoms independently and positively predicted BSE proficiency, suggesting that women who are more knowledgeable about breast cancer may also be more knowledgeable about methods of breast cancer screening. The only theory-related construct that was predictive of BSE proficiency was self-efficacy, a component of both the Health Belief Model and Theory of Planned Behavior. More specifically, BSE proficiency was positively predicted by self-efficacy, which is consistent with findings from prior studies (e.g., Lu, 2001). It appears that women who were confident in their ability to perform BSE were more knowledgeable of how to perform the behavior correctly; indicating that their confidence may be justified.

Of the remaining theory-related constructs, intention, susceptibility, benefits, and being cued by a public health campaign, personal experience of breast symptoms, a family or friend with breast cancer, or encouragement from a friend or relative to perform BSE were significant in preliminary analyses but not the predictive analysis. It is unclear why none of these constructs was associated with BSE proficiency once examined simultaneously with each other as well as personal and demographic variables within the regression. However, the largest of the preliminary correlations was .13 , meaning the associations were not strong when independently associated with BSE proficiency. As variance in BSE proficiency was accounted for within the context of other theory, personal, and demographic variables, these constructs no longer were 
significantly associated with proficiency as it was measured in this study.

In contrast, attitudes, subjective norm, seriousness, barriers, health motivation, and breast cancer fear were not significant even in preliminary analyses. Only a few studies to date have examined BSE proficiency within the context of either the Health Belief Model or Theory of Planned Behavior; thus, the hypothesized relations between these constructs and BSE proficiency are not well established in the literature. Also, these prior studies are multiple decades old (e.g., Alagna \& Reddy, 1984; Champion, 1988) or used a non-American sample (e.g., Lu, 2001). Furthermore, no known study has examined BSE proficiency within the context of the Extended Parallel Process Model. Due to the underdeveloped nature of this literature, the hypotheses regarding relations between the theory constructs and BSE proficiency were based primarily on studies of BSE frequency, as it follows logically that constructs that are theorized to motivate frequency of a health behavior may also motivate higher quality performance of that behavior. However, given that BSE proficiency was not correlated with BSE frequency in the current study or in prior studies (e.g., Alagna \& Reddy, 1984), it is important to recognize that different factors may predict BSE frequency and BSE proficiency.

Finally, concerning the psychosocial variables, body dissatisfaction inversely predicted BSE proficiency. More specifically, women who were more dissatisfied with their bodies were less proficient at BSE. Examining this further, item-level analysis revealed that being more dissatisfied with one's body was associated with the item pertaining to how long it takes to perform BSE $(r=-.11, p=.008)$; the other technical skills composing proficiency were not associated with body dissatisfaction. In brief, women who were more dissatisfied with their bodies believed the proper BSE technique involves taking less time than the recommended 10-15 minutes. Consequently, women who are more dissatisfied with their bodies might spend less 
time performing BSE to diminish any negative affect or cognitions that could be aroused by the self-exam. It should be noted that this is the first known study to examine the relation between BSE proficiency and body dissatisfaction and this relation was small in size, so extrapolation of this finding should be done cautiously. None of the other psychosocial constructs included in the analysis predicted BSE proficiency.

\section{Factors Predicting Informal Breast Awareness Behaviors}

This study also explored factors that may promote or inhibit informal breast awareness practices among women, which were defined as frequency of checking for lumps and frequency of examining one's breasts in the shower. Within the study sample, age positively predicted lump checking frequency. Much like the findings for BSE, perhaps older women are more likely to have been encouraged to practice self-exams to identify breast changes than younger women; thus, they are more likely to engage in lump checking behaviors. Further, these women may have practiced BSE for an extended period of time, then simply modified these self-exams to be more in line with current breast awareness recommendations by adding informal self-exams to their routine. Alternatively, as women age, risk of developing breast cancer increases, which may provoke women to engage in more self-checking behaviors to detect breast abnormalities as they age.

Lump checking was positively predicted by intention to perform BSE and being cued to perform BSE by experiencing breast cancer symptoms, and was inversely associated with perceived barriers to performing BSE. Similarly, shower checking was positively predicted by intention to perform BSE and self-efficacy about performing BSE. Together these results suggest that some of the factors that promote engagement in BSE, such as intention to perform BSE, may 
also positively impact engagement in other breast awareness behaviors, such as lump checking and shower checking. This is consistent with prior findings (e.g., Gürsoy et al., 2011) that showed women who practice BSE were more likely to utilize other methods of breast cancer screening (e.g., mammography, CBE) as well.

There were multiple theory-related constructs that were not predictive of shower or lump checking. More specifically, attitudes, subjective norm, benefits, self-efficacy, health motivation, and being encouraged by friend or relative were significant in preliminary analyses but not the regression predicting lump checking. Likewise, attitudes, subjective norm, susceptibility, benefits, barriers, and health motivation were significant in preliminary analyses but not the regression predicting shower checking. There were several significant correlations among these constructs; this shared variance could have limited their ability to simultaneously predict lump checking or shower checking frequencies in the primary regression analyses.

Furthermore, results of preliminary analyses revealed religious beliefs and organizational religiousness were associated with lump checking frequency, whereas body dissatisfaction and organizational religiousness were associated with shower checking frequency. However, the strongest correlation between the informal breast awareness behaviors and a psychosocial predictor was .08 . None of these psychosocial variables predicted engagement in either of these breast awareness behaviors in the primary regression analyses. Perhaps the inclusion of constructs with stronger associations (e.g., intention) with the breast awareness behaviors accounted for the variance with which these psychosocial variables were related in the preliminary analyses; thus, limiting their unique contribution to the regression.

\section{Relations among the Breast Awareness Behaviors}


Participants, on average, endorsed monthly or near monthly practice of BSE, lump checking, and examining in the shower. These frequency variables were moderately correlated with one another (see Table 3), indicating that the women in this sample perform multiple selfexamination behaviors over the course of each month. Alternatively, the relatively strong interrelations among these variables could indicate that these variables operationally overlapped. For example, if a woman examined her breasts for lumps while in the shower, she could have endorsed both examining in the shower and lump checking behaviors for this single act.

In addition, none of the frequency behaviors were correlated with BSE proficiency. This is a consistent finding across the few studies that have examined both BSE frequency and proficiency (e.g., Alagna \& Reddy, 1984). Women who endorse performing BSE do not necessarily perform the behavior with technical skill (e.g., Stevens et al., 1994), suggesting these women may actually be performing a self-examination more akin to informal breast awareness behaviors than BSE. As a result, these women may not experience the health benefits that have been associated with performing BSE with technical skill, such as reduced risk of death from breast cancer (e.g., Harvey et al., 1997; Newcomb et al., 1991).

\section{Summary of Findings}

Although many personal and demographic factors were included in this study, only a few were associated with engagement in breast awareness behaviors. More specifically, age was inversely associated with BSE proficiency and positively predicted lump checking frequency and engagement in BSE at recommended and excessive frequencies. These findings could reflect actual age differences, or they could reflect cohort differences, as older participants may be more inclined to perform self-exams due to increasing risk of developing breast cancer or being taught 
the behavior prior to recommendations against the practice. Having out-of-date knowledge regarding BSE may also contribute to their less proficient performance. In addition, knowledge of breast cancer risk factors differentiated excessive practitioners from all other frequency groups and predicted BSE proficiency. Similarly, knowledge of breast cancer symptoms predicted BSE proficiency, indicating that women who sought out information about breast cancer may also have sought out information about breast cancer screening. Finally, perceived BSE effectiveness differentiated excessive practitioners from all other frequency groups, with women who overadhered to BSE perceiving the practice to be more effective than women in other groups.

As noted above, components of the Theory of Planned Behavior and Health Belief Model (intention, self-efficacy, perceived barriers, and being cued by a health care provider or relative/friend) significantly predicted engagement in BSE and other breast awareness behaviors in anticipated directions. More specifically, women who had greater intention to perform BSE, were more confident in their ability to perform the behavior correctly, and perceived fewer barriers to performing BSE were more likely to endorse engagement in breast awareness behaviors. Additionally, women who were cued by explicit advice or encouragement from individuals with whom they have personal (e.g., friend, relative) or professional relationships (i.e., health care provider) were more likely to engage in BSE.

Finally, the psychosocial variables examined in this study provided a few new clues into factors influencing breast awareness behavior engagement and proficiency. In particular, trait anxiety, cancer fatalism, and body dissatisfaction were related to breast awareness behaviors in distinctive ways. Regarding the association with anxiety, women who endorsed greater trait anxiety were more likely to never perform BSE or to perform BSE the recommended frequency than women who performed BSE infrequently, indicating that trait anxiety was associated with 
both a total lack of BSE engagement and engaging in BSE monthly or once every three months. In this regard, if excessive practitioners were excluded, a U-shaped function was demonstrated between anxiety and frequency of BSE practice. Higher amounts of trait anxiety were associated with both failure to practice BSE at all and practicing it at the recommended frequency, perhaps with women in the former group desiring to avoid discovering a new lump altogether and women in the latter group performing it "perfectly" to assure that new lumps could be detected expeditiously. Women with less trait anxiety do not avoid BSEs but also do not perform them exactly as prescribed. Notably, this curvilinear relation between anxiety and BSE is consistent with findings from earlier studies that examined how different levels of anxiety may impact health and social behaviors (i.e. Janis, 1955).

Cancer fatalism differentiated regular and infrequent performance of BSE, with those who performed the behavior regularly endorsing greater fatalism. Although this finding may seem counterintuitive, as prior studies have found fatalism to be a barrier to engagement in health screening (e.g., Spurlock \& Cullins, 2006), further examination at the item-level revealed that women performing BSE at recommended rates endorsed fatalistic items associated with predisposition to development of cancer but not inevitable death from cancer. This suggests they may engage in BSE to detect breast cancer as early as possible to increase odds of survival from the disease.

Finally, there were multiple interesting findings pertaining to body dissatisfaction. Excessive practitioners endorsed a higher level of body dissatisfaction compared to all other groups. The association between over-adherence to BSE and body dissatisfaction may be due to the broader association between greater body dissatisfaction and engagement in more frequent body checking behaviors (Vartanian \& Grisham, 2012). Alternatively, taken together, findings 
regarding $\mathrm{CBE}$ and over-adherence, these individuals may view BSE as more preferable than $\mathrm{CBE}$ as it may be less intrusive. Body dissatisfaction was also inversely associated with BSE proficiency in the broader sample, with item-level analysis suggesting those with greater body dissatisfaction believed that BSE takes less time to be performed properly than those with less body dissatisfaction.

Despite prior empirical evidence, multiple psychosocial variables measured in this study did not significantly predict any of the examined outcome behaviors. For example, breast cancer worry was expected to positively impact engagement in breast awareness behaviors, or at least BSE frequency, as had been demonstrated in prior studies (e.g., Erblich et al., 2000; van Dooren et al., 2003). No associations were observed between breast cancer worry or fear and breast awareness behaviors in the current study. Closer examination of the data revealed that $73 \%$ of the sample endorsed the lowest possible level of breast cancer worry. The limited variability in participant responses may account for the lack of associations observed between breast cancer worry and breast awareness behaviors in the current sample. Among samples of women who have personally experienced cancer (who were excluded from the current analyses) or who have experienced multiple friends and family members who have been diagnosed and treated for cancer, different patterns of findings may emerge. Because the current study sample was younger than the BRFSS sample, it is likely that fewer women who participated fell into these categories.

Additionally, religious variables and God locus of health control had been shown to affect engagement in BSE in prior research. These associations were not observed in the present study, which may be explained by sample differences. More specifically, the findings between God locus of health control (e.g., Mitchell et al., 2002) and religious beliefs (e.g., Benjamins, 2006) and BSE behavior were primarily studied within African American populations, who on 
average, were older than the sample in the present study, which was primarily Caucasian. The present sample also endorsed less frequent worship attendance and less involvement in the social aspects of religious communities compared to the samples studied in prior research. Notably, these religious differences are likely not novel to this sample. The Pew Research Center released a series of reports that indicate young adults in the United States are less religious and less likely to attend religious services than older Americans (Pew Research Center, 2010). It is likely that age, ethnicity, and/or cohort differences explain why neither internal nor external aspects of religious involvement failed to significantly influence breast awareness practice within the present study.

Finally, it is important to note that only $15.8-18.8 \%$ percent of the variance of any breast health care behavior was accounted for across analyses, indicating that other variables that were not examined in this study may significantly contribute to women's engagement in breast awareness behaviors, such as body checking, sexual orientation, trauma history, and engagement in the healthcare system.

\section{Implications of Findings}

One potential and unfortunate by-product of the debate surrounding BSE and the recent change in screening recommendations from BSE to breast awareness may be that some women now perceive that self-examination no longer is an important component of breast cancer screening, and furthermore, may believe that self-examination is harmful to their health and well-being. The implications of this are troubling, as self-detection continues to be a significant mode of breast cancer detection for women (Roth et al., 2011; Mac Bride et al., 2012), indicating that self-examination, in some form, should be a fundamental component of women's health 
behavior repertoires.

Although changes in screening recommendations and arguments against BSE have been widely disseminated (e.g., Epstein et al., 1997), a majority of the women in this study (87.7\%) believed that BSE is an effective screening tool to detect breast cancer and nearly half reported performing BSE at a recommended frequency. Because it has been widely suggested that BSE may be harmful to one's health (e.g., Austoker, 2003), it was unanticipated that many of the women in the study would perceive that other people wanted them to perform BSE.

Another interesting implication pertained to self-efficacy and proficiency. Even though women were confident they could perform BSE correctly, they had very limited knowledge of proper BSE technique based on current guidelines. This is consistent with prior studies (e.g., Alagna \& Reddy, 1984) that have found that self-confidence promotes engagement in BSE, but not necessarily BSE skill.

In addition, the study yielded several other interesting implications. Recall that being cued to perform BSE through encouragement from a trusted personal (e.g., family, relative) or professional (e.g., health care provider) source was associated with performing BSE, but less direct sources (e.g., public health campaign) or community involvement (e.g., organizational religiousness) were not associated with engagement in BSE. This suggests that any efforts geared toward the promotion of BSE should include direct encouragement by individuals who are perceived to be competent and trustworthy.

Furthermore, women who were cued by a health care provider were more likely to perform BSE at infrequent or recommended rates. Also, excessive performers may be less likely to discuss appropriate screening behaviors with their health care providers given that many of 
them had never had a clinical breast exam. Together these findings suggest that health care providers may play an important role in educating women about appropriate breast awareness behaviors and breast health. One area that may be especially relevant for health care providers to address is that excessive BSE performance may be counterproductive to women's mental and physical health (Epstein et al., 1997), as this is often omitted from discussions about BSE.

Another interesting finding was that BSE was associated with engagement in other breast awareness behaviors within this sample, specifically frequency of checking for lumps and examining one's breasts in the shower. Prior research has found that women who performed BSE also were more likely to attain CBE and mammography (e.g., Gürsoy et al., 2011). These findings suggest that engaging in one breast screening behavior may activate engagement in other methods of screening. Perhaps this is evidence of the foot-in-the-door effect.

\section{Study Limitations \& Future Directions}

The results of the current study should be interpreted with caution due to limitations associated with the study design and sample. First, the study was correlational in nature, and as a result, directionality of relations and causality cannot be determined. Any assumptions made about directionality were based on theory and prior research; however, it is obviously possible that the assumed directionality was mistaken. Other concerns include the reliance on self-report of retrospective data, which is subject to recall bias. Additionally, it is possible that participants' responses were subject to social desirability; however, a recent study found no relation between social desirability and self-reported engagement in risky health behaviors (e.g., smoking, alcohol use) using an online format (Crutzen \& Göritz, 2010).

There were also a number of limitations associated with the sample. First, the sample was 
generally younger than is typically studied in this area. Also, only $5.4 \%$ of the sample endorsed excessive performance of BSE; while this sample was large enough to identify robust differences between groups, a larger sample of excessive BSE performers may have allowed for identification of smaller, but still statistically significant, effects and may have allowed for greater specificity in the confidence intervals (Tabachnick \& Fidell, 2007). An additional concern relates to sample homogeneity. A majority of the participants identified themselves as Caucasian, relatively young, and well-educated, which limits the ability to make inferences about the generalizability of the findings. It is unknown if similar results would be found in other samples that include larger proportions of African Americans or older adults. A number of factors may have contributed to sample homogeneity, such as greater access to online research among Caucasian women due to higher rates of internet use among older and less educated Caucasians than their African American counterparts (Pew Research Center, 2014). In addition, ethnic minorities may be less willing to participate in health research due to historic mistreatment of ethnic minorities in clinical research (Corbie-Smith, Chomas, \& St. George, 2002).

There were also multiple limitations pertaining to the items that measured BSE. More specifically, participants were asked to rate how frequently they performed BSE, but were not provided a definition of this health behavior. As a result, it was left to the participants to determine what type of self-examination qualified as BSE versus an informal breast exam. Regarding proficiency of BSE, as noted above, participants evidenced limited knowledge of proper BSE technique. Because the proficiency scale was based on American Cancer Society guidelines that were updated in 2012, it is probable that many participants had not yet learned the new guidelines. Those women who learned how to perform BSE prior to 2012 may have based their answers to the proficiency questions on an older set of guidelines, perhaps resulting in 
lower proficiency scores. If their scores were based on older guidelines, the data may have reflected that these women performed BSE more proficiently than the data currently reflects.

The participants also endorsed very low levels of breast cancer worry, organizational religiousness, and to a lesser extent, trait anxiety. For each of these, the mean score was only slightly above the floor of the measure. For example, $73 \%$ of the sample endorsed the lowest possible score on the breast cancer worry scale. This lack of variability in responses may have limited any ability to properly determine associations between these constructs and the breast awareness behaviors that were measured in this study.

Despite these limitations, there are several strengths to the present study. First, the assessment of BSE frequency was categorized into meaningful groups, including those who performed BSE excessively, which allowed for examination of factors which may differentiate these groups. Second, BSE proficiency was included due to its potential association with important health outcomes. Third, informal breast awareness behaviors were included as they reflect current self-examination guidelines. Fourth, breast awareness was studied within the framework of three commonly used and empirically supported health behavior theories. Fifth, psychosocial predictors of breast awareness behaviors were explored in addition to health theory constructs, which is uncommon in the current literature. Finally, the study recruited a national sample.

There are several potentially fruitful areas of investigation in future breast awareness behavior research. Prospective designs should be used to avoid any potential concerns regarding retrospective reporting of breast awareness behaviors. It may also be informative to collect additional data from the present sample at a later date to investigate if their current engagement 
in BSE and other breast exams predict future outcomes, such as use of other breast cancer screening modalities (e.g., mammography), stage of breast cancer at diagnosis, or even breast cancer mortality. Additionally, researchers should investigate whether there are age and cohort differences in breast awareness behaviors. More specifically, given changes in screening recommendations, there may be differences in behavior based solely on which breast care behaviors were promoted when the women were initially learning about screening and establishing screening behaviors. Age differences may also be found due to increasing concern regarding developing breast cancer with age and increasing availability of breast cancer screening options with age (e.g., mammography). Other potential predictors of breast awareness behaviors should also be explored; body checking, women's trauma history, sexual orientation, and engagement in the healthcare system are four areas which may hold some promise. Next, BSE proficiency should be assessed through direct observation of the behavior, perhaps having women perform BSE on themselves or simulated breast models in the presence a healthcare professional. This may be particularly relevant for future research as prior studies (e.g., Hall et al., 1980; Pennypacker, 1980) have found that women are more proficient at BSE and are more successful at identifying breast lesions in both silicone and natural breast tissue after undergoing breast examination training using silicone models.

A final area of future research should include engagement in the healthcare system. With the implementation of the Affordable Care Act, there is wider provision of health insurance and greater access to annual exams. Given that the study suggests that health care providers may play an important role in women's engagement in breast awareness behaviors, greater access to the healthcare system may increase the performance of breast awareness behaviors. Therefore, future studies should collect extensive data regarding participants' interactions with the healthcare 
system (e.g., annual health exams, utilization of community health clinics). Lastly, studying health care providers' attitudes toward breast awareness behaviors may be of great importance with the changing and/or ambiguous recommendations regarding breast awareness. 


\section{References}

Ajzen, I. (1985). From intentions to actions: A theory of planned behavior. In J. Kuhl \& J. Beckman (Eds.), Action-control: From cognition to behavior (pp. 11-39). Heidelberg: Springer.

Alagna, S. W., \& Reddy, D. M. (1984). Predictors of proficient technique and successful lesion detection in breast self-examination. Health Psychology, 3(2), 113-127. doi:10.1037/0278-6133.3.2.113

Amazon. (2012). Mechanical Turk. Retrieved October 7, 2012 from https://www.mturk.com/mturk/welcome

American Cancer Society. (2012). Breast cancer: Early detection. Retrieved October 7, 2012 from http://www.cancer.org/Cancer/BreastCancer/MoreInformation/BreastCancerEarlyDetecti on/breast-cancer-early-detection-acs-recs-bse

American Cancer Society. (2014). American Cancer Society recommendations for early breast cancer detection in women without breast symptoms. Retrieved March 17, 2014 from http://www.cancer.org/cancer/breastcancer/moreinformation/breastcancerearlydetection/b reast-cancer-early-detection-acs-recs

Anderson, B. O., Cheng-Har, Y., Smith, R. A., Shyyan, R., Sener, S. F., Eniu, A., et al. (2008). Guideline implementation for breast healthcare in low-income and middle-income countries. Cancer, 113(8), 2221-2243. doi:10.1002/cncr.23844

Asare, M., Sharma, M., Bernard, A. L., Rojas-Guyler, L., \& Wang, L. (2013). Using the health belief model to determine safer sexual behavior among African immigrants. Journal of Health Care for the Poor and Underserved, 24(1), 120-134. 
Ashton, L., Karnilowicz, W., \& Fooks, D. (2001). The incidence and belief structures associated with breast self-examination. Social Behavior \& Personality, 29(3), 223-229. doi:10.2224/sbp.2001.29.3.223

Austoker, J. (2003). Breast self examination. British Medical Journal, 326(7379), 1-2.

Banning, M. (2011). Black women and breast health: A review of the literature. European Journal of Oncology Nursing, 15(1), 16-22. doi:10.1016/j.ejon.2010.05.005

Becker, M. H. \& Maiman, L. A. (1975). Sociobehavioral determinants of compliance with health and medical care recommendations. Medical Care, 13, 10-24.

Benjamins, M. R. (2006). Religious influences on preventive health care use in a nationally representative sample of middle-age women. Journal of Behavioral Medicine, 29(1), 116. doi:10.1007/s10865-005-9035-2

Benjamins, M. R. (2007). Predictors of preventive health care use among middle-aged and older adults in Mexico: The role of religion. Journal of Cross-Cultural Gerontology, 22(2), 221-234. doi:10.1007/s10823-007-9036-4

Bowen, D., Alfano, C., McGregor, B., \& Andersen, M. (2004). The relationship between perceived risk, affect, and health behaviors. Cancer Detection \& Prevention, 28(6), 409417. doi:10.1016/j.cdp.2004.08.008

Brain, K., Norman, P., Gray, J., \& Mansel, R. (1999). Anxiety and adherence to breast selfexamination in women with a family history of breast cancer. Psychosomatic Medicine, 61(2), 181-187.

Bray, F., McCarron, P., \& Parkin, D. M. (2004). The changing global patterns of female breast cancer incidence and mortality. Breast Cancer research, 6(6), 229-239. doi:10.1186/bcr932 
Brewer, G., \& Dewhurst, A. (2013). Body Esteem and Self-examination in British Men and Women. International Journal of Preventive Medicine, 4(6), 684-689.

Brown, T. A., Cash, T. F., \& Mikulka, P. J. (1990). Attitudinal body-image assessment: Factor analysis of the Body-Self Relations Questionnaire. Journal of Personality Assessment, 55(1-2), 135-144. doi:10.1080/00223891.1990.9674053

Canbulat, N., \& Uzun, O. (2008). Health beliefs and breast cancer screening behaviors among female health workers in Turkey. European Journal of Oncology Nursing, 12(2), 148156. doi:10.1016/j.ejon.2007.12.002

Cash, T. F. (1994).The Multidimensional Body-Self Relations Questionnaire: User's manual. Norfolk, VA: Old Dominion University, Department of Psychology.

Cash, T. F., Winstead, B. A., \& Janda, L. H. (1985). Your body, yourself: A Psychology Today reader survey. Psychology Today, 19(7), 22-26.

Centers for Disease Control and Prevention. (2012). Breast cancer. Retrieved July 24, 2012 from http://www.cdc.gov/cancer/breast/

Centers for Disease Control, Behavioral Risk Factor Surveillance System. (2012). Prevalence and Trends Data (Nationwide, States and DC). Retrieved February 18, 2014 from http://apps.nccd.cdc.gov/brfss/display.asp?cat=WH\&yr=2012\&qkey=8481\&state=UB

Chait, S. R., Thompson, J., \& Jacobsen, P. B. (2009). Relationship of body image to breast and skin self-examination intentions and behaviors. Body Image, 6(1), 60-63. doi:10.1016/j.bodyim.2008.09.003

Champion, V. (1993). Instrument refinement for breast cancer screening behaviors. Nursing Research, 42(3), 139-143.doi:10.1097/00006199-199305000-00003 
Champion, V. (1985). Use of the health belief model in determining frequency of breast selfexamination. Research in Nursing \& Health, 8(4), 373-379.

Champion, V. (1988). Attitudinal variables related to intention, frequency and proficiency of breast self-examination in women 35 and over. Research in Nursing \& Health, 11(5), 283-291.

Champion, V., Skinner, C., Menon, U., Rawl, S., Giesler, R., Monahan, P., \& Daggy, J. (2004). A breast cancer fear scale: psychometric development. Journal of Health Psychology, $9(6), 753-762$.

Chin, Y., Huang, T., \& Hsu, B. (2013). Impact of action cues, self-efficacy and perceived barriers on daily foot exam practice in type 2 diabetes mellitus patients with peripheral neuropathy. Journal of Clinical Nursing, 22(1-2), 61-68. doi:10.1111/j.13652702.2012.04291.x

Clark, M. A., Rogers, M. L., Armstrong, G. F., Rakowski, W., Bowen, D. J., Hughes, T., et al. (2009). Comprehensive cancer screening among unmarried women aged 40-75 years: Results from the Cancer Screening Project for Women. Journal of Women's Health, 18(4), 451-459. doi:10.1089/jwh.2008.1046

Cohen, M. (2002). First-degree relatives of breast-cancer patients: Cognitive perceptions, coping, and adherence to breast self-examination. Behavioral Medicine, 28(1), 15-22. doi:10.1080/08964280209596394

Consedine, N. S. (2012). The demographic, system, and psychosocial origins of mammographic screening disparities: Prediction of initiation versus maintenance screening among immigrant and non-immigrant women. Journal of Immigrant \& Minority Health, 14(4), 570-582. doi:10.1007/s10903-011-9524-Z 
Corbie-Smith, G., Thomas, S. B., St. George, D. M. (2002). Distrust, race, and research. Archives of Internal Medicine, 162(21), 2458-2463. doi:10.1001/archinte.162.21.2458.

Crutzen, R., \& Göritz, A. S. (2010). Social desirability and self-reported health risk behaviors in web-based research: three longitudinal studies. Biomedical Central Public Health, 10, 720-729. doi:10.1186/1471-2458-10-720

Diefenbach, M. A., Miller, S. M., \& Daly, M. B. (1999). Specific worry about breast cancer predicts mammography use in women at risk for breast and ovarian cancer. Health Psychology, 18(5), 532-536. doi:10.1037/0278-6133.18.5.532

Early, J., Armstrong, S., Burke, S., \& Thompson, D. (2011). US female college students' breast health knowledge, attitudes, and determinants of screening practices: New implications for health education. Journal of American College Health, 59(7), 640-647. doi:10.1080/07448481.2010.528098

Egede, L. E., Ellis, C., \& Grubaugh, A. L. (2009). The effect of depression on self-care behaviors and quality of care in a national sample of adults with diabetes. General Hospital Psychiatry, 31(5), 422-427. doi:10.1016/j.genhosppsych.2009.06.007

Epstein, S., Lin, T., Audrain, J., Stefanek, M., Rimer, B., \& Lerman, C. (1997). Excessive breast self-examination among first-degree relatives of newly diagnosed breast cancer patients. High-Risk Breast Cancer Consortium. Psychosomatics, 38(3), 253-261.

Erblich, J., Bovbjerg, D. H., \& Valdimarsdottir, H. B. (2000). Psychological distress, health beliefs, and frequency of breast self-examination. Journal of Behavioral Medicine, 23, 277-292. doi: 0892-7553/00/0600-0277 
Facione, N., Miaskowski, C., Dodd, M., \& Paul, S. (2002). The self-reported likelihood of patient delay in breast cancer: new thoughts for early detection. Preventive Medicine, 34(4), 397-407.

Farmer, D., Reddick, B., D'Agostino, R. r., \& Jackson, S. A. (2007). Psychosocial correlates of mammography screening in older African American women. Oncology Nursing Forum, 34(1), 117-123. doi:10.1188/07.ONF.117-123

Feig, S. A. (2000). Ductal carcinoma in situ: Implications for screening mammography. Radiologic Clinics of North America. 38(4), 653-668. doi: 10.1016/S0033$8389(05) 70192-5$

Frank, J. W., \& Mai, V. (1985). Breast self-examination in young women: More harm than good? Lancet, 654-657.

Fung, S. (1998). Factors associated with breast self-examination behaviour among Chinese women in Hong Kong. Patient Education \& Counseling, 33(3), 233-243. doi:10.1016/S0738-3991(98)00023-8

Gil-Lacruz, M., \& Gil-Lacruz, A. (2010). Health attributions and health care behavior interactions in a community sample. Social Behavior \& Personality: An International Journal, 38(6), 845-858. doi:10.2224/sbp.2010.38.6.845

Gilpin, C., Carson, N., \& Hunter, A. (2000). A preliminary validation of a family history assessment form to select women at risk for breast or ovarian cancer for referral to a genetics center. Clinical Genetics, 58(4), 299-308. doi:10.1034/j.13990004.2000.580408.x 
Glanz, K., \& Bishop, D. (2010). The role of behavioral science theory in development and implementation of public health interventions. Annual Review of Public Health, 31, 399418. doi:10.1146/annurev.publhealth.012809.103604

Glanz, K., Rimer, B. K., \& Lewis, F. M. (2003). Health Behavior and Health Education (3rd Ed.). San Francisco, CA: Jossey-Boss.

Grös, D. F., Antony, M. M., Simms, L. J., \& McCabe, R. E. (2007). Psychometric properties of the State-Trait Inventory for Cognitive and Somatic Anxiety (STICSA): Comparison to the State-Trait Anxiety Inventory (STAI). Psychological Assessment, 19(4), 369-381. doi:10.1037/1040-3590.19.4.369

Grunfeld, E. A., Ramirez, A. J., Hunter, M. S., \& Richards, M. A. (2002). Women's knowledge and beliefs regarding breast cancer. British Journal of Cancer, 86, 1373-1378.

Gullatte, M. M., Brawley, O., Kinney, A., Powe, B., \& Mooney, K. (2010). Religiosity, spirituality, and cancer fatalism beliefs on delay in breast cancer diagnosis in African American women. Journal Religion \& Health, 49, 62-72. DOI 10.1007/s10943-008$9232-8$

Gürsoy, A., Mumcu, H., Çalık, K., Bulut, H., Nural, N., Kahriman, I., et al. (2011). Attitudes and health beliefs associated with breast cancer screening behaviors among Turkish women. Journal of Transcultural Nursing, 22(4), 368-375. doi:10.1177/1043659611414137

Haagensen, C. D. (1952). Self-examination of the breast. Journal of the American Medical Association, 149(4), 356-360.

Hall, D.C., Adams, C.K., Stein, G.H., Stephenson, H.S., Goldstein, M.K., \& Pennypacker, H.S. (1980). Improved detection of human breast lesions following experimental training. Cancer, 462), 408-414. 
Harvey, B. J., Miller, A. B., Baines, C. J., \& Corey, P. N. (1997). Effect of breast selfexamination techniques on the risk of death from breast cancer. Canadian Medical Association Journal, 157(9), 1205-1212. doi:10.1093/jnci/94.19.1420

Holmberg, L., Ekbom, A., Calle, E., Mokdad, A., \& Byers, T. (1997). Breast cancer mortality in relation to self-reported use of breast self- examination: A cohort study of 450,000 women. Breast Cancer Research and Treatment, 43(2), 137-140. doi:10.1023/A:1005788729145

Holt, C., Clark, E., \& Klem, P. (2007). Expansion and validation of the spiritual health locus of control scale: Factorial analysis and predictive validity. Journal of Health Psychology, 12(4), 597-612. DOI:10.1177/1359105307078166

Hosmer, D. W. \& Lemeshow, S. (2000). Applied Logistic Regression (2nd Ed.). Hoboken, NJ: Wiley-Interscience Publication.

Hubbell, A. P. (2006). Mexican American women in a rural area and barriers to their ability to enact protective behaviors against breast cancer. Health Communication, 20, 35-44.

Janis, I. L. (1955). Anxiety indices related to susceptibility to persuasion. The Journal of Abnormal and Social Psychology, 51(3), 663-667. doi:10.1037/h0046765

John E. Fetzer Institute. (1999). Multidimensional measurement of religiousness/spirituality for use in health research: A report of the Fetzer Institute/National Institute on Aging Working Group. Retrieved January 27, 2009 from http://www.fetzer.org/pdf/total_fetzer_book.pdf

Johnstone, B., McCormack, G., Yoon, D., \& Smith, M. L. (2012). Convergent/divergent validity of the Brief Multidimensional Measure of Religiousness/Spirituality: Empirical support 
for emotional connectedness as a "spiritual" construct. Journal of Religion \& Health, 51(2), 529-541. doi:10.1007/s10943-011-9538-9

Juniper, K. C., Oman, R. F., Hamm, R. M., \& Kerby, D. S. (2004). The relationships among constructs in the Health Belief Model and the Transtheoretical Model among AfricanAmerican college women for physical activity. American Journal of Health Promotion, 18(5), 354-357. doi:10.4278/0890-1171-18.5.354

Kara, B., \& Acikel, C. H. (2009).Health beliefs and breast self-examination in a sample of Turkish nursing students and their mothers. Journal of Clinical Nursing, 18(10), 14121421. doi:10.1111/j.1365-2702.2007.02241.x

Katapodi, M. C., \& Aouizerat, B. E. (2005). Do women in the community recognize hereditary and sporadic breast cancer risk factors?. Oncology Nursing Forum, 32(3), 617-623. doi:10.1188/05.ONF.617-623

Kelly, K., Leventhal, H., Baran, J., Schwalb, M., Toppmeyer, D., Much, J., Magee, M. (2000, April). Breast self exams in individuals testing for BRCA1 and BRCA2 Mutations (abstract).Annals of Behavioral Medicine, 22, Supplement.

Kelly, K., Patrick-Miller, L., Leventhal, H., Toppmeyer, D., Much, J., Baran, J., Schwalb, M. (2001, May). Breast cancer screening behaviors and perceived control in individuals interested in testing for BRCA1/2 mutations (abstract). American Society of Clinical Oncology [On-line]. Available: Doc. No. 2423.

Kelly, N. R., Mitchell, K. S., Gow, R. W., Trace, S. E., Lydecker, J. A., Bair, C. E., \& Mazzeo, S. (2012). An evaluation of the reliability and construct validity of eating disorder measures in white and black women. Psychological Assessment, 24(3), 608-617. doi:10.1037/a0026457 
Kenney, B. P., Vaughan, C., \& Cromwell, R. E. (1977). Identifying the socio-contextual forms of religiosity among urban ethnic minority group members. Journal for the Scientific Study of Religion, 16(3), 237-244. doi:10.2307/1385694

Kinney, A., Emery, G., Dudley, W., \& Croyle, R. (2002). Screening behaviors among African American women at high risk for breast cancer: Do beliefs about God matter?. Oncology Nursing Forum, 29(5), 835-843. doi:10.1188/02.ONF.835-843

Lerner, B. H. (2001). The Breast Cancer Wars: Hope, Fear and the Pursuit of a Cure of Twentieth-Century America. NY: Oxford University Press.

Lor, M., Khang, P., Xiong, P., Moua, K., \& Lauver, D. (2013). Understanding Hmong women's beliefs, feelings, norms, and external conditions about breast and cervical cancer screening. Public Health Nursing, 30(5), 420-428. doi:10.1111/phn.12043

Lu, Z. (2001). Effectiveness of breast self-examination nursing interventions for Taiwanese community target groups. Journal of Advanced Nursing, 34(2), 163-170. doi:10.1046/j.1365-2648.2001.01741.x

Mac Bride, M., Pruthi, S., \& Bevers, T. (2012). The evolution of breast self-examination to breast awareness. The Breast Journal, 18(6), 641-643. doi:10.1111/tbj.12023

Mason, T. E., \& White, K. M. (2008). The role of behavioral, normative and control beliefs in breast self-examination. Women \& Health, 47(3), 39-56.

doi:10.1080/03630240802132344

Mayo, R., Ureda, J., \& Parker, V. (2001). Importance of fatalism in understanding mammography screening in rural elderly women. Journal of Women \& Aging, 13(1), 5772. 
McCaul, K. D., Reid, P. A., Rathge, R. W., \& Martinson, B. (1996a). Does concern about breast cancer inhibit or promote breast cancer screening? Basic and Applied Social Psychology, $18,183-194$.

McCaul, K. D., Sandgren, A. K., O’Neill, H. K., \& Hinsz, V. B. (1993). The value of the Theory of Planned Behavior, perceived control, and self-efficacy expectations for predicting health-protective behaviors. Basic and Applied Social Psychology, 14, 231-252.

McCaul, K. D., Schroeder, D. M., \& Reid, P. A. (1996b). Breast cancer worry and screening: Some prospective data. Health Psychology, 15(6), 430-433. doi:10.1037/02786133.15 .6 .430

McLachlan, S., Clements, A., \& Austoker, J. (2012). Patients' experiences and reported barriers to colonoscopy in the screening context: A systematic review of the literature. Patient Education \& Counseling, 86(2), 137-146. doi:10.1016/j.pec.2011.04.010

Miesfeldt, S., Cohn, W., Ropka, M., \& Jones, S. (2001). Knowledge about breast cancer risk factors and hereditary breast cancer among early-onset breast cancer survivors. Familial Cancer, 1(3-4), 135-141. doi:10.1023/A:1021189128084

Miles, A., Voorwinden, S., Chapman, S., \& Wardle, J. (2008). Psychological predictors of information avoidance among older adults: The role of cancer fear and fatalism. Cancer Epidemiology, Biomarkers, and Prevention, 17, 1872-1879. doi:10.1158/1055-9965.EPI88-0074

Millar, M. G. (1997). The effects of emotion on breast self-examination: Another look at the Health Belief Model. Social Behavior \& Personality, 25(3), 223-232. doi:10.2224/sbp.1997.25.3.223 
Miller, A. B., Chamberlain, J., \&Tsechkovski, M. (1985). Self-examination in the early detection of breast cancer. Journal of Chronic Disease, 38, 527-540.

Mitchell, J., Lannin, D. R., Mathews, H. F., \& Swanson, M. S. (2002). Religious beliefs and breast cancer screening. Journal of Women's Health, 11(10), 907-915. doi:10.1089/154099902762203740

Nahcivan, N. O., \& Secginli, S. (2007). Health beliefs related to breast self-examination in a sample of Turkish women. Oncology Nursing Forum, 34(2), 425-432. doi:10.1188/07.ONF.425-432

National Cancer Institute (2012). Breast cancer: Cancer statistics review. Retrieved February 22, 2014 from http://seer.cancer.gov/csr/1975_2010/results_merged/sect_04_breast.pdf

Newcomb, P. A., Weiss, N. S., Storer, B. E., Scholes, D., Young, B. E., \& Voigt, L. F. (1991). Breast self-examination in relation to the occurrence of advanced breast cancer. Journal of the National Cancer Institute, 83(4), 260-265.doi: 10.1093/jnci/83.4.260

Norman, P. \& Hoyle, S. (2004). The Theory of Planned Behavior and breast self-examination: Distinguishing between perceived control and self-efficacy. Journal of Applied Social Psychology, 34, 694-708.

Noroozi, A., Jomand, T., \& Tahmasebi, R. (2011). Determinants of breast self-examination performance among Iranian women: An application of the Health Belief Model. Journal of Cancer Education, 26(2), 365-374. doi:10.1007/s13187-010-0158-y

Pennypacker, H. (1980). Toward an effective technology of instruction in breast selfexamination. International Journal in Mental Health, 11(3), 98-116. 
Petro-Nustus, W., \& Mikhail, B. I. (2002). Factors associated with breast self-examination among Jordanian women. Public Health Nursing, 19(4), 263-271. doi:10.1046/j.15251446.2002.19406.x

Pew Research Forum. (2010). Religion among the millennials. Retrieved February 26, 2014 from http://www.pewforum.org/2010/02/17/religion-among-the-millennials/

Pew Research Forum. (2014). African Americans and technology use: A demographic portrait. Retrieved May 7, 2014 from http://www.pewinternet.org/2014/01/06/african-americansand-technology-use/

Powe, B. D. (1995). Cancer fatalism among elderly Caucasians and African Americans. Oncology Nursing Forum, 22, 1355-1359.

Powe, B. D. (2001). Cancer fatalism among elderly African American women. Journal of Psychosocial Oncology, 19(3-4), 85-95. doi: 10.1300/J077v19n03_07

Powe, B., \& Finnie, R. (2003). Cancer fatalism: the state of the science. Cancer Nursing, 26(6), 454-467.

President's Cancer Panel. (2010). Reducing environmental cancer risk: What can we do now? Retrieved September 6, 2012 from http://deainfo.nci.nih.gov/advisory/pcp/annualReports/index.htm

Ree, M. J., French, D., MacLeod, C., \& Locke, V. (2008). Distinguishing Cognitive and Somatic Dimensions of State and Trait anxiety: Development and validation of the State-Trait Inventory for Cognitive and Somatic Anxiety (STICSA). Behavioural and Cognitive Psychotherapy, 36(3), 313-332. doi:10.1017/S1352465808004232 
Rodin, J., Silberstein, L., \& Striegel-Moore, R. (1985). Women and weight: A normative discontent. In T. B. Sondereregger (Ed.), Psychology and gender (pp. 267-307). Lincoln, NE: University of Nebraska Press.

Ronis, D. L., \& Kaiser, M. K. (1989). Correlates of breast self-examination in a sample of college women: Analyses of linear structural relations. Journal of Applied Social Psychology, 19, 1068-1084. doi:10.1111/j.1559-1816.1989.tb01240.x

Rosenstock, I. M. (1965). Why people use health services. The Milbank Memorial Fund Quarterly, 44, 94-127.

Roth, M. Y., Elmore, J. G., Yi-Frazier, J. P., Reisch, L. M., Oster, N. V., \& Miglioretti, D. L. (2011). Self-detection remains a key method of breast cancer detection for U.S. women. Journal of Women's Health, 20, 1135-1139. doi: 10.1089/jwh.2010.2493

Salmoirago-Blotcher, E., Fitchett, G., Ockene, J. K., Schnall, E., Crawford, S., Granek, I., et al. (2011). Religion and healthy lifestyle behaviors among postmenopausal women: The Women's Health Initiative. Journal of Behavioral Medicine, 34(5), 360-371. doi:10.1007/s10865-011-9322-z

Secginli, S., \& Nahcivan, N. O. (2006). Factors associated with breast cancer screening behaviours in a sample of Turkish women: A questionnaire survey. International Journal of Nursing Studies, 43(2), 161-171. doi:10.1016/j.ijnurstu.2005.02.004

Semiglazov, V. F., Moiseyenko, V. M., Manikhas, A. G., Protsenko, S. A., Kharikova, R. S., Ivanov, V. G., et al. (1999). Role of breast self-examination in early detection of breast cancer: Russia/WHO prospective randomized trial in St. Petersburg. Cancer Strategy, 1, 145-151. 
Skrabanek, P. (1985). False premises and false promises of breast cancer screening. Lancet, 316320.

Spiegel, T. N., Hill, K. A., \& Warner, E. (2009).The attitudes of women with BRCA1 and BRCA 2 mutations toward clinical breast examinations and breast self-examinations. Journal of Women's Health, 18(7), 1019-1024.doi: 10.1089/jwh.2008.1076

Spurlock, W., \& Cullins, L. (2006). Cancer fatalism and breast cancer screening in African American women. The ABNF Journal: Official Journal of the Association of Black Nursing Faculty in Higher Education, Inc, 17(1), 38-43.

Stevens, V. M., Hatcher, J. W., \& Bruce, B. K. (1994). How compliant is compliant? Evaluating adherence with breast self-exam positions. Journal of Behavioral Medicine, 17(4), 523534. doi: 10.1007/BF01857924

Straughan, P. T., \& Seow, A. A. (1995). Barriers to mammography among Chinese women in Singapore: A focus group approach. Health Education Research, 10(4), 431-441. doi:10.1093/her/10.4.431

Stretcher, V., \& Rosenstock, I. M. (1997).The health belief model. In K. Glanz, F. M. Lewis, \& B. K. Rimer (Eds.). Health behavior and health education: Theory, research, and practice. San Francisco, CA: Jossey-Boss.

Susan G. Komen for the Cure. (2012). Understanding breast cancer: Early detection and screening. Retrieved September 9, 2012 from http://ww5.komen.org/breastcancer/earlydetectionampscreening.html

Tabachnick, B. G., \& Fidell, L. S. (2007). Using Multivariate Statistics (5th Ed.). New York, NY: Pearson Education. 
Taylor, T. R., Huntley, E. D., Sween, J., Makambi, K., Mellman, T. A., Williams, C. D., et al. (2012). An exploratory analysis of fear of recurrence among African-American breast cancer survivors. International Journal of Behavioral Medicine, 12, 280-287.

Thomas, D. B., Gao, D. L., Ray, R. M., Wang, W. W., Allison, C. J., Chen, F. L., et al. (2002). Randomized trial of breast self-examination in Shanghai: Final results. Journal of National Cancer Institute, 94(19), 1445-1457. doi: 10.1093/jnci/94.19.1445

Trask, P. C., Paterson, A. G., Wang, C., Hayasaka, S., Milliron, K. J., Blumberg, L. R., et al. (2001). Cancer-specific worry interference in women attending a breast and ovarian cancer risk evaluation program: impact on emotional distress and health functioning. Psycho-Oncology, 10(5), 349-360. doi:10.1002/pon.510

U.S. Preventive Services Task Force. (2009). Screening for breast cancer. Retrieved March 17 , 2014 from http://www.uspreventiveservicestaskforce.org/uspstf/uspsbrca.htm

Umeh, K., \& Rogan-Gibson, J. (2001).Perceptions of threat, benefits, and barriers in breast selfexamination amongst young asymptomatic women. British Journal of Health Psychology, 6(4), 361-372. doi:10.1348/135910701169269

van Dooren, S., Rijnsburger, A., Seynaeve, C., Kriege, A., Duivenvoorden, H., Bartels, C., et al. (2003). Psychological distress and breast self-examination frequency in women at increased risk for hereditary or familial breast cancer. Community Genetics, 6(4), 235241. doi:10.1159/000079385

Vartanian, L., \& Grisham, J. (2012). Obsessive-compulsive symptoms and body checking in women and men. Cognitive Therapy \& Research, 36(4), 367-374. doi:10.1007/s10608011-9356-0 
Wallston, K. A., Malcarne, V. L., Flores, L., Hansdottir, I., Smith, C. A., Stein, M. J., et al. (1999). Does God determine your health? The God Locus of Health Control Scale. Cognitive Therapy and Research, 23(2), 131-142. doi:10.1023/A:1018723010685

Wendt, S. J. (2005). Perception of future risk of breast cancer and coronary heart disease in female undergraduates. Psychology, Health \& Medicine, 10(3), 253-262. doi:10.1080/1354850041233133414

Widaman, K. F. (2006). Best practices in quantitative methods for developmentalists: III. Missing data: What to do with or without them. Monographs of the Society for Research in Child Development, 71(3), 42-64. doi:10.1111/j.1540-5834.2006.00404.x

Wilke, L.G., Broadwater, G., Rabiner, S., Owens, E., Yoon, S., Ghate, S., et al. (2009). Breast self-examination: defining a cohort still in need. The American Journal of Surgery $198(4), 575-579$.

Williams, G. A., Abbott, R. R., Taylor, D. K. (1997). Using focus group methodology to develop breast cancer screening programs that recruit African American women. Journal of Community Health, 22(1), 45-56.

Witte, K. (1994). Fear control and danger control: A test of the extended parallel process model (EPPM). Communication Monographs, 61,113-134.

World Health Organization. (2008). The global burden of disease: 2004 update. Retrieved July 11,2012 from http://www.who.int/healthinfo/global_burden_disease/2004_report_update/en/index.html World Health Organization: International Agency for Research on Cancer. (2008). World cancer report. Retrieved July 10, 2012 from http://www.iarc.fr/en/publications/pdfsonline/wcr/2008/index.p 
Figure 1

Consort Diagram Showing Participant Breakdown

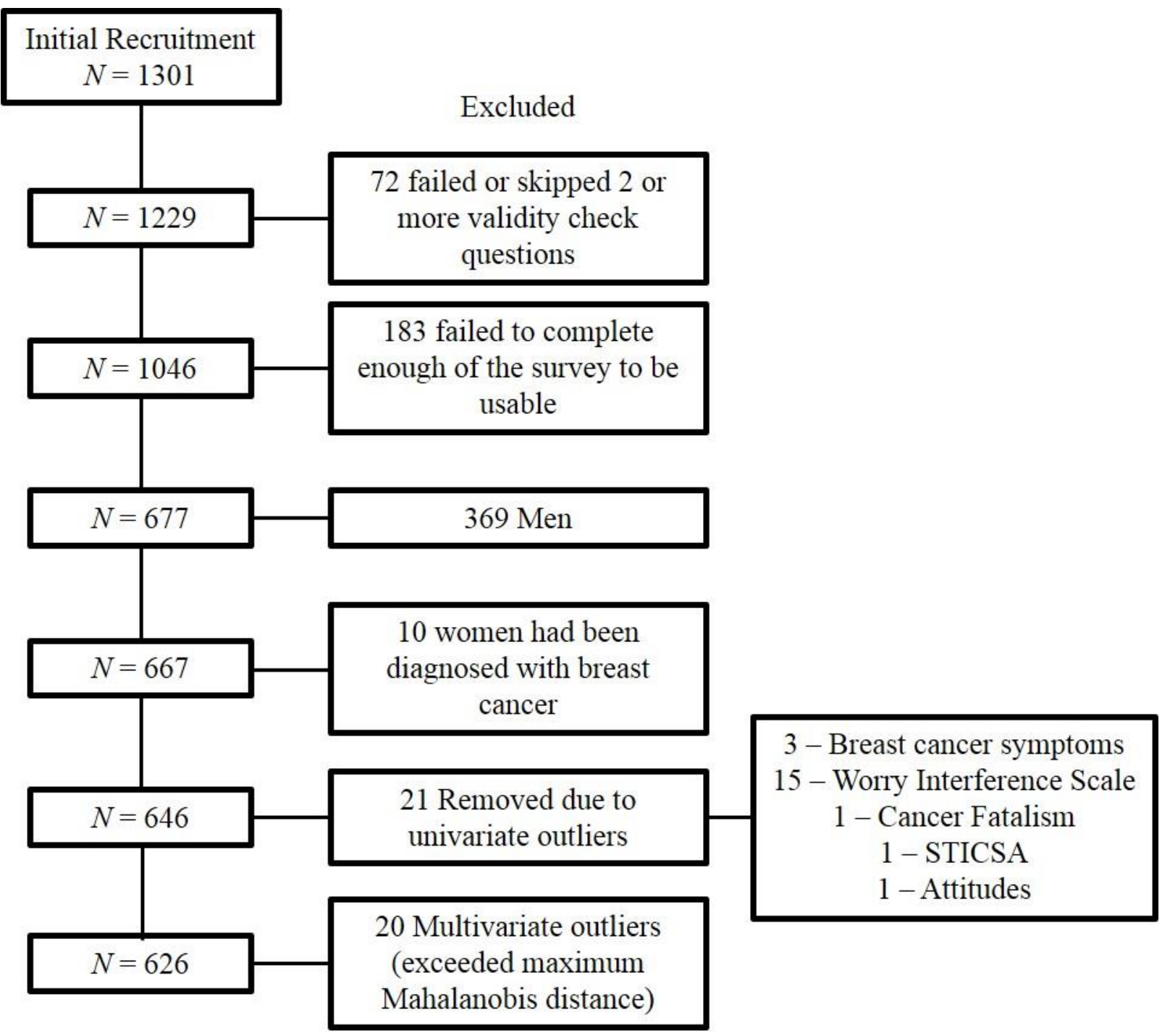


Table 1

Comparisons between BRFSS Sample and the Current Sample.

\begin{tabular}{l|cccccc}
\hline \multicolumn{1}{c|}{ Age (years) } & $18-24$ & $25-34$ & $35-44$ & $45-54$ & $55-64$ & $65+$ \\
\hline BRFSS & $12.4 \%$ & $16.4 \%$ & $16.0 \%$ & $18.1 \%$ & $16.6 \%$ & $20.8 \%$ \\
Current Sample & $24.8 \% * *$ & $40.4 \% * *$ & $18.3 \%$ & $7.1 \% * *$ & $5.6 \% * *$ & $1.8 \% * *$ \\
\hline
\end{tabular}

$\chi^{2}(5)=476.36, p<.001$

Significance determined by comparison between current sample (observed) and BRFSS

(expected) in each age category.

$* p<.05$

$* * p<.01$

\begin{tabular}{l|cccc}
\hline \multicolumn{1}{c|}{ Education } & H.S. Diploma & Some Post- & College + \\
\hline BRFSS & $11.6 \%$ & $29.0 \%$ & $33.1 \%$ & $24.6 \%$ \\
Current Sample & $0.6 \% \%^{* *}$ & $9.3 \% \%^{* *}$ & $41.0 \%^{* *}$ & $49.0 \%^{* *}$ \\
\hline
\end{tabular}

$\chi^{2}(3)=306.02, p<.001$

Significance determined by comparison between current sample (observed) and BRFSS

(expected) in each education category.

$* p<.05$

$* * p<.01$

\begin{tabular}{l|cccccc}
\hline & $\begin{array}{c}\text { Employed } \\
\text { or Self- } \\
\text { Employed }\end{array}$ & Unemployed & Homemaker & Student & Retired & $\begin{array}{c}\text { Unable } \\
\text { to } \\
\text { Work }\end{array}$ \\
\hline BRFSS & $51.0 \%$ & $6.8 \%$ & $11.7 \%$ & $6.0 \%$ & $17.5 \%$ & $6.5 \%$ \\
Current Sample & $64.6 \% \%^{* *}$ & $4.9 \%$ & $12.3 \%$ & $12.4 \%^{* * *}$ & $2.4 \%^{* *}$ & $2.7 \%^{* *}$ \\
\hline
\end{tabular}

$\chi^{2}(5)=165.22, p<.001$

Significance determined by comparison between current sample (observed) and BRFSS (expected) in each employment category.

$* p<.05$

$* * p<.01$

\begin{tabular}{l|cc}
\hline \multicolumn{1}{c|}{ Health Insurance } & Yes & No \\
\hline BRFSS & $84.7 \%$ & $15.3 \%$ \\
Current Sample & $75.4 \% *$ & $23.9 \% * *$ \\
\hline
\end{tabular}

$\chi^{2}(1)=37.07, p<.001$

Significance determined by comparison between current sample (observed) and BRFSS

(expected) in each insurance category.

$* p<.05$

$* * p<.01$ 


\begin{tabular}{l|cccc}
\hline & Normal \\
\multicolumn{1}{c|}{ BMI } & $\begin{array}{c}\text { Underweight } \\
(12.0-18.49)\end{array}$ & $\begin{array}{c}\text { Weight } \\
(18.5-24.99)\end{array}$ & $\begin{array}{c}\text { Overweight } \\
(25.0-29.99)\end{array}$ & $\begin{array}{c}\text { Obese } \\
(30.0+)\end{array}$ \\
\hline BRFSS & $2.4 \%$ & $39.9 \%$ & $29.6 \%$ & $27.5 \%$ \\
Current Sample & $3.2 \%$ & $43.5 \%$ & $23.0 \% * *$ & $30.3 \%$ \\
\hline
\end{tabular}

$\chi^{2}(3)=14.75, p=.002$

Significance determined by comparison between current sample (observed) and BRFSS (expected) in each BMI category.

$* p<.05$

$* * p<.01$

\begin{tabular}{l|cc}
\hline \multicolumn{1}{c|}{ Women aged 40+ who have had a } & & No \\
mammogram within the past 2 years & Yes & $26.0 \%$ \\
\hline BRFSS & $74.0 \%$ & $41.5 \% * *$ \\
Current Sample & $58.5 \% *$ & \\
\hline
\end{tabular}

$\chi^{2}(1)=17.88, p<.001$

Significance determined by comparison between current sample (observed) and BRFSS (expected) in each mammography category.

$* p<.05$

$* * p<.01$

\begin{tabular}{l|ccccc}
\hline \multicolumn{1}{c|}{ General Health } & Excellent & Very Good & Good & Fair & Poor \\
\hline BRFSS & $18.5 \%$ & $32.7 \%$ & $30.9 \%$ & $12.7 \%$ & $4.5 \%$ \\
Current Sample & $11.8 \% * *$ & $39.9 \% * *$ & $37.0 \% * *$ & $8.9 \% * *$ & $2.1 \% * *$ \\
\hline
\end{tabular}

$\chi^{2}(4)=47.62 p<.001$

Significance determined by comparison between current sample (observed) and BRFSS

(expected) in each age category.

$* p<.05$

$* * p<.01$ 
Table 2

Descriptive and Normality Distribution Information for Study Variables.

\begin{tabular}{|c|c|c|c|c|c|c|c|c|}
\hline \multirow[b]{2}{*}{ Variable } & \multirow[b]{2}{*}{$N$} & \multirow[b]{2}{*}{ Mean (S.D.) } & \multicolumn{3}{|c|}{ Pre-Transformation } & \multirow[b]{2}{*}{ Transformation } & \multicolumn{2}{|c|}{ Post-Transformation } \\
\hline & & & Range & Skew & Kurtosis & & Skew & Kurtosis \\
\hline \multicolumn{9}{|c|}{ Outcome Variables } \\
\hline BSE Proficiency & 614 & $6.20(1.81)$ & $1-11$ & 0.07 & -1.68 & None & & \\
\hline Lump Checking* & 625 & $1.64(0.70)$ & $1-5$ & 11.43 & 9.81 & None & & \\
\hline Shower Checking* & 622 & $1.73(0.83)$ & $1-5$ & 9.92 & 1.95 & None & & \\
\hline \multicolumn{9}{|c|}{ Personal and Demographic Variables } \\
\hline BMI* & 627 & $27.55(7.31)$ & $15.1-60.8$ & 10.96 & 5.12 & None & & \\
\hline Financial Difficulties* & 624 & $2.50(1.05)$ & $1-4$ & 0.39 & -6.07 & None & & \\
\hline Perceived BSE Effectiveness* & 624 & $4.23(0.74)$ & $2-5$ & -9.06 & 4.52 & None & & \\
\hline Breast Cancer Risk Factors* & 627 & $4.64(2.42)$ & $0-10$ & 6.15 & -2.27 & None & & \\
\hline Breast Cancer Symptoms* & 627 & $6.13(1.86)$ & $1-8$ & -6.71 & -3.35 & None & & \\
\hline Subjective Breast Cancer Risk & 624 & $1.92(0.73)$ & $1-3$ & 1.24 & -5.70 & None & & \\
\hline Objective Breast Cancer Risk & 625 & $1.92(4.19)$ & $0-34$ & 36.22 & 84.94 & Logarithmic & 13.49 & 2.59 \\
\hline \multicolumn{9}{|c|}{ Theory Variables } \\
\hline Attitudes & 627 & $58.97(9.02)$ & $21-70$ & -10.07 & 4.34 & Square Root & -1.46 & -3.14 \\
\hline Subjective Norm* & 627 & $4.94(1.48)$ & $1-7$ & -6.44 & 0.54 & None & & \\
\hline Intention* & 627 & $3.92(1.00)$ & $1-5$ & -10.37 & 4.00 & None & & \\
\hline Susceptibility & 627 & $11.12(4.63)$ & $5-25$ & 4.44 & -2.09 & Square Root & 0.56 & -4.41 \\
\hline Seriousness & 626 & $21.87(5.58)$ & $7-34$ & -5.03 & -0.36 & Square Root & 0.41 & -0.98 \\
\hline Benefits** & 625 & $22.39(4.13)$ & $6-30$ & -4.62 & 4.03 & None & & \\
\hline Barriers & 625 & $11.12(4.50)$ & $6-30$ & 7.74 & 0.31 & Logarithmic & 1.31 & -5.62 \\
\hline Self-Efficacy*** & 626 & $38.16(8.84)$ & $11-55$ & -5.45 & 0.63 & Square Root & 3.27 & 1.47 \\
\hline Health Motivation** & 625 & $27.13(4.76)$ & $13-35$ & -3.30 & -2.08 & None & & \\
\hline Breast Cancer Fear & 627 & $24.18(8.63)$ & $8-40$ & -1.59 & -3.63 & None & & \\
\hline
\end{tabular}




\begin{tabular}{|c|c|c|c|c|c|c|c|c|}
\hline \multirow[b]{2}{*}{ Variable } & \multirow[b]{2}{*}{$N$} & \multirow[b]{2}{*}{ Mean (S.D.) } & \multicolumn{3}{|c|}{ Pre-Transformation } & \multicolumn{3}{|c|}{ Post-Transformation } \\
\hline & & & Range & Skew & Kurtosis & Transformation & Skew & Kurtosis \\
\hline \multicolumn{9}{|c|}{ Psychosocial Variables } \\
\hline Anxiety & 627 & $33.80(11.01)$ & $21-76$ & 10.63 & -3.34 & Logarithmic & 4.73 & -3.27 \\
\hline Breast Cancer Worry & 626 & $7.81(1.82)$ & $7-17$ & 30.24 & 47.60 & Logarithmic & 24.56 & 28.58 \\
\hline Cancer Fatalism & 627 & $34.76(10.14)$ & $15-63$ & 2.45 & -2.94 & None & & \\
\hline Body Dissatisfaction** & 626 & $3.08(0.98)$ & $1-5$ & -2.30 & 3.87 & None & & \\
\hline God Locus of Health Control & 627 & $13.21(8.68)$ & $6-36$ & 9.46 & -0.94 & Logarithmic & 4.02 & -7.51 \\
\hline Religious Beliefs & 627 & $16.63(6.34)$ & $5-25$ & -2.08 & -6.61 & None & & \\
\hline Organizational Religiousness & 626 & $6.84(3.31)$ & $5-20$ & 21.42 & 20.13 & Logarithmic & 15.42 & 5.88 \\
\hline
\end{tabular}

\section{Note.}

Reported skew and kurtosis statistics are adjusted for standard error.

Variable considered skewed if skew statistic was greater than or equal to $|3|$.

Variable considered kurtotic if kurtosis statistic was greater than or equal to $|3|$.

Variables with negative skew/kurtosis that were transformed were inverted prior to the transformation, then re-inverted posttransformation

BSE: Breast Self-Examination

BMI: Body Mass Index

* Variable not transformed to preserve meaning associated with particular scores.

** Untransformed variable used due to transformation exacerbating skew/kurtosis issues.

***Square root transformation used due to logarithmic transformation exacerbating skew/kurtosis issues. 
Table 3

Correlations between Independent Variables.

\begin{tabular}{llcccc}
\hline & \multicolumn{1}{c}{ Variable } & 1 & 2 & 3 & 4 \\
\hline 1 & BSE Frequency & - & .075 & $.547 * * *$ & $.464 * * *$ \\
2 & BSE Proficiency & & - & .012 & .035 \\
3 & Lump Checking & & & - & $.553 * * *$ \\
4 & Shower Checking & & & & - \\
\hline
\end{tabular}

Note.

$* * * p<.001$ 
Table 4

Descriptive Information for Study Variables for Each BSE Frequency Group.

\begin{tabular}{|c|c|c|c|c|}
\hline Variable & $\begin{array}{c}\text { Never } \\
(N=155) \\
\text { Mean (S.D.) }\end{array}$ & $\begin{array}{c}\text { Infrequent } \\
(N=168) \\
\text { Mean (S.D.) }\end{array}$ & $\begin{array}{c}\text { Recommended } \\
(N=269) \\
\text { Mean (S.D.) } \\
\end{array}$ & $\begin{array}{c}\text { Excessive } \\
(N=34) \\
\text { Mean (S.D.) }\end{array}$ \\
\hline \multicolumn{5}{|c|}{ Outcome Variables } \\
\hline BSE Proficiency & $5.99(1.84)$ & $6.11(1.61)$ & $6.40(1.89)$ & $6.06(1.92)$ \\
\hline Lump Checking & $1.18(0.46)$ & $1.42(0.55)$ & $1.90(0.60)$ & $2.74(0.90)$ \\
\hline Shower Checking & $1.26(0.60)$ & $1.52(0.68)$ & $2.00(0.81)$ & $2.76(0.78)$ \\
\hline \multicolumn{5}{|c|}{ Personal and Demographic Variables } \\
\hline BMI & $26.95(7.46)$ & $27.12(7.38)$ & $28.01(7.08)$ & $28.67(8.04)$ \\
\hline Financial Difficulties & $2.49(1.01)$ & $2.56(1.05)$ & $2.49(1.05)$ & $2.26(1.19)$ \\
\hline Perceived BSE Effectiveness & $4.10(0.84)$ & $4.14(0.70)$ & $4.31(0.69)$ & $4.56(0.66)$ \\
\hline Breast Cancer Risk Factors & $4.49(2.35)$ & $4.36(2.15)$ & $4.77(2.51)$ & $5.79(2.79)$ \\
\hline Breast Cancer Symptoms & $5.79(1.92)$ & $6.23(1.83)$ & $6.26(1.81)$ & $6.26(1.90)$ \\
\hline Subjective Breast Cancer Risk & $1.89(0.74)$ & $1.98(0.72)$ & $1.92(0.73)$ & $1.79(0.73)$ \\
\hline Objective Breast Cancer Risk & $1.70(3.61)$ & $1.72(3.46)$ & $2.31(5.00)$ & $0.97(2.53)$ \\
\hline \multicolumn{5}{|c|}{ Theory Variables } \\
\hline Attitudes & $54.37(10.60)$ & $58.73(8.05)$ & $61.17(7.52)$ & $64.25(6.91)$ \\
\hline Subjective Norm & $4.39(1.42)$ & $4.80(1.46)$ & $5.26(1.41)$ & $5.62(1.46)$ \\
\hline Intention & $3.11(1.07)$ & $3.86(0.76)$ & $4.33(0.77)$ & $4.68(0.77)$ \\
\hline Susceptibility & $10.84(4.68)$ & $11.26(4.43)$ & $11.31(4.70)$ & $10.38(4.78)$ \\
\hline Seriousness & $21.91(5.86)$ & $21.86(5.71)$ & $22.00(5.28)$ & $21.06(5.72)$ \\
\hline Benefits & $20.53(4.38)$ & $22.06(3.89)$ & $23.47(3.72)$ & $24.09(3.98)$ \\
\hline Barriers & $13.57(4.60)$ & $11.31(4.50)$ & $10.05(3.96)$ & $7.41(1.82)$ \\
\hline Self-Efficacy & $31.35(9.60)$ & $38.09(7.38)$ & $41.44(6.74)$ & $44.26(6.82)$ \\
\hline Health Motivation & $25.40(4.66)$ & $26.48(4.67)$ & $28.41(4.50)$ & $28.34(4.74)$ \\
\hline Breast Cancer Fear & $23.54(8.97)$ & $24.40(8.65)$ & $24.31(8.35)$ & $25.40(8.98)$ \\
\hline \multicolumn{5}{|c|}{ Psychosocial Variables } \\
\hline Anxiety & $36.14(11.32)$ & $33.00(11.28)$ & $33.42(10.76)$ & $30.40(8.49)$ \\
\hline Breast Cancer Worry & $8.00(2.19)$ & $7.71(1.74)$ & $7.77(1.68)$ & $7.73(1.28)$ \\
\hline Cancer Fatalism & $35.61(10.44)$ & $33.54(9.53)$ & $35.49(10.34)$ & $31.20(9.30)$ \\
\hline Body Dissatisfaction & $2.93(0.98)$ & $3.12(0.90)$ & $3.10(1.01)$ & $3.35(1.03)$ \\
\hline God Locus of Health Control & $12.06(8.53)$ & $12.66(7.92)$ & $14.48(9.15)$ & $10.97(7.99)$ \\
\hline Religious Beliefs & $15.24(6.60)$ & $16.48(6.19)$ & $17.52(6.18)$ & $16.39(6.03)$ \\
\hline Organizational Religiousness & $6.57(3.32)$ & $6.47(2.86)$ & $7.20(3.52)$ & $6.91(3.33)$ \\
\hline
\end{tabular}


Table 5

One-Way ANOVAs investigating Differences in Predictor Variables by BSE Frequency Groups.

\begin{tabular}{|c|c|c|c|c|c|}
\hline Variable & $d f$ & $F$ & $p$ & $\eta_{p}^{2}$ & Tukey \\
\hline \multicolumn{6}{|c|}{ Personal and Demographic Variables } \\
\hline Age & 3,619 & 18.91 & $<.001$ & .084 & $\mathrm{~N}, \mathrm{I}<\mathrm{R}, \mathrm{E}$ \\
\hline BMI & 3,622 & 1.17 & .321 & .006 & \\
\hline Education & 3,619 & 1.71 & .164 & .008 & \\
\hline Bra Size $^{1}$ & 3,612 & 2.48 & .060 & .012 & \\
\hline Cup Size & 3,617 & 0.31 & .817 & .002 & \\
\hline Financial Difficulties & 3,619 & 0.75 & .525 & .004 & \\
\hline Perceived BSE Effectiveness & 3,619 & 5.71 & .001 & .027 & $\mathrm{~N}, \mathrm{I}<\mathrm{R}, \mathrm{E}$ \\
\hline Age Heard of BSE & 3,603 & 1.86 & .135 & .009 & \\
\hline Breast Cancer Risk Factors & 3,622 & 3.85 & .009 & .018 & $\mathrm{~N}, \mathrm{R}<\mathrm{E}$ \\
\hline Breast Cancer Symptoms & 3,622 & 2.48 & .060 & .012 & $\mathrm{~N}<\mathrm{R}$ \\
\hline Subjective Breast Cancer Risk & 3,619 & 0.76 & .519 & .004 & \\
\hline Objective Breast Cancer Risk & 3,620 & 1.63 & .181 & .008 & \\
\hline
\end{tabular}

\begin{tabular}{|c|c|c|c|c|c|}
\hline \multicolumn{6}{|c|}{ Theory Variables } \\
\hline Attitudes & 3,622 & 24.82 & $<.001$ & .107 & $\mathrm{~N}<\mathrm{I}<\mathrm{R}<\mathrm{E}$ \\
\hline Subjective Norm & 3,622 & 15.33 & $<.001$ & .069 & $\mathrm{~N}<\mathrm{I}<\mathrm{R}<\mathrm{E}$ \\
\hline Intention & 3,622 & 77.29 & $<.001$ & .272 & $\mathrm{~N}<\mathrm{I}<\mathrm{R}<\mathrm{E}$ \\
\hline Susceptibility & 3,622 & 0.76 & .516 & .004 & \\
\hline Seriousness & 3,621 & 0.27 & .847 & .001 & \\
\hline Benefits & 3,622 & 20.65 & $<.001$ & .091 & $\mathrm{~N}<\mathrm{I}<\mathrm{R}, \mathrm{E}$ \\
\hline Barriers & 3,621 & 32.95 & $<.001$ & .137 & $\mathrm{~N}>\mathrm{I}>\mathrm{R}>\mathrm{E}$ \\
\hline Self-Efficacy & 3,621 & 52.92 & $<.001$ & .204 & $\mathrm{~N}<\mathrm{I}<\mathrm{R}, \mathrm{E}$ \\
\hline Health Motivation & 3,620 & 16.07 & $<.001$ & .072 & $\mathrm{~N}, \mathrm{I}<\mathrm{R}, \mathrm{E}$ \\
\hline Breast Cancer Fear & 3,622 & 0.57 & .633 & .003 & \\
\hline \multicolumn{6}{|c|}{ Psychosocial Variables } \\
\hline Anxiety & 3,622 & 4.28 & .005 & .020 & $\mathrm{~N}>\mathrm{I}, \mathrm{R}, \mathrm{E}$ \\
\hline Breast Cancer Worry & 3,621 & 0.68 & .563 & .003 & \\
\hline Body Dissatisfaction $^{1}$ & 3,621 & 2.30 & .077 & .011 & \\
\hline Cancer Fatalism & 3,622 & 3.06 & .028 & .015 & $\mathrm{~N}, \mathrm{R}>\mathrm{E}$ \\
\hline God Locus of Health Control & 3,622 & 3.99 & .008 & .019 & $\mathrm{~N}<\mathrm{R}$ \\
\hline Religious Beliefs & 3,622 & 4.40 & .004 & .021 & $\mathrm{~N}<\mathrm{R}$ \\
\hline Organizational Religiousness & 3,621 & 2.63 & .050 & .013 & $\mathrm{~N}, \mathrm{I}<\mathrm{R}$ \\
\hline
\end{tabular}

Note.

$\mathrm{N}$ : Never;

I: Infrequent

A: Recommended

E: Excessive

1 Post hoc tests did not reveal any significant differences at $p=.10$ 
Table 6

Chi-Square Investigating Differences in BSE Frequency Group Membership by Marital Status.

\begin{tabular}{ll|r|r|r|r}
\hline & & \multicolumn{4}{|c}{ BSE Frequency } \\
\multicolumn{1}{c}{ Marital Status } & & Never & Infrequent & Recommended & Excessive \\
\hline \multirow{2}{*}{ Single, Never Married } & Actual & $59^{\mathrm{T}}$ & 60 & $64^{\mathrm{T}}$ & 7 \\
& Expected & 47.3 & 51 & 81.5 & 10.3 \\
\hline Unmarried, Committed & Actual & 39 & 45 & 54 & 5 \\
Couple & Expected & 35.6 & 38.4 & 61.3 & 7.7 \\
\hline \multirow{2}{*}{ Married } & Actual & $39^{\mathrm{T}}$ & 50 & 105 & 15 \\
& Expected & 52 & 56.1 & 89.6 & 11.3 \\
\hline \multirow{2}{*}{ Divorced, Separated } & Actual & 15 & $9^{*}$ & $39^{\mathrm{T}}$ & 6 \\
& Expected & 17.2 & 18.5 & 29.6 & 3.7 \\
\hline
\end{tabular}

Note.

$\chi^{2}(9)=29.91, p<.001$.

Significance within cells determined by comparison between observed and expected values.

$\mathrm{T}<.10$

$* p<.05$

$* * p<.01$ 
Table 7

Chi-Square Investigating Differences in BSE Frequency Group Membership by Having Ever Had a Mammogram.

\begin{tabular}{ll|r|r|r|r}
\hline & & \multicolumn{4}{|c}{ BSE Frequency } \\
\multicolumn{2}{c|}{} & Never & Infrequent & Recommended & Excessive \\
\hline \multirow{2}{*}{ No } & Actual & $132^{\mathrm{T}}$ & 138 & $171^{*}$ & 21 \\
& Expected & 113.3 & 123.7 & 199.7 & 25.3 \\
\hline \multirow{2}{*}{ Yes } & Actual & $20^{* *}$ & $28^{*}$ & $97 * *$ & 13 \\
& Expected & 38.7 & 42.3 & 68.3 & 8.7 \\
\hline
\end{tabular}

Note.

$\chi^{2}(3)=37.75, p<.001$.

Significance within cells determined by comparison between observed and expected values.

$\mathrm{T}<.10$

$* p<.05$

$* * p<.01$ 
Breast Awareness 102

Table 8

Chi-Square Investigating Differences in BSE Frequency Group Membership by Having Ever Had a Clinical Breast Exam.

\begin{tabular}{ll|r|r|r|r}
\hline \multicolumn{2}{c}{$\begin{array}{c}\text { Ever Had a Clinical Breast } \\
\text { Exam }\end{array}$} & & \multicolumn{3}{c|}{ BSE Frequency } \\
No & & Never & Infrequent & Recommended & Excessive \\
\hline \multirow{2}{*}{ No } & Actual & $39 * *$ & 20 & $18^{* *}$ & 5 \\
& Expected & 20.0 & 22.4 & 35.2 & 4.4 \\
\hline \multirow{2}{*}{ Yes } & Actual & $111^{\mathrm{T}}$ & 148 & 246 & 28 \\
& Expected & 130.0 & 145.6 & 228.8 & 28.6 \\
\hline
\end{tabular}

Note.

$\chi^{2}(3)=30.92, p<.001$.

Significance within cells determined by comparison between observed and expected values.

$\mathrm{T}<.10$

$* p<.05$

$* * p<.01$ 
Table 9

Chi-Square Investigating Differences in BSE Frequency Group Membership by Having Health Insurance.

\begin{tabular}{ll|r|r|r|r}
\hline & & \multicolumn{4}{|c}{ BSE Frequency } \\
Health Insurance & & Never & Infrequent & Recommended & Excessive \\
\hline \multirow{2}{*}{ No } & Actual & 39 & 39 & 65 & 7 \\
& Expected & 36.9 & 40.3 & 64.6 & 8.2 \\
\hline \multirow{2}{*}{ Yes } & Actual & 114 & 128 & 203 & 27 \\
& Expected & 116.1 & 126.7 & 203.4 & 25.8 \\
\hline
\end{tabular}

Note.

$\chi^{2}(3)=0.45, p=.931$. 
Table 10

Chi-Square Investigating Differences in BSE Frequency Group Membership by Cued by Health Care Provider.

\begin{tabular}{|c|c|c|c|c|c|}
\hline \multirow{2}{*}{\multicolumn{2}{|c|}{ Cued by Health Care Provider }} & \multicolumn{4}{|c|}{ BSE Frequency } \\
\hline & & Never & Infrequent & Recommended & Excessive \\
\hline \multirow{2}{*}{ No } & Actual & $74 * *$ & 35 & $50 * *$ & 10 \\
\hline & Expected & 41.8 & 45.4 & 72.6 & 9.2 \\
\hline \multirow{2}{*}{ Yes } & Actual & $81 * *$ & 133 & 219 & 24 \\
\hline & Expected & 113.2 & 122.6 & 196.4 & 24.8 \\
\hline
\end{tabular}

Note.

$\chi^{2}(3)=46.84, p<.001$.

Significance within cells determined by comparison between observed and expected values.

$\mathrm{T}<.10$

$* p<.05$

$* * p<.01$ 
Table 11

Chi-Square Investigating Differences in BSE Frequency Group Membership by Cued by Public Health Campaign.

\begin{tabular}{|c|c|c|c|c|c|}
\hline \multirow{2}{*}{\multicolumn{2}{|c|}{$\begin{array}{c}\text { Cued by Public Health } \\
\text { Campaign }\end{array}$}} & \multicolumn{4}{|c|}{ BSE Frequency } \\
\hline & & Never & Infrequent & Recommended & Excessive \\
\hline \multirow{2}{*}{ No } & Actual & 88 & 95 & 145 & 20 \\
\hline & Expected & 86.2 & 93.4 & 149.5 & 18.9 \\
\hline \multirow{2}{*}{ Yes } & Actual & 67 & 73 & 124 & 14 \\
\hline & Expected & 68.8 & 74.6 & 119.5 & 15.1 \\
\hline
\end{tabular}

Note.

$\chi^{2}(3)=0.60, p=.895$. 
Table 12

Chi-Square Investigating Differences in BSE Frequency Group Membership by Cued by Disclosure by a Celebrity or Public Figure.

\begin{tabular}{ll|r|r|r|r}
\multicolumn{2}{c}{$\begin{array}{c}\text { Cued by Celebrity or Public } \\
\text { Figure }\end{array}$} & & \multicolumn{3}{c|}{ BSE Frequency } \\
\hline \multirow{2}{*}{ No } & & Never & Infrequent & Recommended & Excessive \\
\hline \multirow{2}{*}{ Yes } & Actual & 137 & 149 & 231 & 28 \\
& Expected & 134.9 & 146.3 & 234.2 & 29.6 \\
\hline
\end{tabular}

Note.

$\chi^{2}(3)=1.64, p=.650$. 
Table 13

Chi-Square Investigating Differences in BSE Frequency Group Membership by Cued by Experiencing Breast Cancer Symptoms.

\begin{tabular}{|c|c|c|c|c|c|}
\hline \multirow{2}{*}{\multicolumn{2}{|c|}{$\begin{array}{c}\text { Cued by Breast Cancer } \\
\text { Symptoms }\end{array}$}} & \multicolumn{4}{|c|}{ BSE Frequency } \\
\hline & & Never & Infrequent & Recommended & Excessive \\
\hline \multirow{2}{*}{ No } & Actual & 141 & 149 & 237 & 27 \\
\hline & Expected & 137.2 & 148.7 & 238.1 & 30.1 \\
\hline \multirow{2}{*}{ Yes } & Actual & 14 & 19 & 32 & 7 \\
\hline & Expected & 17.8 & 19.3 & 30.9 & 3.9 \\
\hline
\end{tabular}

Note.

$\chi^{2}(3)=3.73, p=.292$. 
Table 14

Chi-Square Investigating Differences in BSE Frequency Group Membership by Cued by Family or Friend with Breast Cancer.

\begin{tabular}{|c|c|c|c|c|c|}
\hline \multirow[b]{2}{*}{$\begin{array}{c}\text { Cued by Family or Friend } \\
\text { with Breast Cancer }\end{array}$} & & \multicolumn{4}{|c|}{ BSE Frequency } \\
\hline & & Never & Infrequent & Recommended & Excessive \\
\hline \multirow{2}{*}{ No } & Actual & 136 & 141 & 203 & 28 \\
\hline & Expected & 125.8 & 136.3 & 218.3 & 27.6 \\
\hline \multirow{2}{*}{ Yes } & Actual & $19^{\mathrm{T}}$ & 27 & $66^{*}$ & 6 \\
\hline & Expected & 29.2 & 31.7 & 50.7 & 6.4 \\
\hline
\end{tabular}

Note.

$\chi^{2}(3)=10.97, p=.012$.

Significance within cells determined by comparison between observed and expected values.

$\mathrm{T}<.10$

$* p<.05$

$* * p<.01$ 
Table 15

Chi-Square Investigating Differences in BSE Frequency Group Membership by Encouraged by Friend or Relative.

\begin{tabular}{|c|c|c|c|c|c|}
\hline \multirow{2}{*}{$\begin{array}{l}\text { Encouraged by Friend or } \\
\text { Relative }\end{array}$} & & \multicolumn{4}{|c|}{ BSE Frequency } \\
\hline & & Never & Infrequent & Recommended & Excessive \\
\hline \multirow{2}{*}{ No } & Actual & 146 & 144 & 221 & 28 \\
\hline & Expected & 133.5 & 144.7 & 231.6 & 29.3 \\
\hline \multirow{2}{*}{ Yes } & Actual & $9 * *$ & 24 & $48^{\mathrm{T}}$ & 6 \\
\hline & Expected & 21.5 & 23.3 & 37.4 & 4.7 \\
\hline
\end{tabular}

Note.

$\chi^{2}(3)=12.40, p=.006$.

${ }_{\mathrm{T}}<.10$

$* p<.05$

$* * p<.01$ 
Table 16

Multinomial Logistic Regression Predicting BSE Group Membership (Reference $=$ Never $)$.

\begin{tabular}{|c|c|c|c|c|c|c|c|c|c|}
\hline \multirow[b]{2}{*}{ Variable } & \multicolumn{3}{|c|}{ Infrequent } & \multicolumn{3}{|c|}{ Recommended } & \multicolumn{3}{|c|}{ Excessive } \\
\hline & Wald & OR & $95 \% C I$ & Wald & OR & $95 \% C I$ & Wald & $O R$ & $95 \% C I$ \\
\hline \multicolumn{10}{|c|}{ Personal and Demographic Variables } \\
\hline Age & 2.075 & 1.03 & $0.99-1.07$ & $13.53 * * *$ & 1.08 & $1.04-1.12$ & $5.21 *$ & 1.07 & $1.01-1.13$ \\
\hline $\begin{array}{l}\text { Unmarried, Committed Couple } \\
\text { (vs. Single) }\end{array}$ & 0.66 & 0.74 & $0.36-1.52$ & 0.11 & 0.88 & $0.41-1.90$ & 0.07 & 1.23 & $0.24-5.59$ \\
\hline Married (vs. Single) & 0.21 & 1.20 & $0.56-2.54$ & 1.41 & 1.60 & $0.74-3.48$ & 1.05 & 2.08 & $0.51-8.42$ \\
\hline Divorced/Separated (vs. Single) & 2.71 & 0.39 & $0.13-1.20$ & 0.30 & 0.74 & $0.26-2.17$ & 0.01 & 1.08 & $0.16-7.36$ \\
\hline Mammogram & 1.04 & 0.62 & $0.24-1.57$ & 0.07 & 0.88 & $0.36-2.20$ & 0.01 & 1.02 & $0.27-3.94$ \\
\hline Clinical Breast Exam & 0.50 & 1.36 & $0.58-3.20$ & 0.75 & 1.52 & $0.59-3.95$ & 3.04 & 0.23 & $0.04-1.20$ \\
\hline Bra Size & $3.97 *$ & 0.91 & $0.82-0.99$ & 3.72 & 0.91 & $0.82-1.00$ & 0.38 & 1.06 & $0.89-1.26$ \\
\hline Breast Cancer Risk Factors & 0.98 & 0.94 & $0.82-1.07$ & 0.03 & 1.01 & $0.89-1.15$ & $4.30 *$ & 1.26 & $1.01-1.56$ \\
\hline Breast Cancer Symptoms & 1.59 & 1.11 & $0.95-1.30$ & 0.06 & 1.02 & $0.86-1.21$ & 0.85 & 0.87 & $0.64-1.17$ \\
\hline Perceived BSE Effectiveness & 3.31 & 0.70 & $0.48-1.03$ & 0.86 & 0.82 & $0.54-1.25$ & $4.77 *$ & 2.89 & $1.12-7.49$ \\
\hline \multicolumn{10}{|c|}{ Theory Variables } \\
\hline Attitudes & 0.06 & 0.97 & $0.73-1.28$ & 0.06 & 1.04 & $0.77-1.40$ & 0.31 & 1.16 & $0.69-1.97$ \\
\hline Subjective Norm & 0.29 & 0.95 & $0.77-1.16$ & 0.49 & 0.93 & $0.75-1.15$ & 0.07 & 0.95 & $0.65-1.39$ \\
\hline Intention & $15.90 * * *$ & 1.98 & $1.41-2.76$ & $45.46^{* * * *}$ & 3.83 & $2.59-5.67$ & $16.51 * * *$ & 6.89 & $2.72-17.46$ \\
\hline Benefits & 0.13 & 1.02 & $0.93-1.11$ & 0.53 & 1.04 & $0.94-1.14$ & 0.20 & 0.97 & $0.82-1.13$ \\
\hline Barriers & $4.02 *$ & 0.41 & $0.17-0.98$ & $4.31 *$ & 0.38 & $0.15-0.95$ & $8.54 * *$ & 0.06 & $0.01-0.39$ \\
\hline Self-Efficacy & $15.66 * * *$ & 1.95 & $1.40-2.72$ & $20.56 * * *$ & 2.21 & $1.57-3.12$ & $14.16 * * *$ & 2.80 & $1.64-4.80$ \\
\hline Health Motivation & 0.64 & 0.97 & $0.91-1.04$ & 2.99 & 1.06 & $0.99-1.13$ & 0.01 & 1.00 & $0.88-1.12$ \\
\hline Cued by Health Care Provider & $8.76^{* *}$ & 2.76 & $1.41-5.39$ & $7.67 * *$ & 2.73 & $1.34-5.57$ & 0.18 & 1.32 & $0.37-4.73$ \\
\hline $\begin{array}{l}\text { Cued by Family or Friend with } \\
\text { Breast Cancer }\end{array}$ & 0.02 & 1.05 & $0.18-2.32$ & 1.35 & 1.58 & $0.73-3.44$ & 0.01 & 0.97 & $0.25-3.76$ \\
\hline Encouraged by Friend or Relative & $7.42 * *$ & 4.60 & $1.53-13.80$ & $10.44 * *$ & 6.28 & $2.06-19.13$ & $4.35^{*}$ & 5.19 & $1.11-24.35$ \\
\hline
\end{tabular}




\begin{tabular}{|c|c|c|c|c|c|c|c|c|c|}
\hline \multirow[b]{2}{*}{ Variable } & \multicolumn{3}{|c|}{ Infrequent } & \multicolumn{3}{|c|}{ Recommended } & \multicolumn{3}{|c|}{ Excessive } \\
\hline & Wald & $O R$ & $95 \% C I$ & Wald & OR & $95 \% C I$ & Wald & $O R$ & $95 \% C I$ \\
\hline \multicolumn{10}{|c|}{ Psychosocial Variables } \\
\hline Anxiety & $4.01 *$ & 0.37 & $0.14-0.98$ & 0.20 & 0.93 & $0.34-2.54$ & 0.19 & 0.67 & $0.11-4.17$ \\
\hline Cancer Fatalism & 0.75 & 0.99 & $0.96-1.02$ & 1.20 & 1.02 & $0.99-1.05$ & 0.01 & 1.00 & $0.95-1.06$ \\
\hline Body Dissatisfaction & 0.03 & 0.97 & $0.69-1.36$ & 0.50 & 0.96 & $0.68-1.37$ & 3.33 & 1.82 & $0.96-3.46$ \\
\hline God Locus of Health Control & 0.16 & 1.16 & $0.57-2.36$ & 2.29 & 1.77 & $0.84-3.71$ & 0.10 & 0.81 & $0.23-2.90$ \\
\hline Religious Beliefs & 0.49 & 1.03 & $0.95-1.10$ & 0.51 & 0.97 & $0.90-1.05$ & 0.63 & 0.95 & $0.84-1.08$ \\
\hline Organizational Religiousness & 1.22 & 0.56 & $0.20-1.58$ & 1.16 & 0.56 & $0.20-1.60$ & 0.01 & 0.90 & $0.15-5.44$ \\
\hline $\begin{array}{l}\text { Note. } \\
* p<.05 \\
* * p<.01 \\
* * * p<.001 \\
\chi^{2}(78)=412.711, p<.001 . \\
\text { McFadden Pseudo } R^{2}=.291 .\end{array}$ & & & & & & & & & \\
\hline
\end{tabular}


Table 17

Multinomial Logistic Regression Predicting BSE Group Membership (Reference = Infrequent).

\begin{tabular}{|c|c|c|c|c|c|c|}
\hline \multirow[b]{2}{*}{ Variable } & \multicolumn{3}{|c|}{ Recommended } & \multicolumn{3}{|c|}{ Excessive } \\
\hline & Wald & $O R$ & $95 \% C I$ & Wald & $O R$ & $95 \% C I$ \\
\hline \multicolumn{7}{|c|}{ Personal and Demographic Variables } \\
\hline Age & $8.60 * *$ & 1.05 & $1.02-1.08$ & 2.09 & 1.04 & $0.99-1.09$ \\
\hline Unmarried, Committed Couple (vs. Single) & 0.30 & 1.18 & $0.65-2.17$ & 0.47 & 1.66 & $0.39-6.99$ \\
\hline Married (vs. Single) & 0.93 & 1.34 & $0.74-2.43$ & 0.70 & 1.74 & $0.47-6.39$ \\
\hline Divorced/Separated (vs. Single) & 1.69 & 1.89 & $0.72-4.94$ & 1.14 & 2.74 & $0.43-17.40$ \\
\hline Mammogram & 1.12 & 1.44 & $0.74-2.80$ & 0.70 & 1.66 & $0.51-5.47$ \\
\hline Clinical Breast Exam & 0.06 & 1.12 & $0.46-2.72$ & $4.62 *$ & 0.17 & $0.03-0.85$ \\
\hline Bra Size & 0.01 & 1.00 & $0.92-1.09$ & 3.37 & 1.17 & $0.99-1.37$ \\
\hline Breast Cancer Risk Factors & 2.17 & 1.08 & $0.98-1.20$ & $8.45^{* *}$ & 1.34 & $1.10-1.63$ \\
\hline Breast Cancer Symptoms & 1.43 & 0.92 & $0.80-1.05$ & 2.85 & 0.78 & $0.59-1.04$ \\
\hline Perceived BSE Effectiveness & 0.77 & 1.17 & $0.82-1.67$ & $9.04 * *$ & 4.13 & $1.64-10.40$ \\
\hline \multicolumn{7}{|c|}{ Theory Variables } \\
\hline Attitudes & 0.34 & 1.08 & $0.84-1.37$ & 0.53 & 1.20 & $0.73-1.97$ \\
\hline Subjective Norm & 0.05 & 0.98 & $0.82-1.17$ & 0.01 & 1.00 & $0.70-1.44$ \\
\hline Intention & $14.57 * * *$ & 1.94 & $1.38-2.73$ & $7.26^{* *}$ & 3.49 & $1.41-8.65$ \\
\hline Benefits & 0.24 & 1.02 & $0.95-1.10$ & 0.46 & 0.95 & $0.82-1.10$ \\
\hline Barriers & 0.05 & 0.92 & $0.44-1.90$ & $4.45^{*}$ & 0.14 & $0.02-0.87$ \\
\hline Self-Efficacy & 0.89 & 1.13 & $0.87-1.47$ & 2.15 & 1.44 & $0.89-2.33$ \\
\hline Health Motivation & $8.66 * *$ & 1.09 & $1.03-1.15$ & 0.13 & 1.02 & $0.91-1.15$ \\
\hline Cued by Health Care Provider & 0.01 & 0.99 & $0.53-1.85$ & 1.39 & 0.48 & $0.14-1.63$ \\
\hline Cued by Family or Friend with Breast Cancer & 1.92 & 1.50 & $0.85-2.67$ & 0.02 & 0.92 & $0.27-3.20$ \\
\hline Encouraged by Friend or Relative & 0.94 & 1.36 & $0.73-2.56$ & 0.04 & 1.13 & $0.33-3.86$ \\
\hline
\end{tabular}




\begin{tabular}{|c|c|c|c|c|c|c|}
\hline \multirow[b]{2}{*}{ Variable } & \multicolumn{3}{|c|}{ Recommended } & \multicolumn{3}{|c|}{ Excessive } \\
\hline & Wald & $O R$ & $95 \% C I$ & Wald & $O R$ & $95 \% C I$ \\
\hline \multicolumn{7}{|c|}{ Psychosocial Variables } \\
\hline Anxiety & $5.07 *$ & 2.54 & $1.13-5.73$ & 0.46 & 1.82 & $0.32-10.29$ \\
\hline Cancer Fatalism & $5.85^{*}$ & 1.03 & $1.01-1.06$ & 0.19 & 1.01 & $0.96-1.07$ \\
\hline Body Dissatisfaction & 0.01 & 0.99 & $0.75-1.31$ & $4.15^{*}$ & 1.88 & $1.02-3.43$ \\
\hline God Locus of Health Control & 2.16 & 1.53 & $0.87-2.69$ & 0.35 & 0.70 & $0.22-2.27$ \\
\hline Religious Beliefs & 3.26 & 0.95 & $0.89-1.01$ & 1.79 & 0.93 & $0.83-1.04$ \\
\hline Organizational Religiousness & 0.01 & 1.01 & $0.46-2.26$ & 0.32 & 1.62 & $0.31-8.53$ \\
\hline $\begin{array}{l}\text { Note. } \\
* p<.05 \\
* * p<.01 \\
* * * p<.001 \\
\chi^{2}(78)=412.711, p<.001 . \\
\text { McFadden Pseudo } R^{2}=.291 .\end{array}$ & & & & & & \\
\hline
\end{tabular}


Table 18

Multinomial Logistic Regression Predicting BSE Group Membership (Reference $=$ Recommended).

\begin{tabular}{|c|c|c|c|}
\hline \multirow[b]{2}{*}{ Variable } & \multicolumn{3}{|c|}{ Excessive } \\
\hline & Wald & $O R$ & $95 \% C I$ \\
\hline \multicolumn{4}{|c|}{ Personal and Demographic Variables } \\
\hline Age & 0.12 & 0.99 & $0.95-1.04$ \\
\hline Unmarried, Committed Couple (vs. Single) & 0.22 & 1.40 & $0.34-5.68$ \\
\hline Married (vs. Single) & 0.17 & 1.30 & $0.37-4.52$ \\
\hline Divorced/Separated (vs. Single) & 0.19 & 1.45 & $0.27-7.79$ \\
\hline Mammogram & 0.07 & 1.16 & $0.39-3.42$ \\
\hline Clinical Breast Exam & $5.62 *$ & 0.15 & $0.03-0.72$ \\
\hline Bra Size & 3.74 & 1.16 & $0.99-1.36$ \\
\hline Breast Cancer Risk Factors & $5.24 *$ & 1.24 & $1.03-1.50$ \\
\hline Breast Cancer Symptoms & 1.38 & 0.85 & $0.65-1.11$ \\
\hline Perceived BSE Effectiveness & $7.63 * *$ & 3.53 & $1.44-8.62$ \\
\hline \multicolumn{4}{|c|}{ Theory Variables } \\
\hline Attitudes & 0.22 & 1.12 & $0.70-1.79$ \\
\hline Subjective Norm & 0.02 & 1.03 & $0.73-1.45$ \\
\hline Intention & 1.68 & 1.80 & $0.74-4.35$ \\
\hline Benefits & 0.94 & 0.93 & $0.81-1.07$ \\
\hline Barriers & $4.34 *$ & 0.15 & $0.03-0.90$ \\
\hline Self-Efficacy & 1.04 & 1.27 & $0.80-2.00$ \\
\hline Health Motivation & 1.34 & 0.94 & $0.84-1.05$ \\
\hline Cued by Health Care Provider & 1.52 & 0.48 & $0.15-1.54$ \\
\hline Cued by Family or Friend with Breast Cancer & 0.66 & 0.61 & 0.19-1.99 \\
\hline Encouraged by Friend or Relative & 0.11 & 0.83 & $0.26-2.60 /$ \\
\hline
\end{tabular}

\section{Psychosocial Variables}

\begin{tabular}{l|ccc}
\hline Anxiety & 0.16 & 0.72 & $0.14-3.68$ \\
Cancer Fatalism & 0.59 & 0.98 & $0.93-1.03$ \\
Body Dissatisfaction & $4.68^{*}$ & 1.89 & $1.06-3.37$ \\
God Locus of Health Control & 1.89 & 0.46 & $0.15-1.39$ \\
Religious Beliefs & 0.17 & 0.98 & $0.88-1.09$ \\
Organizational Religiousness & 0.35 & 1.60 & $0.34-7.57$ \\
\hline
\end{tabular}

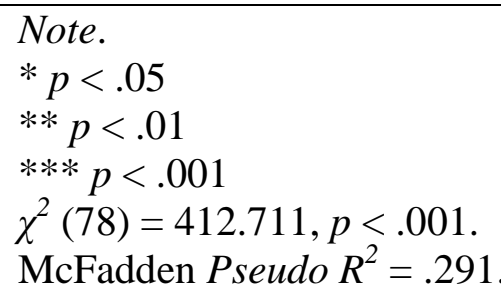


Table 19

Correlations between BSE Proficiency and Personal and Demographic Variables.

\begin{tabular}{|c|c|c|c|c|c|c|c|c|c|c|c|c|c|c|}
\hline & Variable & 1 & 2 & 3 & 4 & 5 & 6 & 7 & 8 & 9 & 10 & 11 & 12 & 13 \\
\hline 1 & BSE Proficiency & - & $-.14 * * *$ & .03 & -.04 & -.01 & .02 & $-.07^{\mathrm{T}}$ & .03 & $-.10^{*}$ & $.24 * * *$ & $.26 * * *$ & $.13 * *$ & $.07^{\mathrm{T}}$ \\
\hline 2 & Age & & - & $.17 * * *$ & $.12 * *$ & $.29 * * *$ & .01 & .05 & .04 & $.55^{* * *}$ & $.07^{\mathrm{T}}$ & $.10^{*}$ & $-.08^{*}$ & -.01 \\
\hline 3 & BMI & & & - & -.03 & $.76^{* * * *}$ & $.39 * * *$ & $-.18 * * *$ & $.10^{*}$ & .06 & .003 & -.03 & $.14 * *$ & $.14 * * *$ \\
\hline 4 & Education & & & & - & $-.07^{\mathrm{T}}$ & .01 & $.13 * *$ & -.03 & .02 & .02 & .06 & -.02 & .03 \\
\hline 5 & Bra Size & & & & & - & $.30 * * *$ & $-.13 * *$ & $.08^{*}$ & $.11 * *$ & .05 & -.01 & $.12 * *$ & $.11^{* *}$ \\
\hline 6 & Cup Size & & & & & & - & -.05 & .03 & -.03 & -.04 & -.01 & $.10^{*}$ & $.11^{* *}$ \\
\hline 7 & Financial Difficulties & & & & & & & - & -.06 & .04 & .03 & -.001 & $-.14 * *$ & -.004 \\
\hline 8 & $\begin{array}{l}\text { Perceived BSE } \\
\text { Effectiveness }\end{array}$ & & & & & & & & - & .01 & -.01 & $.08^{*}$ & -.0003 & -.02 \\
\hline 9 & Age Heard of BSE & & & & & & & & & - & .003 & -.05 & $-.10^{*}$ & -.01 \\
\hline 10 & $\begin{array}{l}\text { Breast Cancer Risk } \\
\text { Factors }\end{array}$ & & & & & & & & & & - & $.37 * * *$ & .05 & .02 \\
\hline 11 & $\begin{array}{l}\text { Breast Cancer } \\
\text { Symptoms }\end{array}$ & & & & & & & & & & & - & .06 & -.003 \\
\hline 12 & $\begin{array}{l}\text { Subjective Breast } \\
\text { Cancer Risk }\end{array}$ & & & & & & & & & & & & - & $.47^{* * *}$ \\
\hline 13 & $\begin{array}{l}\text { Objective Breast } \\
\text { Cancer Risk }\end{array}$ & & & & & & & & & & & & & 一 \\
\hline
\end{tabular}

$$
\begin{aligned}
& \text { Note. } \\
& \mathrm{T} p<.10 \\
& * p<.05 \\
& \text { ** }^{2}<.01 \\
& \text { *** } p<.001
\end{aligned}
$$


Table 20

Correlations between BSE Proficiency and Theory Variables.

\begin{tabular}{|c|c|c|c|c|c|c|c|c|c|c|c|c|}
\hline & Variable & 1 & 2 & 3 & 4 & 5 & 6 & 7 & 8 & 9 & 10 & 11 \\
\hline 1 & BSE Proficiency & - & -.003 & .03 & $.09 *$ & $.13 * *$ & .04 & $.12 * *$ & -.01 & $.11 * *$ & .03 & $.07^{\mathrm{T}}$ \\
\hline 2 & Attitudes & & - & $.32 * * *$ & $.49 * * *$ & .02 & .001 & $.52 * * *$ & $-.54 * * *$ & $.42 * * *$ & $.25^{* * *}$ & -.06 \\
\hline 3 & Subjective Norm & & & - & $.41 * * *$ & .04 & .05 & $.32 * * *$ & $-.27 * * *$ & $.29 * * *$ & $.17 * * *$ & .06 \\
\hline 4 & Intention & & & & - & .06 & $.10 *$ & $.48 * * *$ & $-.38 * * *$ & $.42 * * *$ & $.26 * * *$ & $.09 *$ \\
\hline 5 & Susceptibility & & & & & - & $.24 * * *$ & .01 & $.08 *$ & $-.08 *$ & -.06 & $.26 * * *$ \\
\hline 6 & Seriousness & & & & & & - & $.13^{* *}$ & $.18 * * *$ & -.07 & .06 & $.76^{* * *}$ \\
\hline 7 & Benefits & & & & & & & - & $-.31 * * *$ & $.41 * * *$ & $.28 * * *$ & .06 \\
\hline 8 & Barriers & & & & & & & & - & $.38 * * *$ & $-.22 * * *$ & $.22 * * *$ \\
\hline 9 & Self-Efficacy & & & & & & & & & - & $.30 * * *$ & $-.07^{\mathrm{T}}$ \\
\hline 10 & Health Motivation & & & & & & & & & & - & .04 \\
\hline 11 & Breast Cancer Fear & & & & & & & & & & & - \\
\hline
\end{tabular}

Note.

${ }^{\mathrm{T}} p<.10$

$* p<.05$

$* * p<.01$

$* * * p<.001$ 
Table 21

Correlations between BSE Proficiency and Psychosocial Variables.

\begin{tabular}{|c|c|c|c|c|c|c|c|c|c|}
\hline & Variable & 1 & 2 & 3 & 4 & 5 & 6 & 7 & 8 \\
\hline 1 & BSE Proficiency & - & $.11 * *$ & $.08^{\mathrm{T}}$ & $-.07^{\mathrm{T}}$ & $-.09 *$ & -.03 & $-.09 *$ & -.03 \\
\hline 2 & Anxiety & & - & $.32 * * *$ & $.18 * * *$ & $-.24 * * *$ & -.01 & $-.08 *$ & $-.14 * *$ \\
\hline 3 & Breast Cancer Worry & & & - & $.07^{\mathrm{T}}$ & $-.11 * *$ & .02 & -.02 & -.03 \\
\hline 4 & Cancer Fatalism & & & & - & -.03 & $.25 * * *$ & $.15 * * *$ & .06 \\
\hline 5 & Body Dissatisfaction & & & & & - & -.01 & .05 & .02 \\
\hline 6 & God Locus of Health Control & & & & & & - & $.75 * * *$ & $.54 * * *$ \\
\hline 7 & Religious Beliefs & & & & & & & - & $.60 * * *$ \\
\hline 8 & Organizational Religiousness & & & & & & & & - \\
\hline & $\begin{array}{l}e . \\
<.10 \\
<.05 \\
<.01 \\
p<.001\end{array}$ & & & & & & & & \\
\hline
\end{tabular}


Table 22

One-Way ANOVAs investigating Differences in BSE Proficiency by Potential Categorical Predictors.

\begin{tabular}{lccccc}
\hline \multicolumn{1}{c}{ Predictor } & $d f$ & $F$ & $p$ & $\eta_{p}{ }^{2}$ & Differences \\
\hline Marital Status & 3,595 & 1.60 & .187 & .008 & \\
Mammography & 1,606 & 0.67 & .415 & .001 & \\
Clinical Breast Exam & 1,601 & 1.55 & .214 & .003 & \\
Health Insurance & 1,608 & 1.32 & .251 & .002 & \\
Cued by Health Care Provider & 1,612 & 1.08 & .299 & .002 & \\
Cued by Public Health Campaign & 1,612 & 4.08 & .044 & .007 & $\mathrm{Y}>\mathrm{N}$ \\
Cued by Celebrity of Public Figure & 1,612 & 2.50 & .114 & .004 & \\
Cued by Experiencing Breast Cancer Symptoms & 1,612 & 5.89 & .016 & .010 & $\mathrm{Y}>\mathrm{N}$ \\
Cued by Family or Friend with Breast Cancer & 1,612 & 8.07 & .005 & .013 & $\mathrm{Y}>\mathrm{N}$ \\
Encouraged by Friend or Relative & 1,612 & 6.09 & .014 & .010 & $\mathrm{Y}>\mathrm{N}$ \\
\hline
\end{tabular}

Note.

Y: Yes

N: No 
Table 23

Hierarchical Regression predicting BSE Proficiency.

\begin{tabular}{|c|c|c|c|c|c|}
\hline Variable & Beta & SE Beta & $\beta$ & $t$ & $p$ \\
\hline \multicolumn{6}{|l|}{ Step 1 (Personal and Demographic Variables) } \\
\hline Age & -.030 & .007 & -.193 & -4.13 & $<.001$ \\
\hline Financial Difficulties & -.103 & .068 & -.059 & -1.52 & .130 \\
\hline Age Heard of BSE & .009 & .016 & .027 & 0.59 & .558 \\
\hline Breast Cancer Risk Factors & .126 & .031 & .168 & 4.07 & $<.001$ \\
\hline Breast Cancer Symptoms & .214 & .041 & .216 & 5.16 & $<.001$ \\
\hline Subjective Breast Cancer Risk & .167 & .110 & .067 & 1.52 & .130 \\
\hline Objective Breast Cancer Risk & .085 & .089 & .042 & 0.96 & .340 \\
\hline \multicolumn{6}{|l|}{ Step 2 (Personal, Demographic, and Theory Variables) } \\
\hline Age & -.034 & .007 & -.221 & -4.67 & $<.001$ \\
\hline Financial Difficulties & -.081 & .068 & -.047 & -1.19 & .236 \\
\hline Age Heard of BSE & .013 & .016 & .037 & 0.80 & .427 \\
\hline Breast Cancer Risk Factors & .118 & .031 & .158 & 3.82 & $<.001$ \\
\hline Breast Cancer Symptoms & .188 & .042 & .189 & 4.46 & $<.001$ \\
\hline Subjective Breast Cancer Risk & .063 & .136 & .025 & 0.46 & .644 \\
\hline Objective Breast Cancer Risk & .055 & .093 & .027 & 0.59 & .556 \\
\hline Intention & -.027 & .085 & -.015 & -0.32 & .751 \\
\hline Susceptibility & .153 & .140 & .059 & 1.10 & .273 \\
\hline Benefits & .028 & .020 & .063 & 1.39 & .166 \\
\hline Self-Efficacy & .171 & .075 & .103 & 2.28 & .023 \\
\hline Cued by Public Health Campaign & .155 & .142 & .043 & 1.09 & .276 \\
\hline Cued by Experiencing Breast Cancer Symptoms & .207 & .220 & .037 & 0.94 & .348 \\
\hline Cued by Family or Friend with Breast Cancer & .205 & .193 & .045 & 1.07 & .287 \\
\hline Encouraged by Friend or Relative & .036 & .204 & .007 & 0.17 & .862 \\
\hline Breast Cancer Fear & .001 & .009 & .005 & 0.12 & .903 \\
\hline \multicolumn{6}{|c|}{ Step 3 (Personal, Demographic, Theory, and Psychosocial Variables) } \\
\hline Age & -.033 & .008 & -.211 & -4.37 & $<.001$ \\
\hline Financial Difficulties & -.019 & .072 & -.011 & -0.27 & .788 \\
\hline Age Heard of BSE & .016 & .016 & .047 & 1.01 & .313 \\
\hline Breast Cancer Risk Factors & .117 & .031 & .157 & 3.81 & $<.001$ \\
\hline Breast Cancer Symptoms & .190 & .042 & .191 & 4.50 & $<.001$ \\
\hline Subjective Breast Cancer Risk & .043 & .136 & .017 & 0.32 & .753 \\
\hline Objective Breast Cancer Risk & .057 & .092 & .028 & 0.62 & .536 \\
\hline Intention & -.009 & .086 & -.005 & -0.10 & .918 \\
\hline Susceptibility & .136 & .140 & .052 & 0.98 & .330 \\
\hline Benefits & .033 & .020 & .075 & 1.64 & .101 \\
\hline Self-Efficacy & .209 & .075 & .126 & 2.77 & .006 \\
\hline
\end{tabular}




\begin{tabular}{lrrrrr}
\hline \multicolumn{1}{c}{ Variable } & Beta & SE Beta & \multicolumn{1}{c}{$\beta$} & \multicolumn{1}{c}{$t$} & \multicolumn{1}{c}{$p$} \\
\hline Cued by Public Health Campaign & .155 & .141 & .043 & 1.10 & .271 \\
Cued by Experiencing Breast Cancer Symptoms & .122 & .221 & .022 & 0.55 & .580 \\
Cued by Family or Friend with Breast Cancer & .191 & .192 & .042 & 1.00 & .320 \\
Encouraged by Friend or Relative & .010 & .203 & .002 & 0.05 & .961 \\
Breast Cancer Fear & -.004 & .009 & -.020 & -0.46 & .643 \\
Anxiety & .516 & .275 & .086 & 1.88 & .061 \\
Breast Cancer Worry & .183 & .435 & .018 & 0.42 & .675 \\
Cancer Fatalism & -.006 & .007 & -.035 & -0.85 & .394 \\
Body Dissatisfaction & -.156 & .076 & -.085 & -2.07 & .039 \\
Religious Beliefs & -.016 & .012 & -.055 & -1.35 & .179 \\
\hline
\end{tabular}

Note.

Step 1: $R^{2}=.136$, Adjusted $R^{2}=.125, F(6,579)=12.98, p<.001$.

Step 2: $R^{2}=.161$, Adjusted $R^{2}=.138, F(16,570)=6.85, p<.001 ; R^{2} \Delta=.026, F \Delta(9,570)=$ $1.94, p=.044$.

Step 3: $R^{2}=.181$, Adjusted $R^{2}=.151, F(21,565)=5.95, p<.001 ; R^{2} \Delta=.020, F \Delta(5,565)=$ $2.72, p=.019$. 
Table 24

Correlations between Lump Checking Frequency and Personal and Demographic Variables.

\begin{tabular}{|c|c|c|c|c|c|c|c|c|c|c|c|c|c|c|}
\hline & Variable & 1 & 2 & 3 & 4 & 5 & 6 & 7 & 8 & 9 & 10 & 11 & 12 & 13 \\
\hline 1 & Lump Checking & - & $.16^{* * *}$ & .05 & -.05 & .06 & -.01 & -.06 & $.15 * * *$ & .03 & .06 & .03 & -.04 & -.05 \\
\hline 2 & Age & & - & $.17 * * *$ & $.12 * *$ & $.29 * * *$ & .01 & .05 & .04 & $.55^{* * *}$ & $.07^{\mathrm{T}}$ & $.10 *$ & $-.08 *$ & -.01 \\
\hline 3 & BMI & & & - & -.03 & $.76^{* * *}$ & $.39 * * *$ & $-.18 * * *$ & $.10^{*}$ & .06 & .003 & -.03 & $.14 * *$ & $.14 * * *$ \\
\hline 4 & Education & & & & - & $-.07^{\mathrm{T}}$ & .01 & $.13^{* *}$ & -.03 & .02 & .02 & .06 & -.02 & .03 \\
\hline 5 & Bra Size & & & & & - & $.30 * * *$ & $-.13 * *$ & $.08^{*}$ & $.11 * *$ & .05 & -.01 & $.12 * *$ & $.11^{* *}$ \\
\hline 6 & Cup Size & & & & & & - & -.05 & .03 & -.03 & -.04 & -.01 & $.10^{*}$ & $.11^{* *}$ \\
\hline 7 & Financial Difficulties & & & & & & & - & -.06 & .04 & .03 & -.001 & $-.14 * *$ & -.004 \\
\hline 8 & $\begin{array}{l}\text { Perceived BSE } \\
\text { Effectiveness }\end{array}$ & & & & & & & & - & .01 & -.01 & $.08^{*}$ & -.0003 & -.02 \\
\hline 9 & Age Heard of BSE & & & & & & & & & - & .003 & -.05 & $-.10^{*}$ & -.01 \\
\hline 10 & $\begin{array}{l}\text { Breast Cancer Risk } \\
\text { Factors }\end{array}$ & & & & & & & & & & - & $.37 * * *$ & .05 & .02 \\
\hline 11 & $\begin{array}{l}\text { Breast Cancer } \\
\text { Symptoms }\end{array}$ & & & & & & & & & & & - & .06 & -.003 \\
\hline 12 & $\begin{array}{l}\text { Subjective Breast } \\
\text { Cancer Risk }\end{array}$ & & & & & & & & & & & & - & $.47 * * *$ \\
\hline 13 & $\begin{array}{l}\text { Objective Breast } \\
\text { Cancer Risk }\end{array}$ & & & & & & & & & & & & & - \\
\hline
\end{tabular}

$$
\begin{aligned}
& \text { Note. } \\
& \mathrm{T} p<.10 \\
& * p<.05 \\
& \text { ** }^{2}<.01 \\
& \text { *** } p<.001
\end{aligned}
$$


Table 25

Correlations between Lump Checking Frequency and Theory Variables.

\begin{tabular}{|c|c|c|c|c|c|c|c|c|c|c|c|c|}
\hline & Variable & 1 & 2 & 3 & 4 & 5 & 6 & 7 & 8 & 9 & 10 & 11 \\
\hline 1 & Lump Checking & - & $.19 * * *$ & $.16^{* * *}$ & $.34 * * *$ & -.01 & .01 & $.16^{* * *}$ & $-.25 * * *$ & $.22 * * *$ & $.10 *$ & .03 \\
\hline 2 & Attitudes & & - & $.32 * * *$ & $.49 * * *$ & .02 & .001 & $.52 * * *$ & $-.54 * * *$ & $.42 * * *$ & $.25 * * *$ & -.06 \\
\hline 3 & Subjective Norm & & & - & $.41 * * *$ & .04 & .05 & $.32 * * *$ & $-.27 * * *$ & $.29 * * *$ & $.17 * * *$ & .06 \\
\hline 4 & Intention & & & & - & .06 & $.10^{*}$ & $.48 * * *$ & $-.38 * * *$ & $.42 * * *$ & $.26^{* * * *}$ & $.09 *$ \\
\hline 5 & Susceptibility & & & & & - & $.24 * * *$ & .01 & $.08 *$ & $-.08 *$ & -.06 & $.26 * * *$ \\
\hline 6 & Seriousness & & & & & & - & $.13 * *$ & $.18 * * *$ & -.07 & .06 & $.76^{* * * *}$ \\
\hline 7 & Benefits & & & & & & & - & $-.31 * * *$ & $.41 * * *$ & $.28 * * *$ & .06 \\
\hline 8 & Barriers & & & & & & & & - & $.38 * * *$ & $-.22 * * *$ & $.22 * * *$ \\
\hline 9 & Self-Efficacy & & & & & & & & & - & $.30 * * *$ & $-.07^{\mathrm{T}}$ \\
\hline 10 & Health Motivation & & & & & & & & & & - & .04 \\
\hline 11 & Breast Cancer Fear & & & & & & & & & & & - \\
\hline
\end{tabular}

Note.

${ }^{\mathrm{T}} p<.10$

$* p<.05$

$* * p<.01$

$* * * p<.001$ 
Table 26

Correlations between Lump Checking Frequency and Psychosocial Variables.

\begin{tabular}{|c|c|c|c|c|c|c|c|c|c|}
\hline & Variable & 1 & 2 & 3 & 4 & 5 & 6 & 7 & 8 \\
\hline 1 & Lump Checking & - & -.02 & .01 & -.03 & .04 & .04 & $.07^{\mathrm{T}}$ & $.07^{\mathrm{T}}$ \\
\hline 2 & Anxiety & & - & $.32 * * *$ & $.18 * * *$ & $-.24 * * *$ & -.01 & $-.08 *$ & $-.14 * *$ \\
\hline 3 & Breast Cancer Worry & & & - & $.07^{\mathrm{T}}$ & $-.11 * *$ & .02 & -.02 & -.03 \\
\hline 4 & Cancer Fatalism & & & & - & -.03 & $.25 * * *$ & $.15^{* * *}$ & .06 \\
\hline 5 & Body Dissatisfaction & & & & & - & -.01 & .05 & .02 \\
\hline 6 & God Locus of Health Control & & & & & & - & $.75^{* * *}$ & $.54 * * *$ \\
\hline 7 & Religious Beliefs & & & & & & & - & $.60 * * *$ \\
\hline 8 & Organizational Religiousness & & & & & & & & - \\
\hline & $\begin{array}{l}e . \\
<.10 \\
<.05 \\
<<.01 \\
p<.001\end{array}$ & & & & & & & & \\
\hline
\end{tabular}


Table 27

One-Way ANOVAs investigating Differences in Lump Checking Frequency by Potential Categorical Predictors.

\begin{tabular}{lrrrrr}
\hline \multicolumn{1}{c}{ Predictor } & $d f$ & \multicolumn{1}{c}{$F$} & \multicolumn{1}{c}{$p$} & \multicolumn{1}{c}{$\eta_{p}{ }^{2}$} & Differences \\
\hline Marital Status & 3,606 & 1.72 & .162 & .008 & \\
Mammography & 1,618 & 16.95 & $<.001$ & .027 & $\mathrm{Y}>\mathrm{N}$ \\
Clinical Breast Exam & 1,612 & 0.64 & .423 & .001 & \\
Health Insurance & 1,619 & 0.03 & .869 & .001 & \\
Cued by Health Care Provider & 1,623 & 0.02 & .890 & .001 & \\
Cued by Public Health Campaign & 1,623 & 0.59 & .443 & .001 & \\
Cued by Celebrity of Public Figure & 1,623 & 0.36 & .547 & .001 & \\
Cued by Experiencing Breast Cancer & 1,623 & 17.74 & $<.001$ & .028 & $\mathrm{Y}>\mathrm{N}$ \\
Symptoms & 1,623 & 2.60 & .107 & .004 & \\
Cued by Family or Friend with Breast Cancer & 1,623 & 3.14 & 0.77 & .005 & $\mathrm{Y}>\mathrm{N}$ \\
Encouraged by Friend or Relative & & & & &
\end{tabular}

$\mathrm{Y}: \mathrm{Yes}$

$\mathrm{N}: \mathrm{No}$ 
Table 28

Hierarchical Regression predicting Lump Checking Frequency.

\begin{tabular}{|c|c|c|c|c|c|}
\hline Variable & Beta & SE Beta & $B$ & $t$ & $p$ \\
\hline \multicolumn{6}{|l|}{ Step 1 (Personal and Demographic Variables) } \\
\hline Age & .005 & .003 & .078 & 1.55 & .121 \\
\hline Perceived BSE Effectiveness & .136 & .037 & .144 & 3.63 & $<.001$ \\
\hline Mammography & .177 & .081 & .110 & 2.19 & .029 \\
\hline \multicolumn{6}{|c|}{ Step 2 (Personal, Demographic, and Theory Variables) } \\
\hline Age & .006 & .003 & .094 & 1.96 & .051 \\
\hline Perceived BSE Effectiveness & .073 & .039 & .077 & 1.88 & .061 \\
\hline Mammography & .053 & .077 & .033 & 0.69 & .493 \\
\hline Attitudes & -.007 & .027 & -.014 & -0.27 & .785 \\
\hline Subjective Norm & -.006 & .020 & -.014 & -0.33 & .743 \\
\hline Intention & .209 & .033 & .299 & 6.28 & $<.001$ \\
\hline Benefits & -.013 & .008 & -.078 & -1.62 & .107 \\
\hline Barriers & -.234 & .081 & -.132 & -2.90 & .004 \\
\hline Self-Efficacy & .025 & .028 & .040 & 0.90 & .369 \\
\hline Health Motivation & -.002 & .006 & -.012 & -0.29 & .769 \\
\hline Cued by Experiencing Breast Cancer Symptoms & .364 & .082 & .165 & 4.43 & $<.001$ \\
\hline Encouraged by Friend or Relative & .007 & .076 & .003 & 0.09 & .926 \\
\hline \multicolumn{6}{|c|}{ Step 3 (Personal, Demographic, Theory, and Psychosocial Variables) } \\
\hline Age & .006 & .003 & .100 & 2.05 & .041 \\
\hline Perceived BSE Effectiveness & .074 & .039 & .078 & 1.90 & .058 \\
\hline Mammography & .051 & .077 & .032 & 0.66 & .509 \\
\hline Attitudes & -.005 & .027 & -.010 & 0.85 & .516 \\
\hline Subjective Norm & -.007 & .020 & -.016 & -0.37 & .710 \\
\hline Intention & .212 & .034 & .303 & 6.32 & $<.001$ \\
\hline Benefits & -.013 & .008 & -.079 & -1.62 & .107 \\
\hline Barriers & -.226 & .081 & -.128 & -2.79 & .005 \\
\hline Self-Efficacy & .026 & .028 & .041 & 0.93 & .355 \\
\hline Health Motivation & -.002 & .006 & -.012 & -.030 & .761 \\
\hline Cued by Experiencing Breast Cancer Symptoms & .365 & .082 & .166 & 4.43 & $<.001$ \\
\hline Encouraged by Friend or Relative & .007 & .076 & .004 & 0.09 & .925 \\
\hline Religious Beliefs & -.004 & .005 & -.040 & -0.85 & .397 \\
\hline Organizational Religiousness & .038 & .089 & .020 & 0.43 & .668 \\
\hline
\end{tabular}

Note.

Step 1: $R^{2}=.051$, Adjusted $R^{2}=.046, F(3,606)=10.88, p<.001$.

Step 2: $R^{2}=.187$, Adjusted $R^{2}=.171, F(12,597)=11.46, p<.001 ; R^{2} \Delta=.136, F \Delta(9,597)=$ $11.11, p<.001$.

Step 3: $R^{2}=.188$, Adjusted $R^{2}=.169, F(14,595)=9.86, p<.001 ; R^{2} \Delta=.001, F \Delta(2,595)=$ $0.36, p=.697$. 
Table 29

Correlations between Checking in Shower Frequency and Personal and Demographic Variables.

\begin{tabular}{|c|c|c|c|c|c|c|c|c|c|c|c|c|c|c|}
\hline & Variable & 1 & 2 & 3 & 4 & 5 & 6 & 7 & 8 & 9 & 10 & 11 & 12 & 13 \\
\hline 1 & Shower Checking & - & $.09^{*}$ & -.03 & $-.07^{\mathrm{T}}$ & .01 & -.01 & -.06 & $.10^{*}$ & -.01 & .05 & .01 & $-.11 * *$ & $-.09 *$ \\
\hline 2 & Age & & - & $.17 * * *$ & $.12^{* *}$ & $.29 * * *$ & .01 & .05 & .04 & $.55^{* * *}$ & $.07^{\mathrm{T}}$ & $.10^{*}$ & $-.08 *$ & -.01 \\
\hline 3 & BMI & & & - & -.03 & $.76^{* * * *}$ & $.39 * * *$ & $-.18 * * *$ & $.10^{*}$ & .06 & .003 & -.03 & $.14 * *$ & $.14 * * *$ \\
\hline 4 & Education & & & & - & $-.07^{\mathrm{T}}$ & .01 & $.13 * *$ & -.03 & .02 & .02 & .06 & -.02 & .03 \\
\hline 5 & Bra Size & & & & & - & $.30 * * *$ & $-.13 * *$ & $.08^{*}$ & $.11 * *$ & .05 & -.01 & $.12 * *$ & $.11^{* *}$ \\
\hline 6 & Cup Size & & & & & & - & -.05 & .03 & -.03 & -.04 & -.01 & $.10^{*}$ & $.11^{* *}$ \\
\hline 7 & Financial Difficulties & & & & & & & - & -.06 & .04 & .03 & -.001 & $-.14 * *$ & -.004 \\
\hline 8 & $\begin{array}{l}\text { Perceived BSE } \\
\text { Effectiveness }\end{array}$ & & & & & & & & - & .01 & -.01 & $.08^{*}$ & -.0003 & -.02 \\
\hline 9 & Age Heard of BSE & & & & & & & & & - & .003 & -.05 & $-.10^{*}$ & -.01 \\
\hline 10 & $\begin{array}{l}\text { Breast Cancer Risk } \\
\text { Factors }\end{array}$ & & & & & & & & & & - & $.37 * * *$ & .05 & .02 \\
\hline 11 & $\begin{array}{l}\text { Breast Cancer } \\
\text { Symptoms }\end{array}$ & & & & & & & & & & & - & .06 & -.003 \\
\hline 12 & $\begin{array}{l}\text { Subjective Breast } \\
\text { Cancer Risk }\end{array}$ & & & & & & & & & & & & - & $.47^{* * *}$ \\
\hline 13 & $\begin{array}{l}\text { Objective Breast } \\
\text { Cancer Risk }\end{array}$ & & & & & & & & & & & & & - \\
\hline
\end{tabular}

$$
\begin{aligned}
& \text { Note. } \\
& \mathrm{T} p<.10 \\
& * p<.05 \\
& \text { ** }^{2}<.01 \\
& \text { *** } p<.001
\end{aligned}
$$


Table 30

Correlations between Checking in Shower Frequency and Theory Variables.

\begin{tabular}{|c|c|c|c|c|c|c|c|c|c|c|c|c|}
\hline & Variable & 1 & 2 & 3 & 4 & 5 & 6 & 7 & 8 & 9 & 10 & 11 \\
\hline 1 & Shower Checking & - & $.25 * * *$ & $.13^{* *}$ & $.33 * * *$ & $-.09 *$ & .01 & $.18 * * *$ & $-.23 * * *$ & $.26^{* * *}$ & $.10^{*}$ & .03 \\
\hline 2 & Attitudes & & - & $.32 * * *$ & $.49 * * *$ & .02 & .001 & $.52 * * *$ & $-.54 * * *$ & $.42 * * *$ & $.25^{* * *}$ & -.06 \\
\hline 3 & Subjective Norm & & & - & $.41 * * *$ & .04 & .05 & $.32 * * *$ & $-.27 * * *$ & $.29 * * *$ & $.17 * * *$ & .06 \\
\hline 4 & Intention & & & & - & .06 & $.10^{*}$ & $.48 * * *$ & $-.38 * * *$ & $.42 * * *$ & $.26 * * *$ & $.09 *$ \\
\hline 5 & Susceptibility & & & & & 一 & $.24 * * *$ & .01 & $.08 *$ & $-.08 *$ & -.06 & $.26 * * *$ \\
\hline 6 & Seriousness & & & & & & - & $.13^{* *}$ & $.18 * * *$ & -.07 & .06 & $.76^{* * * *}$ \\
\hline 7 & Benefits & & & & & & & - & $-.31 * * *$ & $.41 * * *$ & $.28 * * *$ & .06 \\
\hline 8 & Barriers & & & & & & & & - & $.38 * * *$ & $-.22 * * *$ & $.22 * * *$ \\
\hline 9 & Self-Efficacy & & & & & & & & & - & $.30 * * *$ & $-.07^{\mathrm{T}}$ \\
\hline 10 & Health Motivation & & & & & & & & & & - & .04 \\
\hline 11 & Breast Cancer Fear & & & & & & & & & & & - \\
\hline
\end{tabular}

Note.

${ }^{\mathrm{T}} p<.10$

$* p<.05$

$* * p<.01$

$* * * p<.001$ 
Table 31

Correlations between Checking in Shower Frequency and Psychosocial Variables.

\begin{tabular}{|c|c|c|c|c|c|c|c|c|c|}
\hline & Variable & 1 & 2 & 3 & 4 & 5 & 6 & 7 & 8 \\
\hline 1 & Shower Checking & - & -.01 & -.003 & .03 & $.08 *$ & .06 & .07 & $.07^{\mathrm{T}}$ \\
\hline 2 & Anxiety & & - & $.32 * * *$ & $.18 * * *$ & $-.24 * * *$ & -.01 & $-.08 *$ & $-.14 * *$ \\
\hline 3 & Breast Cancer Worry & & & - & $.07^{\mathrm{T}}$ & $-.11 * *$ & .02 & -.02 & -.03 \\
\hline 4 & Cancer Fatalism & & & & - & -.03 & $.25 * * *$ & $.15 * * *$ & .06 \\
\hline 5 & Body Dissatisfaction & & & & & - & -.01 & .05 & .02 \\
\hline 6 & God Locus of Health Control & & & & & & - & $.75 * * *$ & $.54 * * *$ \\
\hline 7 & Religious Beliefs & & & & & & & - & $.60 * * *$ \\
\hline 8 & Organizational Religiousness & & & & & & & & - \\
\hline & $\begin{array}{l}e . \\
<.10 \\
<.05 \\
<.01 \\
p<.001\end{array}$ & & & & & & & & \\
\hline
\end{tabular}


Table 32

One-Way ANOVAs investigating Differences in Checking in Shower Frequency by Potential Categorical Predictors.

\begin{tabular}{lccccc}
\hline \multicolumn{1}{c}{ Predictor } & $d f$ & $F$ & $p$ & $\eta_{p}{ }^{2}$ & Differences \\
\hline Marital Status & 3,603 & 1.54 & .204 & .008 & \\
Mammography & 1,614 & 2.84 & .092 & .005 & $\mathrm{~N}<\mathrm{Y}$ \\
Clinical Breast Exam & 1,609 & 0.03 & .872 & .001 & \\
Health Insurance & 1,616 & 0.74 & .392 & .001 & \\
Cued by Health Care Provider & 1,620 & 0.38 & .537 & .001 & \\
Cued by Public Health Campaign & 1,620 & 0.02 & .879 & .001 & \\
Cued by Celebrity of Public Figure & 1,620 & 0.05 & .823 & .001 & \\
Cued by Experiencing Breast Cancer & 1,620 & 0.65 & .419 & .001 & \\
Symptoms & 1,620 & 0.07 & .799 & .001 & \\
Cued by Family or Friend with Breast Cancer & 1,620 & 2.66 & .103 & .004 & \\
Encouraged by Friend or Relative & & & & & \\
\hline Note. & & & &
\end{tabular}

Note.

Y: Yes

$\mathrm{N}$ : No 
Table 33

Hierarchical Regression predicting Checking in Shower Frequency.

\begin{tabular}{|c|c|c|c|c|c|}
\hline Variable & Beta & SE Beta & $\beta$ & $t$ & $p$ \\
\hline \multicolumn{6}{|c|}{ Step 1 (Personal and Demographic Variables) } \\
\hline Age & .005 & .004 & .072 & 1.39 & .166 \\
\hline Education & -.076 & .037 & -.083 & -2.04 & .042 \\
\hline Perceived BSE Effectiveness & .096 & .045 & .086 & 2.13 & .034 \\
\hline Subjective Breast Cancer Risk & -.088 & .052 & -.078 & -1.71 & .089 \\
\hline Objective Breast Cancer Risk & -.051 & .042 & -.056 & -1.22 & .223 \\
\hline Mammography & .059 & .096 & .032 & 0.62 & .537 \\
\hline \multicolumn{6}{|c|}{ Step 2 (Personal, Demographic, and Theory Variables) } \\
\hline Age & .005 & .004 & .074 & 1.49 & .136 \\
\hline Education & -.061 & .036 & -.067 & -1.70 & .091 \\
\hline Perceived BSE Effectiveness & -.008 & .047 & -.007 & -0.17 & .866 \\
\hline Subjective Breast Cancer Risk & -.071 & .060 & -.063 & -1.17 & .241 \\
\hline Objective Breast Cancer Risk & -.039 & .041 & -.042 & -0.95 & .344 \\
\hline Mammography & -.054 & .093 & -.029 & -0.59 & .556 \\
\hline Attitudes & .035 & .033 & .057 & 1.08 & .281 \\
\hline Subjective Norm & -.016 & .024 & -.029 & -0.67 & .500 \\
\hline Intention & .219 & .040 & .268 & 5.41 & $<.001$ \\
\hline Susceptibility & -.045 & .061 & -.038 & -0.73 & .466 \\
\hline Benefits & -.008 & .010 & -.041 & -0.81 & .418 \\
\hline Barriers & -.186 & .098 & -.090 & -1.89 & .060 \\
\hline Self-Efficacy & .070 & .034 & .094 & 2.02 & .044 \\
\hline Health Motivation & -.004 & .007 & -.021 & -0.51 & .610 \\
\hline \multicolumn{6}{|c|}{ Step 3 (Personal, Demographic, Theory, and Psychosocial Variables) } \\
\hline Age & .005 & .004 & .076 & 1.51 & .131 \\
\hline Education & -.061 & .036 & -.067 & -1.70 & .090 \\
\hline Perceived BSE Effectiveness & -.007 & .047 & -.006 & -0.15 & .879 \\
\hline Subjective Breast Cancer Risk & -.068 & .061 & -.061 & -1.13 & .260 \\
\hline Objective Breast Cancer Risk & -.038 & .041 & -.042 & -0.94 & .348 \\
\hline Mammography & -.054 & .093 & -.029 & -0.58 & .562 \\
\hline Attitudes & .035 & .033 & .057 & 1.06 & .288 \\
\hline Subjective Norm & -.016 & .024 & -.029 & -0.67 & .503 \\
\hline Intention & .220 & .041 & .270 & 5.42 & $<.001$ \\
\hline Susceptibility & -.045 & .062 & -.039 & -0.73 & .463 \\
\hline Benefits & -.008 & .010 & -.041 & -0.82 & .413 \\
\hline Barriers & -.182 & .099 & -.088 & 1.84 & .066 \\
\hline Self-Efficacy & .068 & .035 & .092 & 1.96 & .049 \\
\hline Health Motivation & -.005 & .007 & -.027 & -0.61 & .541 \\
\hline
\end{tabular}




\begin{tabular}{lrrccc}
\hline \multicolumn{1}{c}{ Variable } & Beta & SE Beta & $\beta$ & $t$ & $p$ \\
\hline Body Dissatisfaction & .016 & .034 & .019 & 0.47 & .642 \\
Organizational Religiousness & .002 & .089 & .001 & 0.03 & .978 \\
\hline
\end{tabular}

Note.

Step 1: $R^{2}=.037$, Adjusted $R^{2}=.027, F(6,593)=3.77, p=.001$.

Step 2: $R^{2}=.158$, Adjusted $R^{2}=.138, F(14,585)=7.83, p<.001 ; R^{2} \Delta=.121, F \Delta(8,585)=$ 10.50, $p<.001$.

Step 3: $R^{2}=.158$, Adjusted $R^{2}=.135, F(16,583)=6.84, p<.001 ; R^{2} \Delta=.0003, F \Delta(2,583)=$ $0.11, p=.898$. 